\title{
STUDENT PERCEPTIONS OF INDEPENDENT LIVING SKILLS DEVELOPMENT AS A RESULT OF THE RESIDENCE HALL EXPERIENCE
}

A Dissertation
presented to
the Faculty of the Graduate School
at the University of Missouri
In Partial Fulfillment
of the Requirements for the Degree
Doctor of Education
boni Burch
Dr. Bradley Curs, Dissertation Supervisor
July 2021


(C) Copyright by Joni Burch, 2021 
The undersigned, appointed by the dean of the Graduate School, have examined the dissertation entitled

\section{STUDENT PERCEPTIONS OF INDEPENDENT LIVING SKILLS DEVELOPMENT AS A RESULT OF THE RESIDENCE HALL EXPERIENCE}

presented by Joni Burch, a candidate for the degree of Doctor of Education, and hereby certify that, in their opinion, it is worthy of acceptance.

Dr. Bradley Curs

Dr. Jennifer Fellabaum-Toston

Dr. Casandra Harper Morris

Dr. Tyler Page 


\section{DEDICATION}

As I consider the culmination of my higher education journey, I think back to the beginning. Jenni Burch, my Kentucky-born and raised Mom, paved the way for me. In my senior year of high school, I surprised everyone, including myself, and committed to going to college out of state. For three years, while I did not have my own vehicle, Jenni drove 12 hours round trip to get me to and from home for breaks. She didn't tell me until years later that she had never driven on an interstate until she took me to college. This is just one example of the thousands of ways Jenni has always loved me. I love you, Mom, and I am forever grateful for your love, support, and your eternal commitment to my dreams. 


\section{ACKNOWLEDGEMENTS}

In the past, and to some degree still, academia has felt like a very intimidating and foreign environment. Even while enrolled in this program, I felt like an imposter at times. Several people have helped me embrace my scholar-practitioner identity and navigate this culminating academic experience. The following list, while not comprehensive, is a few people who have been especially instrumental on this leg of my journey. Dr. Jennifer Fellabaum-Toston - You have always been the face and the heart of the ELPA program for me. When I first met you at the ELPA informational session you hosted on-campus, I immediately felt a connection with you. Your classes, your presence, and your influence have shifted my practice and my mindset. Thank you for helping me embrace my identity and practice as a scholar-practitioner.

Dr. Brad Curs - When I was initially assigned as your dissertation advisee, I was unsure what to expect. It turns out that your approach to advising was exactly what I needed to get the most out of this process. I consistently learned from you and felt supported by you. We hit a stride and I felt an ease with how we worked through the process together. I am so grateful for the time, thoughtfulness, and care you committed to my learning and the successful completion of this dissertation.

Dr. Tim Wall - At some point during a summer session, you pulled me aside and shared a message of "you belong here; your voice/perspective are important." Your words were powerful and have stuck with me. Your aptitude matches your love for this work. You are the type of educator that I look up to. I am so grateful that I was able to be in your classroom and soak up some of that Dr. Wall magic. 
Kristi Schulte - You saw potential in me right out of graduate school and helped set me on a path. In the beginning, I didn't know what to make of all your books and your intentional approach to learning and whatnot. After some time, you lit a fire in me and became my go-to person to "nerd out" with. The pieces I love most about this work are deeply connected to the foundation for learning that you helped establish. Thank you for being the first to push me to dig deeper and root my work in scholarship and thoughtfulness.

Dr. Tina Sheppard - When you offered to review and provide feedback on my research proposal, you meant it. What you offered up may have felt small to you, but you helped give me some much-needed traction. I sincerely appreciate your no-nonsense feedback that is always balanced with warmth and humor.

Dr. Dorie Paine - For the past four years, you consistently supported me as I have completed this degree program. You held space as I was away from work to attend class, you have patiently indulged my need to share the latest 'new' topic I have learned about in class, and you have allowed me to process what I am learning about our students through my dissertation research. Thank you for seeing me through this process! Dr. Mia Starmer-Reisweber - I am not sure I would have applied for this program if it weren't for your enthusiastic persistence. You helped me fall in love with learning. I am forever grateful for your influence in my life. You are an invaluable mentor and friend. Jefferson City Cohort - My love and admiration for this talented group of educators is endless. Learning alongside each of you has been an honor. To Merilee and Steph- the time spent with you in the car for two years going to and from class is counted among my most special memories. I am so grateful to count you both as dear friends. 


\section{TABLE OF CONTENTS}

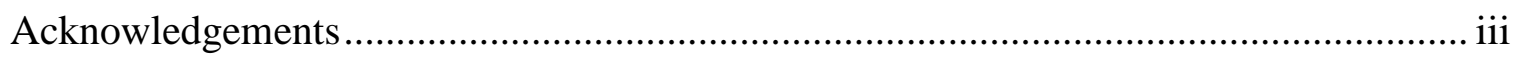

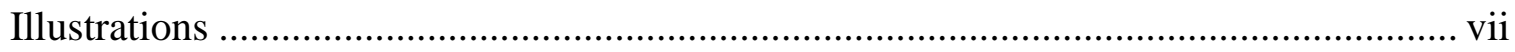

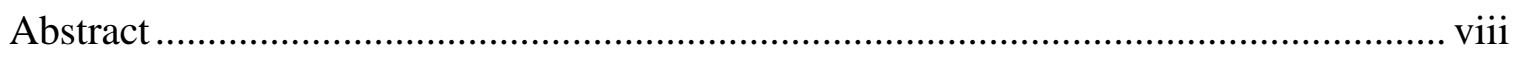

Section One:Introduction to the Dissertation-in-Practice ........................................... 1

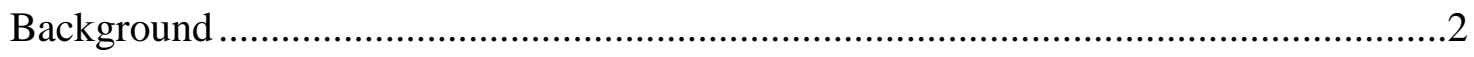

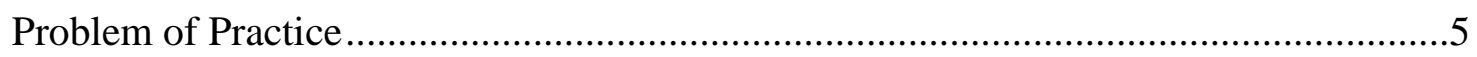

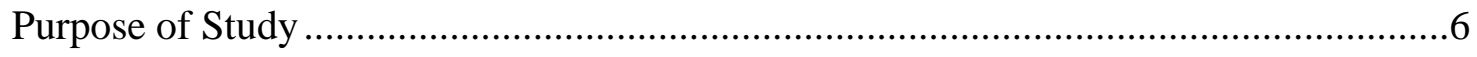

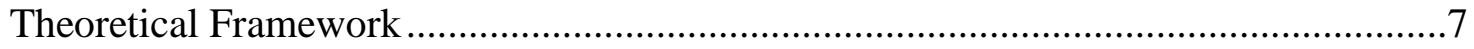

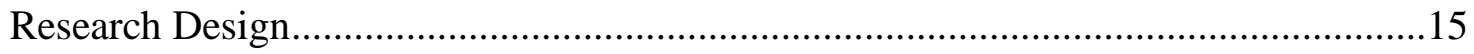

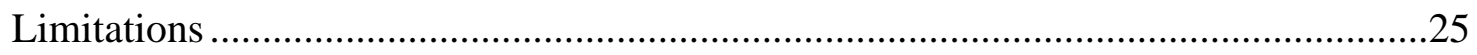

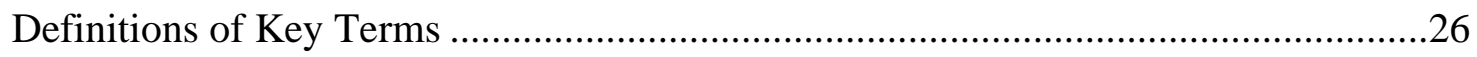

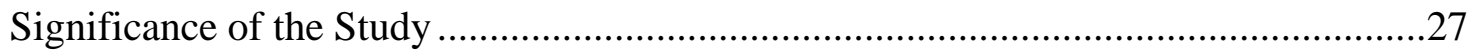

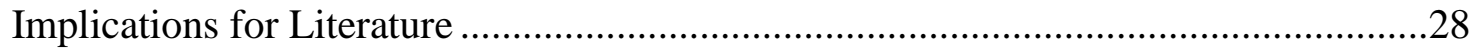

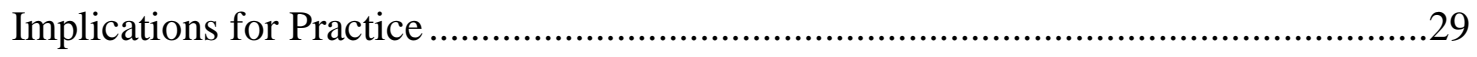

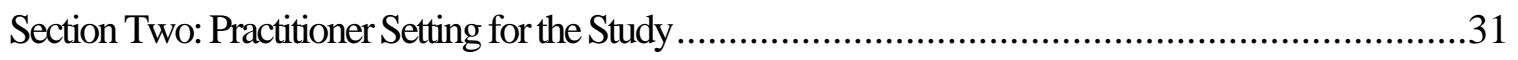

Setting: Department of Residential Life at Missouri S\&T .......................................32

Implications for Research in the Practitioner Setting ..........................................36

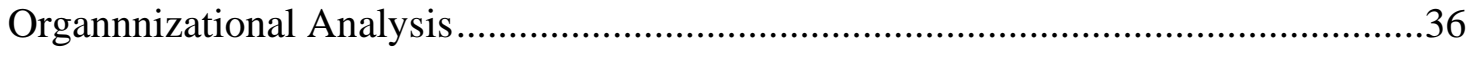

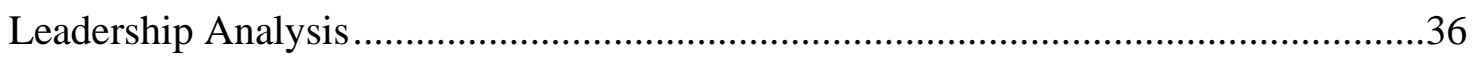


Section Three: Scholarly Review

Standards for Facilitating Learning Beyond the Classroom .....................................41

Student Affairs Paradigm Shift ...........................................................................44

Astin: Understanding the Impact of Environment ...............................................47

Outcome: Independent Living Skills Development.............................................49

Environment: Residential Education and Experience............................................56

Inputs: Personal Characteristics and Pre-College Experiences ..................................60

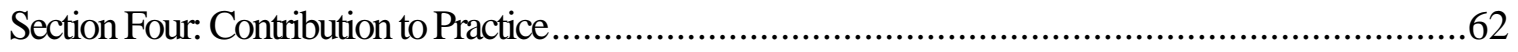

Plan for Dissemination.........................................................................................63

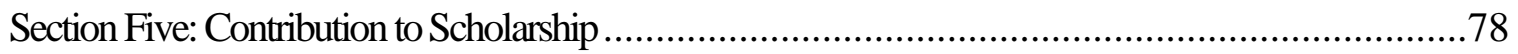

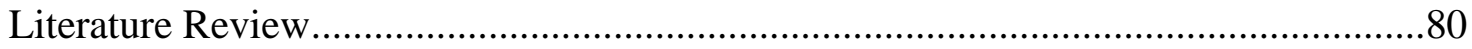

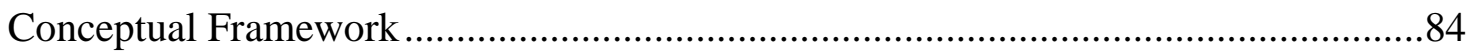

Research Methodology ................................................................................. 91

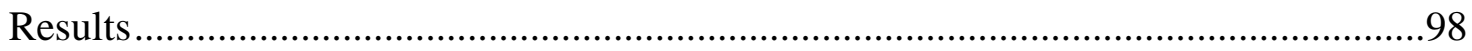

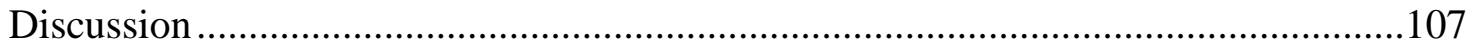

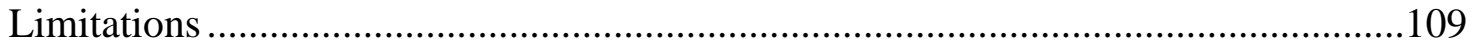

Implications for Research and Literature .....................................................109

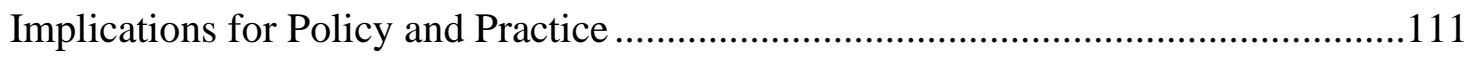

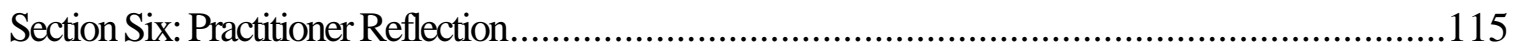

The Dissertation Process and My Role as an Educational Practitioner ......................116 
The Dissertation Process and My Role as a Scholar.

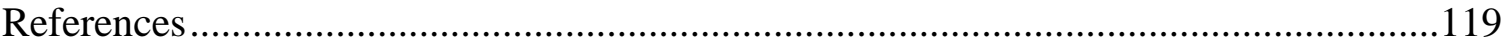

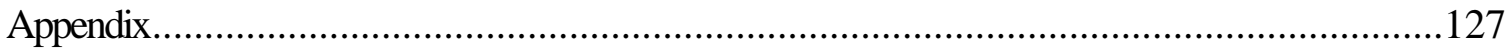

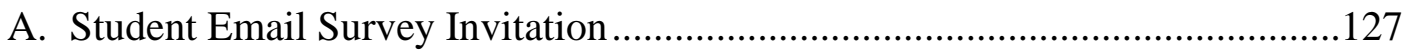

B. Focus Group Registration Form........................................................ 128

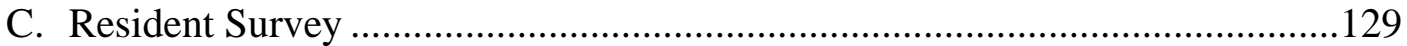

D. Focus Group Protocol ....................................................................................141

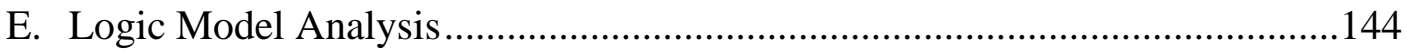

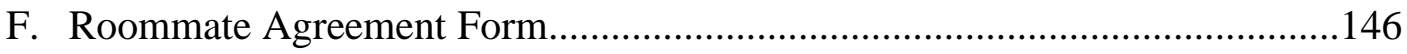

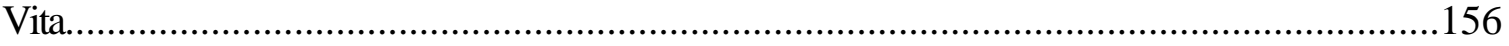




\section{ILLUSTRATIONS}

$\begin{array}{lll}\text { Figure } & \text { Page }\end{array}$

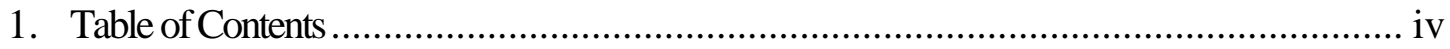

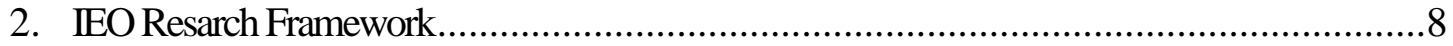

3. Managing Student Life and Learning in Residence Halls (Blimling, 2015) .........13

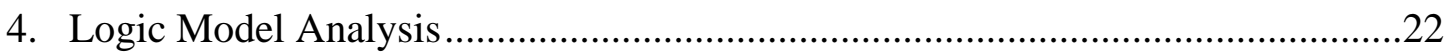

5. Missouri S\&T Educational Priority, Learning Objectives, and Goals.....................34

6. The Data Information Knowledge Wisdom Pyramic .............................................48

7. The Essential Elements of a Curricular Model for Learning Beyond the

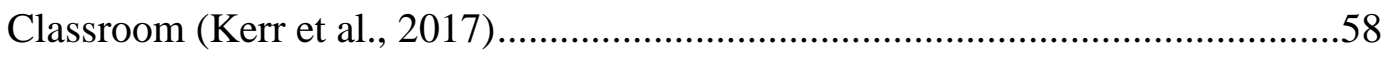

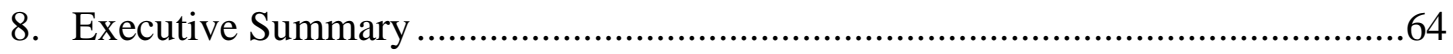

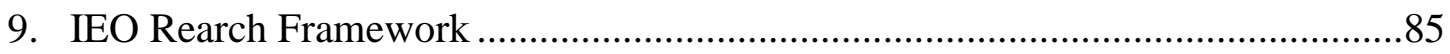

10. Managing Student Life and Learning in Residence Halls (Blimling, 2015) .........88

11. Sociodemographic Characteristics of Survey Respondents....................................93

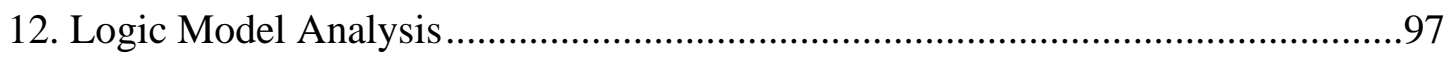

13. Independent Living Skills Quantitative Data Report............................................98 


\begin{abstract}
This mixed-methods case study examined how students perceived the development of independent living skills because of their residence hall experience. Using Astin's (1993) Inputs-Environment-Outputs (IEO) framework to guide the research methodology and analyze data, this study highlighted the importance of students living with, and among, their peers in shared living space. Sharing living spaces with peers was found to be a key contributor to developing interpersonal and intrapersonal skills. Students expressed the importance of the residence hall experience during their first year and highlighted the relationship with their Resident Assistant as the most significant residence hall intervention strategy. Upperclass students discussed wanting fewer points of contact with residence hall staff, resources, and programs. Lastly, residence hall leadership positions (Resident Assistant and Hall Government involvement) were noted as significant contributors to developing independent living skills associated with interacting with others. Findings will inform adjustments to the Resident Assistant role in upperclass student living areas and help address specific learning strategies that students shared some helpful perspective and insight regarding their effectiveness (e.g., roommate agreement). This study established a research framework that will support future research regarding the residence hall experience.
\end{abstract}




\section{SECTION ONE}

INTRODUCTION TO THE DISSERTATION-IN-PRACTICE 
Over 2,100 colleges and universities across the United States offer on-campus housing and just over 3.2 million students reside on-campus while attending college (National Center for Educational Statistics, 2019). In the state of Missouri, 64 colleges and universities offer on-campus housing with over 68,000 students living on-campus (National Center for Educational Statistics, 2019). Missouri University of Science and Technology (Missouri S\&T), the location for this study, houses 95\% of the first-time, first-year students and $45 \%$ of all undergraduate students in college-owned, -operated, or -affiliated housing.

The first residence halls began to be constructed by universities in the 1930s. Hevel (2016) explained that beginning in the 1930s, to manage the chaos related to student behavior in the residence halls, the Dean of Students position evolved into a livein staff role. Deans of Men and Deans of Women became established roles at universities across the United States. Deans created student government groups that enforced housing rules to prepare students to take part in the American democracy post-graduation.

The Student Learning Imperative, published by the American College Personnel Association (ACPA) in 1996, tasked student affairs practitioners to "intentionally create the conditions that enhance student learning and personal development" (p. 1). Practitioners were challenged to consider how to align their practices to foster selfreflection, problem-solving skills, interpersonal relationship skills, and personal development. Practitioners were challenged to ensure our work focuses on contributing to our university mission and students' educational and personal goals. Twenty-five years later, this publication continues to serve as a call to action for student affairs practitioners and a reminder of the purpose practitioners pursue. 
Learning Reconsidered (Learning Reconsidered 1): A Campus-Wide Focus on the Student Experience (Keeling, 2004) and Learning Reconsidered 2: A Practical Guide to Implementing a Campus-Wide Focus on the Student Experience (Keeling, 2006) served as road maps that outlined the path for student learning beyond the classroom for student affairs practitioners. The National Association of Student Personnel Administrators (NASPA) and The American College Personnel Association (ACPA)supported the creation and publication of both Learning Reconsidered 1 and 2. The elements outlined in Learning Reconsidered 2 include considerations of how learning happens, identifying the environments where student learning happens, aligning learning strategies with the university mission, and using learning outcomes to drive learning strategies. These elements were integral in developing the residential curriculum approach to student learning in residence halls.

Residential education programs have showcased a notable evolution on the heels of the student affairs paradigm shift with the residential curriculum approach's conception. Kerr and Tweedy (2006) describe the University of Delaware's experiences, where the residential curricular approach, later referred to as the curricular approach to student affairs or the curricular approach to learning beyond the classroom, was first established. A curricular approach emphasizes student learning beyond the classroom by using learning goals, outcomes, and educational strategies to steer student learning strategies implemented by residence hall staff. Assessment serves to gauge how learning strategies impact students. Harper and Quaye (2009) called out the shallow attempt at student learning previously utilized in residence halls as the "myth of magical thinking" 
(p. 23). The curricular approach includes the intentional implementation of learning strategies in residence halls paired with assessing their effectiveness.

Missouri S\&T's Department of Residential Life's educational priority and student learning objectives and outcomes ultimately aim to support students in seeking and obtaining meaningful employment in their chosen field. Residential Life's role in learning beyond the classroom starts with students becoming connected to the university community. Once students are connected, their wellness as they navigate their higher education experience is paramount. Missouri S\&T Residential Life works with a highachieving student population. Department staff recognize from our work that managing mental well-being needs through the student of concern and student conduct processes, that personal wellness is a crucial contributor to student success. Lastly, developing skills that contribute to lifelong success, rooted in career preparation, rounds out the student experience on-campus and launches students into post-college life. Through the lens of residential life professionals, our department staff recognize that developing independent living skills to thrive personally is foundational to moving into the professional world post-college.

The curricular framework is more than academic buzzwords that sound impressive. Missouri S\&T’s Residential Life's department leans on our educational priority as a mantra to ground our decisions and ensure we consider how we expend our resources. Student learning objectives guide our staff training programs, student programming and motivate our partnerships with campus stakeholders and educational experts. My role as Associate Director allows me the opportunity to keep this framework at the forefront of our work. I oversee and lead our staff training programs, manage our 
residence hall staff's efforts in developing learning opportunities for residence hall students, and facilitate assessment practices to gauge how effective our efforts are when meeting our objectives and outcomes. This research study allows me to provide deeper insight into how students move toward lifelong success and what role the residence hall experience at Missouri S\&T plays in supporting their development of independent living skills.

\section{Problem of Practice}

Residential life programs face growing criticism from university leadership, students, families, and even state lawmakers (Derosier, 2017). Some universities uphold a requirement that new students live on campus for a specific time period. The cost of oncampus housing options and the rising cost of higher education draw scrutiny (DouglasGabriel, 2015, Oliver, 2019). Factors such as maintaining facilities and operation costs associated with programming and staffing contribute to the inflated price to live oncampus (Derosier, 2017, Kerr et al., 2020). These areas of scrutiny lead to residential life staff defending the benefits of on-campus living. Mayhew et al. (2016) ascertain that most research studies regarding on-campus living experiences do not reasonably address the benefits of living on-campus. Learning Reconsidered 2 (2006) explains that the means, knowledge, and staffing resources to evaluate programs' impact are often left out when implementing learning strategies (Keeling, 2006).

This study investigates the student experience as they develop interpersonal and intrapersonal skills development. Interpersonal and intrapersonal skills have a direct correlation to a student's sense of belonging. Specifically, studies have demonstrated that depression, feelings of isolation, and social anxiety are significantly reduced when 
college students experience a sense of belonging (O'Keeffe, 2013; Moeller et al., 2020). The significant problem of practice that I explored addresses the need to know more about how student development happens in the residence halls. Limited research exists that highlights effective strategies to facilitate student development in the residence halls. Missouri S\&T's residential life department has established a set of learning outcomes that emphasize the development of independent living skills. Due to the intensive opportunity, residence halls offer students regarding peer interactions, insight from this study offers insight into how students develop interpersonal and intrapersonal skills in the residence halls. Findings will improve our residential education program and highlight how the development of interpersonal and intrapersonal skills best occurs in residence halls.

\section{Purpose of the Study}

This study contributes to the knowledge about the learning and development strategies implemented by residence hall staff that are most helpful in supporting students' development of independent living skills, as well as what strategies are less effective or need adjustments. This research is essential as previous research that narrowly looks at residence hall learning strategies and their impact on these skills does not exist. The purpose of this mixed-methods case study is to describe how the Department of Residential Life at Missouri S\&T impacts students' perceptions of learning as it relates to developing independent living skills, with special focus on interpersonal and intrapersonal skills development. I explore the department's educational interventions and strategies used to develop independent living skills. This research may also highlight opportunities to realign educational and engagement strategies to address learning outcomes better. 
Bresciani et al. (2009) explain, "Outcomes-based assessment uses the results of the assessment to change and improve how a program, a department, a division, or an institution contributes to student learning" (p. 16). Continuous improvement or striving to provide students with the most meaningful learning opportunities means that our curriculum beyond the classroom is reviewed regularly and improved based on outcomes assessment. This established value related to continuous improvement bolsters framing this research as a case study program review. The aim is to utilize research findings to determine best practice for impacting students' ability to practice independent living skills.

This study addressed the following research question: How do students perceive their development of interpersonal and intrapersonal skills due to the residence hall experience at Missouri S\&T? To date, limited research exists that describes the specific process for determining a curricular approach's influence has on student learning. This study contributes to scholarship by adding to the existing research addressing student learning in residence halls.

\section{Theoretical Framework}

In this case study, I applied Astin's (1993) Inputs-Environments-Outcomes (IEO) framework to guide my research. Astin's framework helps identify how the college experience influences students. Student pre-college experiences (I), the residence hall environment (E), and student development of interpersonal and intrapersonal skills (O) make up the components of this study. Figure 2 highlights these specific components. In this section, I describe the components that make up the IEO framework in this study. 


\section{Figure 2}

IEO Research Framework

\section{Input: Personal Characteristics \& Pre-College Experiences}

- Sociodemographic traits (sex, race/ethnicity, socioeconomic status)

- Psychosocial qualities (self-confidence, social experiences, motiviation, self-management)

\section{Environment: Residence Hall Experience}

- Relationship with residence hall staff

- Participation in educational programs

- Engagement with other students living in the residence hall community

\section{Outcome: Interpersonal \& Intrapersonal Skills} Development

- Perception of learning related to the development of interpersonal and intrapersonal skills

Context is important. Scholar-practitioners cannot take a prescriptive approach to establish strategies for student learning. Learning is not one size or strategy fits all. The IEO framework first establishes what characteristics students possess as they enter college. Educational practitioners account for these characteristics as they create programs that aim to address independent living skills. Dean (2013) explains,

Students learn and develop as a result of their interactions with the total collegiate environment, including the programs and services with which they engage. We need to understand our students, we need to understand the programs and services they experience, and we need to understand the effects that their experiences have on their learning and development. (p. 28) 
When we measure outcomes, we must do so with the intent to address any

changes that may need to occur with our programs because of the insight gained from our research (Dean, 2013). The following subsections highlight some additional frameworks that bolster the IEO framework and add additional context to this research study.

\section{Outcome: Developing Interpersonal and Intrapersonal Skills}

In the context of Astin's theory (1993), outcomes include characteristics, knowledge, attitudes, beliefs, and values that a student possesses because of their college experience. Astin describes outcomes as a function or development of inputs and environments. This sub-section outlines the specific outcomes associated with independent living skills, looking closely at interpersonal and intrapersonal skills, that this study explores.

Chickering and Reisser (1993) establish a framework for considering how college students develop their identity. Their framework includes seven developmental vectors or tasks that students face when they attend college. These tasks are not accomplished all at once. Instead, these developmental markers are acquired after repeated experience, which fosters or facilitates development. The college environment offers many avenues for learning. Much of this learning occurs beyond the classroom experience.

For this study, Chickering and Reisser's third vector, developing autonomy, inform research on developing interpersonal and intrapersonal skills. This vector's successful mastery involves managing to be emotionally self-sufficient and learning to navigate life without the persistent need for comfort, affirmation, and approval from others. This vector also establishes the developmental tasks of taking care of oneself from a practical standpoint by becoming independent from one's family unit. This transition 
includes participating in activities related to managing day-to-day tasks that address personal needs. For college-age students, this could consist of problem solving, initiative, and self-direction.

The Council for the Advancement of Standards (CAS) published "Frameworks for Assessing Learning and Development Outcomes (FALDOs)" under the leadership of principal author Dr. Terrell Strayhorn and his associates (2006). The authors describe a digestible explanation of rationale and methods for assessment. Learning assessment addresses two distinct purposes: improvement and accountability. The term improvement suggests the importance of a summative approach to gathering insight into developing programs, policies, or educational strategies. The act of accountability considers the summative impact of programs, policies, and strategies, addressing overall effectiveness.

For this study, I use the FALDOs to serve as a framework for exploring specific variables related to developing independent living skills. The authors describe the developmental phase of working toward independence to be characterized by "increased emotional and instrumental independence, which includes self-directedness and freedom from the need for validation of others. A clear sense of identity leads toward selfacceptance, self-reliance, and ultimately an understanding of one's connectedness with others" (p. 79). To elaborate further, the authors provided the following list of constructs related to developing interpersonal and intrapersonal skills.

- $\quad$ Exhibits ability to function interdependently

- $\quad$ Makes decisions and acts in congruence with personal values

- Identifies personal, work, and lifestyle values

- $\quad$ Accepts supervision as needed 
- $\quad$ Functions without need for constant reassurance from others

- $\quad$ Acknowledges individual strengths and weaknesses

- $\quad$ Sets and pursues individual goals (Strayhorn et al., p. 80)

Strayhorn et al. (2006) acknowledge that this list is not comprehensive of all possible variables. It does serve as a starting point for assessing learning related to developing independent living skills.

Interpersonal and intrapersonal skills fall under the larger umbrella of emotional intelligence. Emotional intelligence, using the most basic definition, refers to the ability to recognize and navigate one's own emotions as well as the emotions of others (Goleman \& Cherniss, 2001). Emotional intelligence has great significance for college students because they are launched into community living and collaborative learning which creates many situations in which they must learn to navigate social interactions and relationships.

Goleman (1998) established a competency model which describes four constructs of emotional intelligence. These constructs which align with interpersonal and intrapersonal skills include self-awareness, self-management, social awareness, and relationship management. Self-awareness is the act of identifying one's own emotions, understanding the impact of their emotions, and appropriately using their emotions to guide decision making. Self-management establishes that an individual can manage their own emotions and compulsions which leads them to better adapt to change. Social awareness is the capability to anticipate, recognize, and respond to another person's emotions. Lastly, relationship management is the ability to influence, motivate, and support other people with navigating conflict (Goleman, 1998). Goleman emphasized that 
these competencies are not natural gifts or talents, rather they must be learned and actively pursued by individuals. Goleman's model bolsters the work of Strayhorn et al. (2006) by narrowing the lens, focusing on how emotional intelligence supports the competence of interpersonal and intrapersonal skills.

\section{Environment: Residence Hall Experience}

While Astin (1993) emphasizes several environmental factors resulting in a spectrum of outcomes intended to result from the college experience, this study focuses on how the residence hall environment impacts independent living skills development. Residence halls, as a stand-alone entity, foster student learning just from their pure existence. Blimling (2015) explains,

If residence life professionals did nothing but assigned students to residence halls and left students alone, students would still learn from each other. What they learned, how much they learned, and how safe the environments might be is open to conjecture. (p. 88)

Residential life professionals and student staff work to enhance the residence hall environment by providing experiences that optimize student learning. This section outlines some specific strategies in which residence hall staff employ to shape experiences in the residence halls to promote independent living skills development.

There are five critical aspects of a residential life professional's work, established by Blimling (2015), that we call upon to create learning experiences in the residence halls. These dimensions include: (1) developing and using residential curriculums and learning experiences; (2) employing instructional methods; (3) managing the learning environment; (4) providing advocacy and institutional representation; and (5) conducting 
and using assessment. Table 1 offers some examples of strategies for each of the five student learning areas in the residence halls. I investigate these examples of learning strategies to identify how they impact student learning related to developing independent living skills.

Table 1

Managing Student Life and Learning in Residence Halls (Blimling, 2015)

Managing Student Life and Learning in Residence Halls

\begin{tabular}{|c|c|}
\hline Student Learning Dimension & Example of Learning Strategies \\
\hline $\begin{array}{l}\text { Developing and Using } \\
\text { Residential Curriculums } \\
\text { and Learning } \\
\text { Experiences } \\
\end{array}$ & $\begin{array}{l}\text { - Student Conduct } \\
\text { - Residence Hall Government } \\
\text { - Programs and Activities } \\
\text { - Learning Communities }\end{array}$ \\
\hline $\begin{array}{ll}2 & \text { Employing Instructional } \\
\text { Methods }\end{array}$ & $\begin{array}{l}\text { - Counseling and Advising Students, Making } \\
\text { Referrals as Needed } \\
\text { - Structuring the Peer Environment, Utilizing } \\
\text { Resident Assistants } \\
\text { - Direct Feedback and Support } \\
\text { - Crisis Management }\end{array}$ \\
\hline $\begin{array}{l}3 \text { Managing the Learning } \\
\text { Environment }\end{array}$ & $\begin{array}{l}\text { - Emergency Management } \\
\text { - Student Safety } \\
\text { - Building Maintenance } \\
\text { - Building Services (front desk operations, } \\
\quad \text { mail, laundry) } \\
\end{array}$ \\
\hline $\begin{array}{l}4 \text { Providing Advocacy and } \\
\text { Institutional } \\
\text { Representation }\end{array}$ & $\begin{array}{l}\text { - Parent Relations } \\
\text { - Student Advocacy } \\
\text { - Efforts to Improve the Quality of Student } \\
\text { Life } \\
\text { - Building Liaison Relationships with other } \\
\text { Campus Departments }\end{array}$ \\
\hline $\begin{array}{l}5 \text { Conducting and Using } \\
\text { Assessment }\end{array}$ & $\begin{array}{l}\text { - Student Satisfaction Surveys } \\
\text { - Learning Assessment } \\
\text { - Resident Assistant Training Assessment }\end{array}$ \\
\hline
\end{tabular}

Transition to adulthood is supported by feedback from others, which helps students recognize their movement toward their goals. Blimling (2015) describes what this feedback process looks like for students: 
Faced with the fundamental problems of understanding and controlling their worlds in ways that make them more predictable and easier to transition into adulthood, students sometimes struggle, make poor decisions, and need feedback and support that helps them move forward with their development. (p.82)

Students may feel stuck when faced with a dilemma. Residence hall staff customarily provide feedback to students on various developmental subjects, including academic success, relationships, campus involvement, self-management, navigating roommate dynamics, and personal behavior.

Making referrals to campus support services such as counseling, student health, and academic support services is an important intervention strategy for students who need additional support in moving through challenges. Blimling elaborates, "Although students often have the basic knowledge they need to resolve problems, they frequently need help in evaluating the options and circumstances objectively" (p. 83). The student sometimes initiates this feedback process. Other times, residence hall staff initiate this process through the student conduct process, residence hall programs or hall governance groups, or peers' referrals.

\section{Inputs: Personal Characteristics and Pre-College Experiences}

Astin (1993) describes inputs, or personal characteristics, and experiences students bring as they enter college. These characteristics may include demographic details such as class standing, race, and gender, in addition to factors such as the ACT or SAT scores and personal motivation. This sub-section further elaborates on input factors that influence student development of independent living skills. 
Ethnic and racial, among additional important social, personal, or cultural attributes, may influence the impact a student's experience in residence halls. Tierney (1992) expressed that becoming connected to a campus community may be more challenging for students with cultural backgrounds and values that do not align with most of their peers. They may express that they feel less supported on campus. In contrast, Chang et al. (2006) described the intensive personal development and learning fostered through interactions among students with varying backgrounds. These opposing considerations highlight the spectrum of impact of residence hall environments on a diverse student population.

Women studying science, technology, engineering, and math (STEM) represent $17.3 \%$ of the overall population of first-year women enrolled in higher education, whereas 32.2\% of men enrolled major in STEM fields of study (Pryor et al., 2009). The competitive nature of STEM fields has been established as a barrier for women to connect with their peers. STEM courses often emphasize competition in the classroom. Competition in the classroom emphasizes individual academic success versus encouraging a shared, cooperative learning experience (Correll \& Hewitt, 1997; Sax et al., 1996; Strenta et al., 1994). Barker and Garvin-Doxas (2004) established that women preference cooperative forms of learning over a competitive environment. Missouri S\&T has a strong focus on STEM fields, and the gender ratio closely aligns with what Pryor et al. (2009) described.

\section{Research Design}

This sub-section outlines the study design used to capture insights about residence hall students' development of independent living skills at Missouri S\&T. Using Astin's 
(1993) IEO framework. This mixed-methods case study examines the environmental factors which may have contributed to student's development. The following research question guides this study: How do students perceive their development of interpersonal and intrapersonal skills due to the residence hall experience at Missouri S\&T? This subsection is arranged using five topics: description of the case study, research setting, participant description, data collection tools, and data analysis.

\section{Case Study}

Merriam and Tisdell (2016) describe case study research as "the search for meaning and understanding" (p. 37). This case study carries great significance for me. My priority as an educational practitioner is ensuring students are learning and developing skills beyond the classroom. A case study research approach helps me understand students' particular experiences in the residence halls at Missouri S\&T and explore how the residence hall environment facilitates their independent living skills

development. The end product is a "richly descriptive" (p. 26) collection of students' experiences, informing my educational practice in the residence halls.

Creswell (2013) defines case study research as "a qualitative approach in which the investigator explores a bounded system (a case) ...through detailed, in-depth data collection involving multiple sources of information (e.g., observations, interviews, audio-visual material, and documents and reports), and reports a case description and case-based themes" (p. 97). Residence halls at Missouri S\&T are the bounded system where the case, residence hall student learning, is explored. 


\section{Setting}

This illustrative mixed-methods case study involves residence hall students who have lived in the residence halls at Missouri University of Science and Technology (Missouri S\&T). Missouri S\&T is a public land grant institution and member of the University of Missouri System. Most of the 8,096 students study engineering, business, sciences, and mathematics. However, the 99 degree programs offered also address subjects such as information science and technology, humanities, and arts. (Missouri S\&T, 2020).

Merriam (1998) established that the most significant case study research characteristic is setting the case's boundaries. Merriam explains, "...the case as a thing, a single entity, a unit around which there are boundaries" (p. 27). For this research study, the case is the student learning strategies implemented as a part of the residential curriculum. This case study aimed to provide "an intensive, holistic description and analysis of a bounded phenomenon" (p. xiii). The bounded phenomenon is the development of independent living skills in the residence halls.

The residence halls at Missouri S\&T include both traditional style and suite or apartment-style units. Traditional style residence halls refer to double occupancy bedrooms, typically shared with one other individual, with shared community restrooms located on each floor. Each floor shares a lounge and kitchen space where students gather to study and socialize. Suite or apartment-style units offer additional privacy for students. This housing option includes private and double occupancy bedrooms located in a suite with anywhere between 4 to 8 students. Semi-private restrooms are in each suite or apartment and only shared among the individuals assigned to that particular suite or 
apartment versus the entire residence hall floor. Suites and apartments include living room space and furniture, kitchen or kitchenette, and washer and dryer units (Missouri S\&T, n.d.).

While suite or apartment-style housing options are popular among college students and their families, it does serve to establish a challenge for residence hall staff. Suite and apartment-style housing increase the barriers or number of doors between Resident Assistant staff and students. This set-up creates a unique challenge for fostering relationships and interactions with residents. Furthermore, students living in suite-style or apartment-style housing do not have to leave their space as frequently as students living in traditional residence halls. This behavior is primarily due to the amenities provided in their suite or apartment, such as a restroom, kitchen, lounge space, washer, and dryer. The minor inconvenience of students going down the hall to use the bathroom or going to the first floor to do laundry offers students an opportunity to interact with their peers, including their Resident Assistant. Every day or regular interactions among peers and residence hall staff serve as a foundation for further connection and learning.

Due to the physical differences noted above between suite or apartment-style and traditional housing, my findings report unique and similar ways learning occurs in both types of housing options. This distinction is essential as insights about how the physical environment impacts student engagement in learning strategies inform our continued residential curriculum approach to developing independent living skills in each housing area (Brown et al. 2019). 


\section{Participants}

This study engaged students living in the residence halls at Missouri S\&T during the 2019-2020 academic year. Looking at the Spring 2020 fourth week occupancy numbers, the total occupancy in the residence halls was 1,625 students (A. Walters, personal communication, April 7, 2021). All students living in residence as of the fourth week of the Spring 2020 semester received an email (see Appendix A) sent from the Residential Life department email account on my behalf, inviting them to participate in this research study. The email included a link to a survey that prompted students to reflect on their perceived development of independent living skills. 124 students completed the survey. Once students submitted the survey, their web browser automatically loaded an optional focus group registration form (see Appendix B). Interested participants completed the focus group registration form and submitted their responses. Krueger and Casey (2009) advise that the optimal size for a focus group is five to eight participants. For this study, I facilitated two focus groups involving a total of 11 student participants.

The research protocol was submitted for approval by the Institutional Review Board (IRB) at the University of Missouri. Upon approval for research from the IRB, residence hall student participant contact was made via the housing software system email function with permission and support of the Director of Residential Life. This message was sent from the Residential Life department email account on my behalf.

\section{Data Collection Tools}

This study's primary instrument was a survey (Appendix C) distributed to students who lived in the residence halls during the 2019-2020 academic year. Creswell (2009) explains, "A survey design provides a quantitative or numeric description of trends, 
attitudes, or opinions of a population by studying a sample of that population" (p. 145). A survey was the best choice to start this two-stage research study as it helped capture a wide variety of perspectives.

Survey respondents provided a retrospective account of their experiences in the residence halls related to developing independent living skills. The survey asked participants to indicate their level of competence before and after living in the residence halls at Missouri S\&T. The three competence areas include interpersonal, intrapersonal, and practical skills. Participants then indicated how residence hall support resources such as staff, other students, educational programs, residence hall government, student conduct interventions, and services impacted their development of independent living skills. After participants submitted their survey responses, they were redirected to a registration form to opt into participating in a follow-up focus group.

Krueger and Casey (2009) explain that focus groups have five consistent features: they involve people, these individuals share specific characteristics, qualitative data is collected, there is focused discussion, and they support understanding the topic being researched. This study aims to engage individuals who live in the residence halls to gather qualitative data to highlight their lived experiences related to developing independent living skills due to the residence hall experience. Krueger and Casey explain that focus groups can be used for evaluation purposes, considering what works well and what does not. Focus group questions explored different student engagement strategies and asked participants to explain the impact these strategies have had on their development of independent living skills (see Appendix D). 
Krueger and Casey (2009) highlight that focus groups help researchers to see the topic at hand "through the eyes and hearts of the target audience" (p. 8). The core goal for utilizing a focus group was to understand how residence hall students perceive, understand, and value the residence hall experience related to developing independent living skills. As a researcher, I aimed to identify how our residence hall experience may be improved to emphasize further how we promote independent living skills. Krueger and Casey explain that focus groups involve a three-stage process. Krueger and Casey's first stage was addressed through my research, which includes understanding the residence hall students' perceptions of developing independent living skills in the residence halls. As a result of this research, learning strategies will be adjusted to impact independent living skills development more strongly and purposefully. Future research studies will address how these adjustments have affected skills development leading to further revision of learning strategies and evaluation.

I recruited a student research assistant familiar with the residence hall experience to help capture focus group members' insights. Each focus group interview was recorded and transcribed using transcription software. Having the focus groups recorded and transcribed allowed my research assistant and I to stay focused and utilize the semistructured interview approach to gain valuable insight from focus group participants instead of being concerned with notetaking.

\section{Data Analysis}

Focus group data was read and initially categorized using open coding. Merriam and Tisdell (2016) describe open coding as being open to any themes that come up in the data versus searching for specific themes. After reviewing focus group transcripts and 
notes, open coding notes were used to identify categories. This process is referred to as analytical coding, which allows researchers to extrapolate and consider the meaning of what participants share.

Categorized data was then analyzed by looking for patterns utilizing a logic model. Astin's (1993) IEO framework, described in the theoretical framework section, is mirrored in the logic model used for data analysis (see Table 2). Logic models allow researchers to identify cause-effect scenarios. For this case study, the cause-effect relationship being studied looks at what residence hall learning strategies influence students' development of independent living skills. Based on themes that emerge, theories about how the residence hall experiences influence student's development of independent living skills may be identified (Baškarada, 2014).

\section{Table 2}

Logic Model Analysis

\begin{tabular}{|c|c|c|c|}
\hline & Input & Environment & Outcomes \\
\hline $\begin{array}{l}\text { Framework } \\
\text { description }\end{array}$ & $\begin{array}{l}\text { Personal } \\
\text { Characteristics and } \\
\text { Pre-College } \\
\text { Experiences }\end{array}$ & $\begin{array}{l}\text { Residence hall } \\
\text { experiences }\end{array}$ & $\begin{array}{l}\text { Perception of } \\
\text { learning related to the } \\
\text { development of } \\
\text { interpersonal and } \\
\text { intrapersonal skills }\end{array}$ \\
\hline
\end{tabular}

\begin{tabular}{llll}
\hline & & $\begin{array}{c}\text { - Relationship with } \\
\text { residence hall staff }\end{array}$ & \\
Research & • Prior experiences & - Participation in & • Participant \\
Study & reported by & educational programs & perceptions of \\
Details and & students that they & - Engagement with other & $\begin{array}{l}\text { learning related to } \\
\text { the development of }\end{array}$ \\
Findings & bring to Missouri & students living in the & interpersonal and \\
& S\&T & residence hall & intrapersonal skills \\
& & community &
\end{tabular}

\section{Validity and Reliability}


Merriam and Tisdell (2016) ascertain, "validity and reliability are concerns that can be approached through careful attention to a study's conceptualization and the way in which the data are collected, analyzed, and interpreted, and the way in which the findings are presented" (p. 238). The four concepts most strongly adopted in qualitative research to ensure validity and reliability include credibility, transferability, dependability, and confirmability. This sub-section describes how these concepts were utilized in this research to account for validity and reliability.

Credibility. Merriam and Tisdell explain that internal validity or credibility speaks to how research findings align with the reality of what is being studied. One strategy Merriam and Tisdell offer to help support validity are to ensure that there are enough participants providing insight about a phenomenon or occurrence that saturation is met. Saturation occurs when no new information or insights are revealed from additional data being collected.

This study invited students living in the residence halls during the 2019-2020 academic year, using the fourth week of Spring 2020 occupancy, to participate in this study. Fourth-week occupancy was 1,625 students. Of these students, 124 responded to the survey, and 11 students participated in two focus groups. After sending a survey reminder email and facilitating the second focus group, it was clear that any new data would be redundant, and saturation had been met.

Triangulation, one of the most utilized strategies to increase credibility, involves engaging in more than one method or sample group (Merriam \& Tisdell, 2016). Data was triangulated by using three sources of data including quantitative and qualitative survey data along with focus groups. Focus groups to unpack survey data further and ensure 
understanding of survey responses. Two focus groups were facilitated, engaging 11 student participants. Focus group questions were adjusted to target specific themes that came up in survey data and further explore assumptions.

Transferability. Transferability considers to what extent research findings can be applied to other scenarios or, in this instance, other residential life programs (Merriam and Tisdell, 2016). Many residential life programs employ a curricular approach to their work (Brown, 2021). As such, findings may be easily considered by departments as to help inform their practice as they work to implement learning strategies. The rich description of the research setting, the research methodology, and the findings will support transferability to other residential life programs.

Dependability. Merriam and Tisdell (2016) establish that reliability is the degree to which research outcomes could be duplicated. These assertions are not made without acknowledging that reliability is a problematic concept when completing qualitative research involving human behavior. Considering that the human experience is unique, particularly in different environments when it comes to qualitative research, reliability looks a bit different. Merriam and Tisdell explain that the important consideration when addressing dependability ensuring that the results are consistent with the data.

The scope in which research results are consistent with the data being collected was reviewed and discussed with the student research assistant and department director. To support this review, the focus group protocol was consistently followed, and notes were taken alongside the protocol (Krueger \& Casey, 2009). This review process contributed to the validity of this study by weighing in on the dependability of the 
research findings or the degree to which the results are consistent with the data collected (Merriam \& Tisdell, 2016).

Confirmability. Merriam and Tisdell (2016) describe confirmability as the assurance that research findings are shaped by participants more so than they are defined by the researcher. One strategy they offer to account for confirmability is for researchers to practice reflexivity. Reflexivity is the practice of researchers considering their own positionality within the study and considering how this may influence the research process.

Reflexivity was considered throughout the study, including topic selection, developing methodology, data analysis, and establishing research findings. The research findings were confirmed by utilizing a logic model for coding and drawing conclusions about the data (see Appendix E). Assumptions from focus groups were discussed with a research assistant immediately following each focus group. This step allowed me to process through my reactions and conclusions during the focus group process (Merriam \& Tisdell, 2016). Quantitative data were analyzed using a T-test which helped establish numeric reliability when making assumptions about research findings.

\section{Limitations}

This retrospective study relied on participant reflections on previous experiences in the residence halls. It is assumed that participant-reported experiences are honest reflections of lived experiences. Krueger and Casey (2009) identify some critical limitations for utilizing focus groups. Participants tend to discuss their experiences in a more thoughtful or positive light. However, much of human behavior is unconscious. The 
triangulation of qualitative data through two different focus groups aimed to address this potential limitation.

Due to the university's response to the COVID-19 pandemic, most residence hall students and Resident Assistant staff moved out of the residence halls in the middle of March. This shift meant that students did not live in the residence halls for approximately eight weeks of the spring 2020 semester. As such, participants had a more limited experience to draw from.

\section{Definitions of Key Terms}

Residence halls: A residence hall is a building designed to house student residents on a college campus.

Residential life: A department at a university that provides on-campus housing for students in addition to ongoing, regular support and resources aimed at promoting student success, well-being, and persistence.

Residential curriculum: Residential curriculum, or sometimes referred to as a curricular approach, describes an intentional approach to fostering learning in university residential life programs.

Traditional residence hall: Traditional-style residence halls describe double occupancy bedrooms, typically shared with one other individual, with shared community restrooms located on each floor. Each floor shares a lounge and kitchen space where students gather to study and socialize.

Suite or apartment-style residence hall: Suite or apartment-style units offer additional privacy for students. This housing option includes private and double occupancy bedrooms located in a suite with anywhere between 4 to 8 students. Semi-private 
restrooms are located in each suite or apartment and only shared among the individuals assigned to that particular suite or apartment versus the entire residence hall floor. Suites and apartments include amenities such as living room space and furniture, kitchen or kitchenette, and in certain areas, washer and dryer units

Resident Assistant (RA): The RA is a paraprofessional role and typically held by undergraduate students who are sophomore standing or above. RAs live in an assigned community or residence hall floor where they serve in a peer mentor role and advise a select number of resident students.

Resident Director (RD): RDs are full-time professional staff members who live and work in residence halls. Individuals in these roles focus on building relationships with students, mentoring, and providing educational programs that address personal, professional, and academic development topics in addition to administrative tasks associated with residence hall management. RDs typically have master's degrees in higher education and student development.

\section{Significance of the Study}

The stories captured regarding the lived experiences and learning that is taking place in residence halls at Missouri S\&T provide valuable context as our department continues to develop and enhance our educational strategies that address the development of independent living skills offered in the residence halls. Findings indicated the need to adjust learning strategies and staff engagement with upperclass students. If we aim to build on the residence hall experiences offered to first-year students, we must establish 
strategies that support independent living skills development as students progress into their second year and beyond.

An added benefit is being able to share our story about our residence hall program with interested parties. There is value in describing a scholarly approach to families, students, administrators, and faculty on-campus. Being able to reference scholarly literature, best practice, and research findings is a valuable tool for establishing credibility as a department and promoting the impact of learning beyond the classroom. With the heightened sense of accountability in higher education and residential life, being able to clearly describe the impact of programs and how they support student learning is imperative and what we do to pursue continual improvement (Kennedy, 2016).

\section{Implications for Literature}

As noted in the introduction section, there is an existing gap in the literature that addresses the curricular approach for learning beyond the classroom. This study helps to address this gap by exploring one of our department's student learning outcomes and identifying ways in which it is being fulfilled by residential learning strategies. This example of learning assessment serves as a framework for other practitioners to explore how the learning outcomes they have established as part of a residential curriculum are being addressed through their efforts. Findings indicated a significant shift in what students need and want as they move into their second year living in the residence halls and beyond. There is a substantial amount of literature that addresses persistence in the sophomore year (Hunter, 2010; Schaller, 2018). However, looking specifically at the residence hall experience and needs of students in their second year and beyond is a more focused area of study that this study highlights. 


\section{Implications for Practice}

There are two key audiences that I will share findings with: current and past department full-time staff and Student affairs division leadership. This section outlines how I will disseminate details of my research findings to these groups, including a description of documents, format for meeting in person, and rationale for this contribution. I am most eager to share findings with my department staff. These individuals are most closely connected to the work and research included in this study. While I will invite all full-time department staff to participate, the Resident Directors are the staff specifically tasked with implementing and overseeing the student learning strategies described in this study. I will present my research and findings to the department staff during a department meeting. Resident Directors will receive a copy of section five of this dissertation in advance so they may read and review more in-depth details of the study. I have prepared a one-page executive summary and PowerPoint for the department meeting to serve as a visual aid while discussing the key points outlined in the executive summary. I will send my executive summary to division leadership to highlight the findings and action items that resulted from this study.

This study's significance sits largely within the Department of Residential Life at Missouri S\&T. This study showcases one example of how our work to promote student learning is established through a scholarly approach. This research is an important benefit to external constituents. Additionally, internally, this research will inform our practice and help our department adjust our learning strategies. 


\section{Summary}

The curricular approach to engaging students beyond the classroom in higher education has been a rewarding venture with the Department of Residential Life at Missouri S\&T. Curriculum in any setting is intended to address specific learning objectives. Evaluation of impact is a significant gap among practitioners in student affairs (Kennedy, 2016). Through this research study, exploration of curricular strategies' impact will inform practice, promote continual assessment, and explore valuable insight about how to best assess learning in and beyond the classroom. 


\section{SECTION TWO}

PRACTITIONER SETTING FOR THE STUDY 
The purpose of this mixed-methods case study is intrinsically tied to the setting the residence halls at Missouri S\&T. This study describes how the learning strategies implemented by staff with the Department of Residential Life at Missouri S\&T impact student's perceptions of developing independent living skills. Findings will inform educational practitioners working in the residence halls and further support student learning beyond the classroom. This section describes the Department of Residential Life at Missouri S\&T, analyzes the organization, and highlights my professional role with the department.

\section{Setting: Department of Residential Life at Missouri S\&T}

Missouri S\&T is a mid-size research institution enrolling 6,462 undergraduate students and 1,634 graduate students (Missouri S\&T, 2020). The institution is known for engineering programs but offers 99-degree programs that include arts, science, business, and technology. The Department of Residential Life at Missouri S\&T has a housing capacity of 2,057 students. Fall 2019 fourth week occupancy was 1,844 students and Spring 2020 fourth week occupancy was 1,625 students (A. Walters, personal communication, April 7, 2021). Students are required to live on campus during their first and second years. The class-standing breakdown of students living in the residence halls on campus during the Fall 2019 semester included 845 first-year students, 625 sophomore students, and 374 upperclass students (A. Walters, personal communication, October 21, 2020).

The residence halls include both traditional style and suite or apartment-style units. Traditional style residence halls describe double occupancy bedrooms, typically shared with one other individual, with shared community restrooms located on each floor. 
Each floor shares a lounge and kitchen space where students gather to study and socialize. Suite or apartment-style units offer additional privacy for students. This housing option includes private and double occupancy bedrooms located in a suite with anywhere between 4 to 8 students. Semi-private restrooms are in each suite or apartment and only shared among the individuals assigned to that suite or apartment versus the entire residence hall floor. Suites and apartments include living room space and furniture, kitchen (or kitchenette), and in certain areas, washer and dryer units (Missouri S\&T, n.d.).

While suite or apartment-style housing options are popular among college students and their families, it does serve to establish a challenge for residence hall staff. Suite and apartment-style housing increase the barriers or number of doors between Resident Assistant staff and students. This setup creates a unique challenge for fostering relationships and interactions with residents. Furthermore, students living in suite-style or apartment-style housing do not have to leave their space as frequently as students living in traditional residence halls. This behavior is primarily due to the amenities provided in their suite or apartment, such as a restroom, kitchen, lounge space, washer, and dryer. The minor inconvenience to students that they must go down the hall to use the bathroom or go to the first floor to do laundry offer an opportunity to interact with other students, including their Resident Assistant. Every day or regular interactions among peers and residence hall staff serve as a foundation for further connection and learning.

Due to the physical differences noted above between suite or apartment-style and traditional housing, my findings will specifically note unique and similar ways learning occurs in both types of housing options. This distinction is essential as insights about how 
the physical environment impacts student engagement in learning strategies will inform our continued residential curriculum approach to developing independent living skills in each housing area (Brown et al., 2019).

The Residential Life department at Missouri S\&T shifted our approach to student engagement and learning by establishing an educational priority and student learning objectives and outcomes. The educational priority statement is our promise to students regarding what they can expect to gain from living in the residence halls. It summarizes the learning objectives and highlights that by living in the residence halls, we aim to provide students with opportunities to connect with others, focus on their wellness, and work toward lifelong success. Figure 1 outlines the specifics of these guiding principles. Learning objectives one and three are most reflected in this research as they address student development related to awareness of how they interact and impact others as well as how they manage the ability to development independent living skills.

The first learning objective, experiencing connectedness, involves students identifying with and connecting with a community. Whether the community is a residence hall community, fraternity or sorority, or student organization the opportunity to connect with others is rich in providing developmental opportunities. Once a student finds a connection within a community, they then have the opportunity to mindfully contribute to their community. This implies an awareness of how one impacts the community with their words and actions. The culminating experience when engaging in a community is finding value and supporting those who may come from different backgrounds or possess a different identity. The third learning objective, developing skills that contribute to lifelong success, establishes the importance of obtaining and 
developing skills that will ultimately support career readiness. Examples related to interpersonal and intrapersonal skills center around effective communication skills.

\section{Figure 1}

Missouri S\&T Educational Priority, Learning Objectives, and Goals

\begin{tabular}{|c|c|}
\hline & Missouri S\&T Educational Priority Statement \\
\hline & $\begin{array}{l}\text { Upon completion of their on-campus residential experience students will have } \\
\text { fostered meaningful connections, developed skills for personal wellness, and } \\
\text { demonstrated responsibility for lifelong success. }\end{array}$ \\
\hline & Missouri S\&T Student Learning Objectives and Outcomes: \\
\hline 1) & $\begin{array}{l}\text { Each student will experience a sense of connectedness } \\
\text { o Students will be able to: } \\
\text { - Identify and connect with a community } \\
\text { - Demonstrate mindful contributions to their communities } \\
\text { - Understand their impact within social interactions } \\
\text { - Find value in engaging with individuals of diverse backgrounds }\end{array}$ \\
\hline 2) & $\begin{array}{l}\text { Each student will develop skills related to personal wellness } \\
\text { ○ Students will be able to: } \\
\text { - Identify and utilize wellness and mental health resources } \\
\text { - Understand personal needs related to wellness } \\
\text { - Practice self-care } \\
\text { - Demonstrate healthy support of others }\end{array}$ \\
\hline 3) & $\begin{array}{l}\text { Each student will develop skills contributing to lifelong success } \\
\text { o Students will be able to: } \\
\text { - Communicate effectively and professionally } \\
\text { - Develop skills for independent living } \\
\text { - Identify opportunities to promote career readiness }\end{array}$ \\
\hline
\end{tabular}




\section{Implications for Research in the Practitioner Setting}

This research is needed at Missouri S\&T because it allows the educational practitioners working in the department to continue enhancing their residential education programs and strategies. Assessment practices are essential to the continued development of programs. Learning assessment helps to ensure student needs are being met. The organization's impact includes added knowledge regarding how specific strategies such as student interactions with residence hall staff, participation in the roommate agreement process, and residence hall services affect student development and learning. Research findings help influence necessary adjustments to residence hall learning strategies or validate that the existing practices are effective.

\section{Organizational Analysis}

Bolman and Deal (2017) offer the human resource frame as a viewpoint for evolving an organization. To accomplish our educational priority, objectives, and outcomes, Missouri S\&T's Department of Residential Life utilizes a tiered staffing structure. The residence hall experience is shaped by residence hall staff, including Resident Assistants (RAs). RAs are students who serve in a peer mentor role. RAs are typically assigned to a residence hall floor or community and advise a select number of resident students. Resident Director (RD) staff are full-time staff who live and work in residence halls. Individuals in these roles focus on building relationships with students, mentoring, and providing educational programs that address personal, professional, and academic development topics. The residence halls offer a unique opportunity for peer-topeer interactions, which I explore with this study. 
Bolman and Deal's human resource framework is a helpful lens to analyze research data from a staff training and supervision perspective. Themes related to how we do our work in the residence halls emerged from the research data. Bolman and Deal highlight the importance of allowing employees to perform their jobs well. Research findings will inform adjustments to job duties and areas where additional training or support may be needed. A key example of this shift is the changes to how RAs in primarily first-year living communities engage their residents versus RAs in primarily returning student communities. Adjustments to RA expectations will be made to account for each group's needs and wants from their residence hall experience. I anticipate that these adjustments will increase RA job satisfaction as they may see a more direct impact from their work with residents.

Our department's tiered staffing structure requires leadership on multiple levels. Our leadership practice centers on productive relationships, mutual benefit between the department and individuals, and learning. An extensive training program serves as a foundation for sustaining and improving upon our residential education program. This study explores our student engagement strategies' effectiveness and identifies opportunities to improve our staff training programs.

\section{Leadership Analysis}

My journey of linking theory and research to practice was propelled forward when I began to accept my new identity as a scholar-practitioner. Perry (2016) suggests, "The Steward of the Practice sits in two worlds - the world of practice and the world of scholarship" (p. 302). As a practitioner, I use my job-related training to perform specific skills. As a scholar, I must utilize research to address problems of practice. Taking a 
critical look at the residence hall experience and exploring how we address our learning goals is an essential step to being a scholar-practitioner. This study serves as a framework for future research that informs my practice.

Embracing the identity as a scholar-practitioner was accompanied by a heightened sense of responsibility. Three core themes surfaced in my practice: scholarship, the role data plays, and balancing acting as a leader and manager. Scholarship connects with being a persistent learner and contributing to the existing knowledge within our field. Poston and Boyer (1990) explained, "What we urgently need today is a more inclusive view of what it means to be a scholar- a recognition that knowledge is acquired through research, through synthesis, through practice, and through teaching" (p. 24). Integrating research in my practice lends a sense of credibility to my work. Exploring insights other scholars have contributed to the field of residential life has widened my perspective.

As a leader in my department, I have provided professional development for my team to broaden our professional perspective. Some examples of professional development include discussions on shared readings of journal articles, participation in webinars offered by leading scholars in our field, or simply encouraging them to explore what research exists on a specific problem of practice they are facing. In addition to research findings being shared with department staff, the research process will be highlighted and used as an example to propel future department research studies as we further expand upon our knowledge about how our efforts influence student learning.

\section{Summary}

As the Associate Director for our department, I oversee staff hiring, supervision, and training in addition to providing direction for our residential curriculum efforts. My 
positionality is critical to this study. My role was also an important consideration to be mindful of as I interacted with research participants. I maintain a level of power and influence to create positive change in the residence halls if utilized appropriately. By presenting findings to department staff, I aim to showcase and role model scholarpractitioner work and highlight ways to adjust our work to facilitate student learning and development. 
SECTION THREE

SCHOLARLY REVIEW 
The purpose of this mixed-methods case study was to describe how the Department of Residential Life at Missouri S\&T impacts students' perceptions of learning related to developing independent living skills. The goal was to better understand to what extent educational initiatives are addressing the development of independent living skills. The specific research question guiding this study is: How do students perceive their development of interpersonal and intrapersonal skills due to the residence hall experience at Missouri S\&T?

Student affairs, as a professional field, has experienced a significant evolution over the past century. Our field has moved from a parental approach toward an emphasis on student learning (Barr \& Desler, 2000). This section is organized as follows: First, I discuss standards for facilitating student learning beyond the classroom. I highlight a series of scholarly resources that have provided traction for our field's evolution and eventual paradigm shift to a curricular approach. The scholars who crafted this research have paved a path which informs my study exploring how students perceive their development of interpersonal and intrapersonal skills in residence halls. Next, I review relevant literature using Astin's (1993) Inputs-Environment-Outputs (IEO) model as a framework. Lastly, I define and discuss how independence is developed in early adulthood. The significant problem of practice related to this evolution is the gap in knowledge regarding how a curricular approach impacts student learning independent living skills.

\section{Standards for Facilitating Student Learning Beyond the Classroom}

The Council for the Advancement of Standards (CAS) in Higher Education has served the higher education community since 1979. The Council's mission is as follows: 
"CAS, a consortium of professional associations in higher education, promotes the use of its professional standards for the development, assessment, and improvement of quality student learning, programs, and services" (CAS, 2015). CAS has published a series of standards addressing various areas within higher education to guide our work. For this study, the CAS standards for learning and development will best add context.

Six domains make up the CAS learning and development outcomes: knowledge acquisition, cognitive complexity, intrapersonal development, interpersonal competence, humanitarianism, civic engagement, and practical competence. Each domain includes more specific learning outcome dimensions and examples of what behaviors or skills make up that dimension. The practical competence domain encompasses the development of independence, the focus of this study. The dimension under the practical competence domain that addresses independence is managing personal affairs. The examples provided for this learning dimension focus on self-sufficiency, time management, and financial management. These dimensions lack some more fundamental examples of independent living, including personal care, problem-solving skills, and self-advocacy. This study will include these additional dimensions.

To allow scholar-practitioners to dig deeper into assessment practices, CAS published Frameworks for Assessing Learning and Development Outcomes under the leadership of principal author Dr. Terrell Strayhorn and his associates (2006). Strayhorn and associates succinctly summarize theoretical contexts, relevant variables and provide assessment examples for a collective of categories for student learning from career choice to spiritual awareness. This resource is easily digestible and offers thoughtful implementation options for scholar-practitioners. 
For this study's purpose, I explore the framework for assessing student learning and development regarding independence. The authors describe the developmental phase of working toward independence to be characterized by "increased emotional and instrumental independence, which includes self-directedness and freedom from the need for validation of others. A clear sense of identity leads toward self-acceptance, selfreliance, and ultimately an understanding of one's connectedness with others" (p. 79). To elaborate further, the authors provided the following list of variables related to developing independence.

- Exhibits self-reliant behaviors

- Exhibits ability to function interdependently

- Manages time effectively

- Makes decisions and acts in congruence with personal values

- Identifies personal, work, and lifestyle values

- Manages personal finances well

- Accepts supervision as needed

- Functions without need for constant reassurance from others

- Acknowledges personal strengths and weaknesses

- Sets and pursues individual goals (Strayhorn et al., p. 80)

The authors acknowledge that this list is not comprehensive of all possible variables. It does serve as a starting point for assessing learning related to developing independence. 


\section{Student Affairs Paradigm Shift}

One of the pioneers in Student affairs, LeBaron Russell Briggs, was appointed Student Dean at Harvard in 1890. As Student Dean, Briggs addressed student behavior. Instead of taking a punitive approach, Briggs recognized the value of learning both in and beyond the classroom. His approach was among the first steps toward establishing a student affairs approach. Over the next 50 years, education pioneers such as Briggs continued to be concerned with the student experience beyond the classroom (Barr \& Dessler, 2000).

The Student Personnel Point of View was published in 1937 and later revised in 1949 by the American Council on Education Studies. This work established a philosophy and framework for the newly vested profession of student affairs. The authors asserted, "The development of students as whole persons interacting in social situations is the central concern of student personnel work and other education agencies. This emphasis on contemporary education is an essential part of the student personnel point of view" (p. 2). The authors outlined several conditions related to a student's development. Orientation to the college environment, academic success skills, living environment, sense of belonging, wellness, self-awareness, and career exploration and readiness were among the authors' conditions.

The Student Personnel Point of View was instrumental in moving our profession away from the idea of in loco parentis or faculty taking on a disciplinary and parental role. Instead, student affairs staff members had the opportunity to impact student learning and development (Barr \& Desler, 2000). However, this publication did not age flawlessly. There is a nationalist messaging that fails to account for diverse experiences. 
The authors express, "The cultural patterns of America have been, and will continue to be, deeply affected by the emergence of the United States as a world power. With the nation's new status in world affairs, the preservation of basic freedoms and responsibilities at home becomes increasingly important" (p. 4). This statement, noting the United States as a world power, preserving fundamental freedoms, alludes to a sense of us versus them. The revised publication, published in 1949, was written as post-World War II veterans entered college utilizing the Servicemen's Readjustment Act (U.S. Department of Education, 1993). Roberts (2012) highlights that the most significant differences between the 1937 and 1949 of the student personnel point of view included moving toward specializations, shifting from enhancing learning to providing services, and less of a focus on community and more on individualized attention to student needs.

Fast forward nearly 100 years, and our field has experienced a dramatic paradigm shift. During the 1990s through the 2000s, student affairs work was further established and rooted in student development and learning. The Student Learning Imperative, published by the American College Personnel Association (ACPA) in 1996, incites student affairs practitioners to "intentionally create the conditions that enhance student learning and personal development" (p. 1). ACPA outlined five characteristics of a learning-oriented student affairs division. These characteristics dictate:

1. The student affairs division mission complements the institution's mission, with the enhancement of student learning and personal development being the primary goal of student affairs programs and services.

2. Resources are allocated to encourage student learning and personal development. 
3. Student affairs professionals collaborate with other institutional agents and agencies to promote student learning and personal development.

4. The division of student affairs includes staff who are experts on students, their environments, and teaching and learning processes.

5. Student affairs policies and programs are based on promising practices from the research on student learning and institution-specific assessment data.

Practitioners had to consider how to align their practices to foster self-reflection, problem-solving skills, interpersonal relationship skills, and personal development. We must also ensure our work focuses on contributing to our university mission and students' educational and personal goals.

Twenty-five years later, this publication continues to serve as a call to action for student affairs practitioners and a reminder of our purpose. The characteristics outlined in this research served as a launching pad for continued elaboration on our work's nuances in student affairs. Learning Reconsidered 1: A Campus-Wide Focus on the Student Experience (Keeling, 2004) and Learning Reconsidered 2: A Practical Guide to Implementing a Campus-Wide Focus on the Student Experience (Keeling, 2006) bolster student affairs practitioner's work and serve as a road map toward student learning. A consortium of the major student affairs professional organizations published Learning Reconsidered 1 and Learning Reconsidered 2. Richard Keeling took the lead in compiling the research in these works.

When these publications came out, I was still very new in the field. It felt over my head and did not align with my previous experiences in student affairs and residential life. The paradigm shift toward focusing on student learning was significant and very 
apparent to me. Years later, the critical approaches outlined in Learning Reconsidered 1 and Learning Reconsidered 2 are simply a part of my intuitive practice. The elements outlined in Learning Reconsidered 2 guide the implementation, including considerations of how learning happens, identifying the environments where student learning happens, aligning learning strategies with the university mission, and using learning outcomes to drive learning strategies. Most notable for this study, Learning Reconsidered 2 describes the path for assessing our educational strategy's impact, which I will address later in this scholarly review.

\section{Astin: Understanding the Impact of Environment}

This sub-section will discuss Astin's (1993) IEO framework and review relevant literature addressing the framework's three areas. Astin established a framework for considering how college impacts students by looking at inputs-environments-outcomes. This framework, which is among the most cited theories used in higher education, acknowledges that students have experiences that occur before coming to college and general attributes that influence their college engagement and how they develop or change due to the college environment. Inputs, or personal attributes, may include sociodemographic factors and lived experiences before coming to college. Experiences such as personal trauma, relationships with others, or death of a close relative or friend have a significant impact on a person's development. Demographic information such as class standing, race, gender, ACT or SAT scores, and citizenship also influence input. Considering these personal characteristics and experiences, researchers may consider how the college environment impacts student learning, leading to specific outcomes. 
Inputs, coupled with the college environment, work hand and hand to mold student development. The environment includes student affairs programs, residential life staff interactions, policies, and faculty. This model indicates that any research intended to discern how the college experience impacts students will include substantial bias if measures to control inputs are not considered. Often, the research findings that do not utilize IEO will overestimate the learning strategy's impact (Astin, 1993). Executing research and collecting data is only one part of the journey toward understanding how students develop independent living skills. According to Kennedy (2016), "In the world of campus housing assessment, data points are the clay that will become bricks, but having the data isn't always enough" (p. 55). Kennedy explains that data requires a cohesive process of gathering, organization, and arrangement to highlight themes among the data as we create connections. That sounds so simple, but many scholar-practitioners consider data management a daunting task, especially when using software to manage data. Challenges with managing data is an obstacle that Kennedy implores us to overcome. The author references Russell Ackoff's journal article From Data to Wisdom, to expand upon this notion.

Ackoff (1989) created the Data Information Knowledge Wisdom (DIKW) pyramid, illustrated in Figure 3, to describe how data moves to wisdom. Ackoff explains that data represents aspects of factors such as programs or environments. The elements which we collect as data come about due to our observations. The data we collect is relevant until we can download it into a usable form. Information is the breakdown of data and is simply the answer to questions. Ackoff explains that these questions often start with who, what, when, and how many. 


\section{Figure 3}

The Data Information Knowledge Wisdom Pyramid

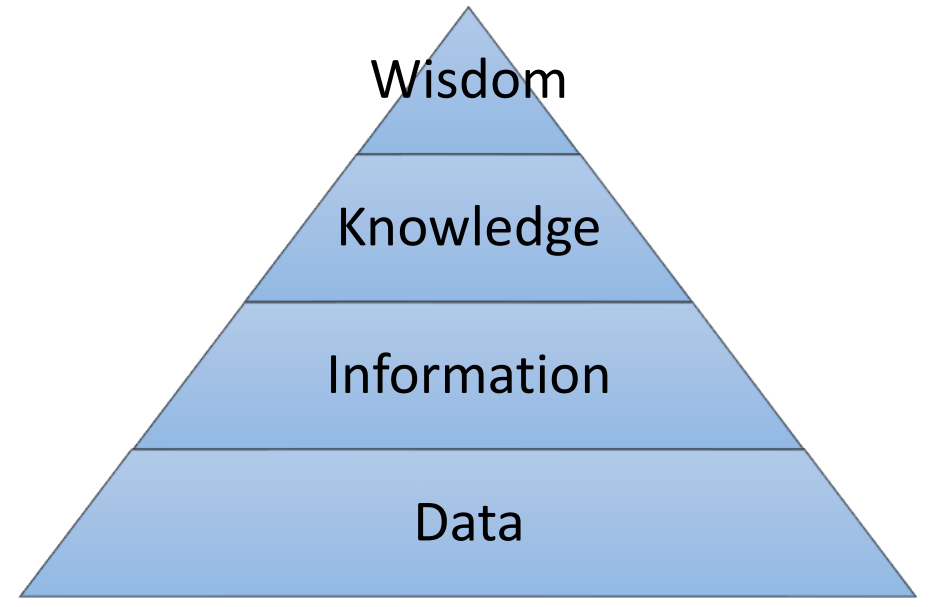

Knowledge is the process of taking information and turning it into action.

Knowledge has the fluid ability to be passed from one person who has it to another who does not. Individuals may attain knowledge through lived experiences. Wisdom is the final step. Wisdom allows us to utilize the insights we gain from data collection and create positive change. As a scholar-practitioner, this framework is empowering. Often data reporting is sold as a means for accountability or maintaining funding for programs. Ackoff's framework highlights this study's path and emphasizes the ultimate motivation for engaging in program review research. The focus of this research is ultimately to provide more significant opportunities for student learning.

\section{Outcome: Independent Living Skills Development}

This sub-section will highlight literature that discusses independent living skills development. Including literature that addresses independent living skills development is essential to this study as it defines specific skills that our department works to develop in students. 


\section{Defining Independence and Emerging Adulthood}

"[Independence] has to do with a sense of one's own identity. It involves an ability to act independently and to exert some control over one's environment and includes a sense of task mastery, internal locus of control, self-agency, and self-efficacy" (Benard, 1995, p. 67). College-age students living on their own for the first time in a residence hall can explore their independence as they move into adulthood. Buzz words such as those noted in this established definition of independence point to understanding oneself and being rooted in the knowledge of having agency and control of one's choices, life direction, and priorities.

Arnett (2000) noted that individuals only begin to define themselves as adults in their late twenties and early thirties. Similarly, individuals age 18-25 do not identify as adolescence. They indicate that they are neither adults nor adolescents. Hence, Arnett describes individuals in this age range as emerging adults. Arnett draws upon the foundation work explored by Erikson (1968), Levinson (1978), and Keniston (1971) and the conclusions they made about emerging adulthood. These three researchers all described emerging adulthood as an internal grapple between a sense of self and finding one's place in society to move toward being an established member of society. Arnett acknowledges their contributions but rebukes by noting that societal changes challenge their theories. The timeframe for the transition to adulthood has shifted to the late twenties. The late teens and early twenties are consumed with perusing the many options for one's life (Arnett, 2000).

Chickering and Reisser (1993) establish a framework for considering how college students develop their identity. Their framework includes seven developmental vectors or 
tasks that students face when they attend college. These tasks are not accomplished all at once. Instead, these developmental markers are acquired after repeated experiences, which fosters or facilitates development. For this study, Chickering and Reisser's third vector, developing autonomy, will inform research on developing independent living skills. This vector establishes the developmental tasks of taking care of oneself from a practical standpoint by becoming independent from one's family unit. This transition includes participating in activities related to managing day-to-day tasks that address personal needs. For college-age students, this could consist of problem solving, initiative, and self-direction. Emotional independence and being able to self-soothe and work through problems effectively are a part of this vector.

Emerging adulthood is also a phase of one's life that allows for time to grapple with identity. Arnett (2000) explains that love, work, and worldviews are among the critical aspects of identity explored. Establishing identity comes about by testing out a broad spectrum of life experiences. For this study, establishing identity related to work is among the most significant. Through the college experience, emerging adults become more attentive to working toward a profession. College students do this by trying on different majors of study, frequently changing their degree programs more than once. Arnett argues that this behavior is not necessarily fully intended to lead to the path to adulthood. "On the contrary, the explorations of emerging adulthood are in part explorations for their own sake, part of obtaining a broad range of life experiences before taking on enduring — and limiting_adult responsibilities" (p. 474).

The drive to collect a broad range of life experiences may increase risky behaviors such as unprotected sex, substance use, and unsafe driving. Another motivator 
for engaging in risky behavior is sensation seeking. Arnett notes, "Emerging adults can pursue novel and intense experiences more freely than adolescents because they are less likely to be monitored by parents..." (p. 475). Emerging adults also tend not to have roles such as parent or spouse, which may deter them from engaging in risky behaviors. The accountability to others that accompany these roles leads to a decrease in risky behavior (Arnett, 2000).

\section{Developing Independence}

Now that I have established what independent behaviors look like, it is crucial to explore how students develop independent living skills. Mayhew, et al. (2016) describe psychosocial changes experienced during the college years. A key source of psychosocial development in college includes experiences that cause chaos or disruption. The college environment offers students the opportunity to face unique challenges. These challenges move individuals along Erikson's eight stages of psychosocial development. Erikson $(1963,1968)$ explains that challenges result in developing strengths that support the individual to resolve subsequent challenges. This development occurs sequentially from birth to adulthood. Traditional college-age students tend to straddle stages five and six, focusing on identity development and relationships (McCleod, 2018). Mayhew et al. (2016) found a significant increase in leadership, positive self-concept, and independence from perceived authority figures due to the college experience. The researchers did note that some students backslide concerning identity development during this period. (Mayhew et al., 2016).

Concerning the impact of on-campus residential living, Mayhew et al. (2016) report some concerning insights. "...on-campus residence in the twenty-first century is 
sparse for most outcomes, and the findings often do not suggest benefits of the experience" (p. 545). The researchers note mixed findings of subject matter proficiency, cognitive growth, and attitudes related to diversity. A collection of research studies report that residing on campus harms mental health, most notably in the first year of college (Mayhew et al., 2016).

Still, researchers continue to identify positive results from living on campus. Blimling (2015) explains that the most typical type of independent living option within on-campus housing is apartments owned and managed by the university. The significance of offering apartment-style housing on campus fosters opportunities to develop the selfconfidence needed to pursue independence. Blimling (2015) describes, "The community experience of conventional residence halls that is so important to their psychosocial development and to their integration into the university community as first- and secondyear students become less critical as they mature and seek increased independence" (p. 113). Students face new encounters related to managing roommate relationships and a shared living environment when they transition to apartment-style housing (Blimling, 2015).

\section{Interpersonal and Intrapersonal Skills Development}

As this study evolved, I narrowed my focus when looking at independent living skills to concentrate on interpersonal and intrapersonal skills development. Chickering and Reisser (1993) established developing mature interpersonal relationships as the fourth of their seven vectors related to identity development. The developmental tasks in this vector include "development of intercultural and interpersonal tolerance and appreciation of differences, as well as the capacity for healthy and lasting intimate 
relationships with partners and close friends" (Evans et al., p. 39). The residence hall environment offers students ample opportunity to experience situations that require them to manage relationships and engage with others. Similarly, intrapersonal skills are stretched in the residence halls as students learn to navigate life, circumstances, and challenges independently. The National Research Council (2011) describes intrapersonal skills as "talents or abilities that reside within the individual and aid him or her in problem solving" (p. 63). Examples of these skills include self-management, time management, personal development, self-regulation, adaptability, and executive functioning. While living in a residence hall, away from one's family, the autonomy offered is bolstered by support resources, staff, and peers to help ensure students persist and effectively navigate developmental challenges.

Interpersonal and intrapersonal skills fall under the larger umbrella of emotional intelligence. Emotional intelligence, using the most basic definition, refers to the ability to recognize and navigate one's own emotions as well as the emotions of others (Goleman, 2001). Emotional intelligence has great significance for college students because they are launched into community living and collaborative learning which creates many situations in which they must learn to navigate social interactions and relationships.

Goleman established a competency model which describes four constructs of emotional intelligence. These constructs which align with interpersonal and intrapersonal skills include self-awareness, self-management, social awareness, and relationship management. Self-awareness is the act of identifying one's own emotions, understanding the impact of their emotions, and appropriately using their emotions to guide decision 
making. Self-management establishes that an individual can manage their own emotions and compulsions which leads them to better adapt to change. Social awareness is the capability to anticipate, recognize, and respond to another person's emotions. Lastly, relationship management is the ability to influence, motivate, and support other people with navigating conflict (Goleman, 1998). Goleman emphasized that these competencies are not natural gifts or talents, rather they must be learned and actively pursued by individuals.

Lopes et al. (2003), found that emotional intelligence directly impacts an individual's satisfaction with social relationships. Most notably research participants expressed having greater levels of emotional regulation which led to them being more likely to report experiencing positive relationships with others. Interpersonal and intrapersonal skills directly connect to navigating relationships which is an essential skill when it comes to a student experiencing a sense of belonging. Strayhorn (2012) defines sense of belonging in college students as:

In terms of college, sense of belonging refers to students' perceived social support on campus, a feeling or sensation of connectedness, and the experience of mattering or feeling cared about, accepted, respected, valued by, and important to the campus community or others on campus such as faculty, staff, and peers. (p. 4)

The residence hall experience centers around community living and connections. Supporting students in navigating interpersonal relationships and pursuing their own sense of belonging is essential. Depression, feelings of isolation, and social anxiety are significantly reduced when college students experience a sense of belonging (Moeller et 
al., 2020; O'Keeffe, 2013). Residence hall intervention and engagement strategies have the capacity to support students as they seek social connections in pursuit of belonging.

\section{Summary}

Scholars in student affairs are gathering momentum in fully embracing and practicing the curricular approach to student learning beyond the classroom. However, a substantial gap in peer-reviewed research and literature on the residential curricular approach still exists. A handful of scholar-practitioners have forged a path and are among the most cited researchers in our field (Blimling, 2015; Kennedy, 2016; Lichterman and Bloom, 2019; Stauffer \& Kimmel, 2019; Kerr \& Tweedy, 2006; Kerr et al., 2017). A large amount of these publications concentrates on practitioners and the application of a curricular approach. While the publications are beneficial, there is a lack of research exploring student learning in residential settings. This study aims to build upon the existing scholarship to address this gap in peer-reviewed research.

\section{Environment: Residential Education and Experience}

This subsection will discuss literature that describes the residential education strategies employed by the Department of Residential Life at Missouri S\&T. These strategies are established to impact student learning and development. The residential experience and environment are designed with intention. This section explores the critical aspects of facilitating the student experience in the residence halls.

\section{Residential Curriculum Approach}

Residential education programs have showcased a notable evolution on the heels of the student affairs paradigm shift with the residential curriculum approach, or the curricular approach to learning beyond the classroom, conception. Kerr and Tweedy 
(2006) describe the University of Delaware's experiences, where the residential curricular approach was first established. A curriculum approach emphasizes student learning beyond the classroom by using learning goals, outcomes, and educational strategies to steer student learning strategies implemented by residence hall staff. Assessment serves to gauge how learning strategies impact students. Shaun Harper and Stephen John Quaye (2009) called out the shallow attempt at student learning or the resistance to a more thoughtful curricular approach as the "myth of magical thinking" (p. 23). Kerr et al., (2017) describe this concept best:

We should move beyond a pervasive but unfounded belief that learning happens outside the classroom because we plan with good intentions and offer activities that students enjoy. Instead, the curricular model applies the knowledge we have acquired about how students learn best to ensure that we are contributing to the learning that occurs at college. (p. 23) Besides providing best practice guidelines for our work, the curricular approach offers legitimacy to the residential life professional field. Learning Reconsidered 2 (Keeling, 2006) noted how learning outside of the classroom has been systematically separated from classroom learning and distinctly labeled as co-curricular learning, which has played a significant role in diminishing our work's impact among the higher education community. Student affairs practitioners study and research student development and learning extensively in graduate programs. Our professional organizations publish extensive research studies on student learning to help inform our practice. Kerr et al. (2017) describe the importance of student affairs professionals 
becoming comfortable with the identity of scholar-practitioner and the impact this identity has on the success of a curricular approach.

Kerr et al. (2017) established a framework that highlighted the curricular approach specifically outlined for practitioners regarding their approach to engaging students in learning. The critical elements of a curricular learning approach include strategies that are intentional, developmentally sequenced, and defined by the institution's mission. ACPA endorsed a set of guidelines to support residential life departments across the country in shifting to a curricular approach to student engagement. Kerr et al. (2017) published the Ten Essential Elements of a Curricular Model for Learning Beyond the Classroom (Figure 4). These guidelines serve as the foundation for the residential life department in this study as student learning outcomes were developed and learning strategies implemented. The Ten Essential Elements of a Curricular Model for Learning Beyond the Classroom are cyclical. Assessment methods are to be used to inform how the curriculum flexes or grows. Assessment is a critical step that can easily be underutilized. 


\section{Figure 4}

Ten Essential Elements of a Curricular Model for Learning Beyond the Classroom

\section{Ten Essential Elements of a Curricular Model for Learning Beyond the Classroom}

1. Directly connected to institutional mission

2. Learning goals and outcomes are derived from a defined educational priority

3. Based on research and development theory

4. Departmental learning outcomes drive the development of educational strategies

5. Traditional programs may be one type of strategy - but not the only one

6. Student leaders and staff members play key roles in implementation but are not expected to be educational experts

7. Represents developmentally sequenced learning

8. Campus partners are identified and integrated into plans

9. Plan is developed through a review process

10. Cycle of assessment for student learning and educational strategies

Ten Essential Elements of a Curricular Model for Learning Beyond the Classroom (Kerr et al., 2017)

As our department worked through the 10 essential elements, relying on learning outcomes to guide the programs and strategies we implement has been vital. We used our institution's educational priorities to develop our department's learning outcomes. The focus on our outcomes empowers us to eliminate anything that may detract from working toward our outcomes. Our team relies on concepts of essentialism described by author Greg McKeown (2014). McKeown explains that focusing on what is essential involves doing less. In doing less, we can focus our resources, time, and energy. We were able to eliminate strategies that did not align with our identified outcomes. Assessing how we meet our established outcomes has also been essential to our program. This research study aligns with this priority as I will explore how the residence hall experience influences student learning related to developing independent living skills. 


\section{Inputs: Personal Characteristics and Pre-College Experiences}

Astin (1993) describes inputs as personal characteristics and experiences students bring as they enter college. These characteristics may include demographic details such as class standing, race, and gender, in addition to factors such as work experience, extracurricular activities, and personal motivation. This study looks at pre-college experiences that influence independent living skills development to most effectively gauge the impact of the residence hall experience. Not all students arrive on-campus with equal footing or levels of independence. Being mindful of these varied experiences and levels of competence is crucial to ascertaining the impact of the learning strategies implemented in residence halls.

Scholar-practitioners cannot take a prescriptive approach to establish strategies for student learning. Learning is not one size or strategy fits all. The IEO framework first establishes what characteristics students possess as they enter college. Educational practitioners account for these characteristics as they create programs that aim to address independent living skills. Dean (2013) explains,

Students learn and develop as a result of their interactions with the total collegiate environment, including the programs and services with which they engage. We need to understand our students, we need to understand the programs and services they experience, and we need to understand the effects that their experiences have on their learning and development. (p. 28)

Considering these personal characteristics and experiences, researchers may explore how the college environment impacts student learning, leading to specific outcomes. Inputs, coupled with the college environment, work hand and hand to mold 
student development. The environment includes student affairs programs, residential life staff interactions, policies, and faculty. 
SECTION FOUR

CONTRIBUTION TO PRACTICE 
There are two key audiences that I will share findings with: current and past department full-time staff and Student affairs division leadership. This section outlines how I will disseminate details of my research findings to these groups, including a description of documents, format for meeting in person, and rationale for this contribution.

I am most eager to share findings with my department staff. These individuals are most closely connected to the work and research included in this study. While I will invite all full-time department staff to participate, the Resident Directors are the staff specifically tasked with implementing and overseeing the student learning strategies described in this study. I will present my research and findings to the department staff during a department meeting.

\section{Types of Documents}

Resident Directors will receive section five of this dissertation in advance to read and review more in-depth details of the study. I have prepared a one-page executive summary and PowerPoint for the department meeting to serve as a visual aid while discussing the key points outlined in the program evaluation report. Basic elements of documents used to showcase this research study include the study's purpose, research question, theoretical framework, research design, and findings.

\section{Rationale for this Contribution Type}

The goal of this research study was to serve as a program review and describe the impact of our residential curriculum strategies and how they promote student learning as it pertains to interpersonal and intrapersonal skills development. The presentation of research and findings to department staff and invested individuals is an opportunity to 
implement changes and advancements to our residential curriculum due to research findings. I have already set plans in motion for Resident Director staff to engage in summer research projects to address upperclass housing engagement strategies and revise the roommate agreement. The staff are eager to utilize research methods to explore these topics and more. 


\section{Executive Summary \\ Student Perceptions of Independent Living Skills Development as a Result of the Residence Hall Experience \\ Research Purpose}

The purpose of this mixed-methods case study is to describe how the Department of Residential Life at Missouri S\&T has impacted student's perceptions of learning as it relates to developing independent living skills, paying special attention to interpersonal and intrapersonal skills, as a result of their residence hall experience.

\section{Research Methods}

Participants included students who lived in the residence halls at Missouri S\&T during the 2019-2020 academic year.

Instruments:

- This study's primary instrument was a survey distributed to students who lived in the residence halls during this timeframe. Using a post-then-pre method (Pratt et al., 2000), survey respondents provided a retrospective account of their competency related to independent living skills both prior to and after living in the residence halls at Missouri S\&T.

- The focus groups provided an opportunity to unpack and further explore responses to the resident survey and highlight the impact of specific learning strategies implemented in the residence halls.

\section{Summary of Results}

- The most significant development of interpersonal and intrapersonal skills results from sharing space with peers.

- Upperclass students find value in simply knowing their RA and that they are available should they need assistance. However, first-year students express that their RA is important in making personal connections and navigating personal challenges.

- Students who served in the RA role indicated significant development with communication and conflict management skills. Several participants expressed that RA training was a high-impact learning opportunity.

- Residence hall government student leaders reported significant development of communication skills. Many also noted an increase in their ability to manage their time as a result of balancing their leadership position responsibilities and their role as a student leader.

\section{Implications for Policy and Practice}

- Explore adjustments to the RA role in primarily upperclass communities

- Revise the roommate agreement document and process to address the document's length, content, and implementation timing.

- Implement educational programs intended for very specific groups of students, facilitated by subject matter experts.

- Reconsider single-gender communities to better support the experience of women living in the residence halls.

\section{References}

Pratt, C. (2000). Measuring program outcomes: Using retrospective pretest methodology. The American Journal of Evaluation, 21(3), 341-349. 


\section{Student Perceptions of Interpersonal and Intrapersonal Skills Development as a Result of the Residence Hall Experience}

Presented by Joni Burch, Ed.D.

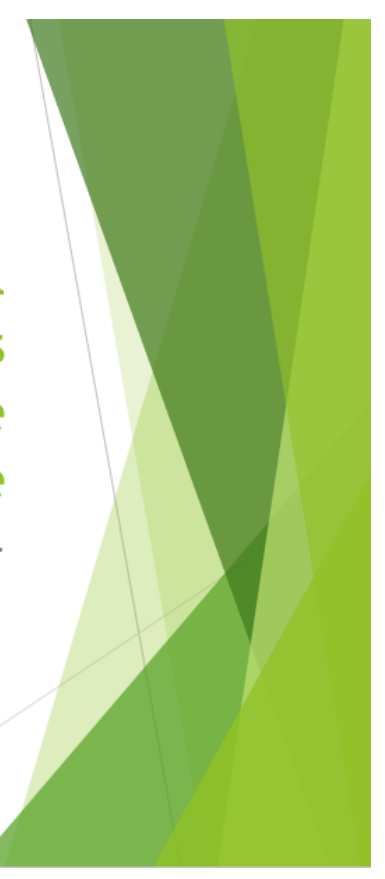

Thank you for joining me today. I am eager to share the results of my dissertation research study. Some of you may be familiar with my topic, as I know, I have discussed it with many of you. This presentation will highlight the problem of practice, purpose, and theoretical frame that shaped my research. I will highlight the research methods used and discuss the results and implications for policy, practice, future research, and literature. 


\section{Problem of Practice \& Research Purpose}

Problem of practice

- Understanding the benefits of living on-campus (Mayhew et al., 2016)

- Know more about how learning happens in the residence halls

- Research Purpose

- Describe how the Department of Residential Life at Missouri S\&T impacts student's perceptions of learning independent living skills, paying special attention to interpersonal and intrapersonal skills, as a result of their residence hall experience.

This study addresses the following research question: How do students perceive their development of interpersonal and intrapersonal skills due to the residence hall experience at Missouri S\&T?

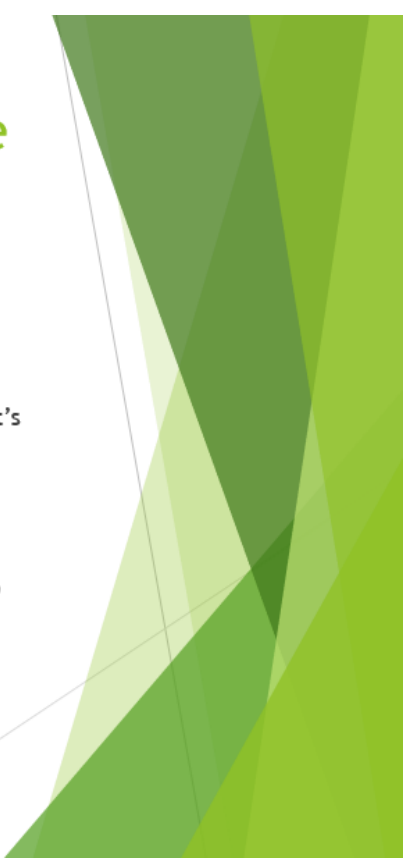

The problem of practice that I explored was twofold: looking at the benefits of living oncampus and learning more about how learning happens in the residence halls.

My research purpose was to explore and ultimately be able to describe how our department impacts student's perception of learning independent living skills, paying special attention to interpersonal and intrapersonal skills as a result of their residence hall experiences.

Research question: How do students perceive their development of interpersonal and intrapersonal skills due to the residence hall experience at Missouri S\&T? 


\section{Theoretical Framework}

- Astin (1993): Understanding the impact of environment

- Inputs-Environment-Outcomes (I-E-O)
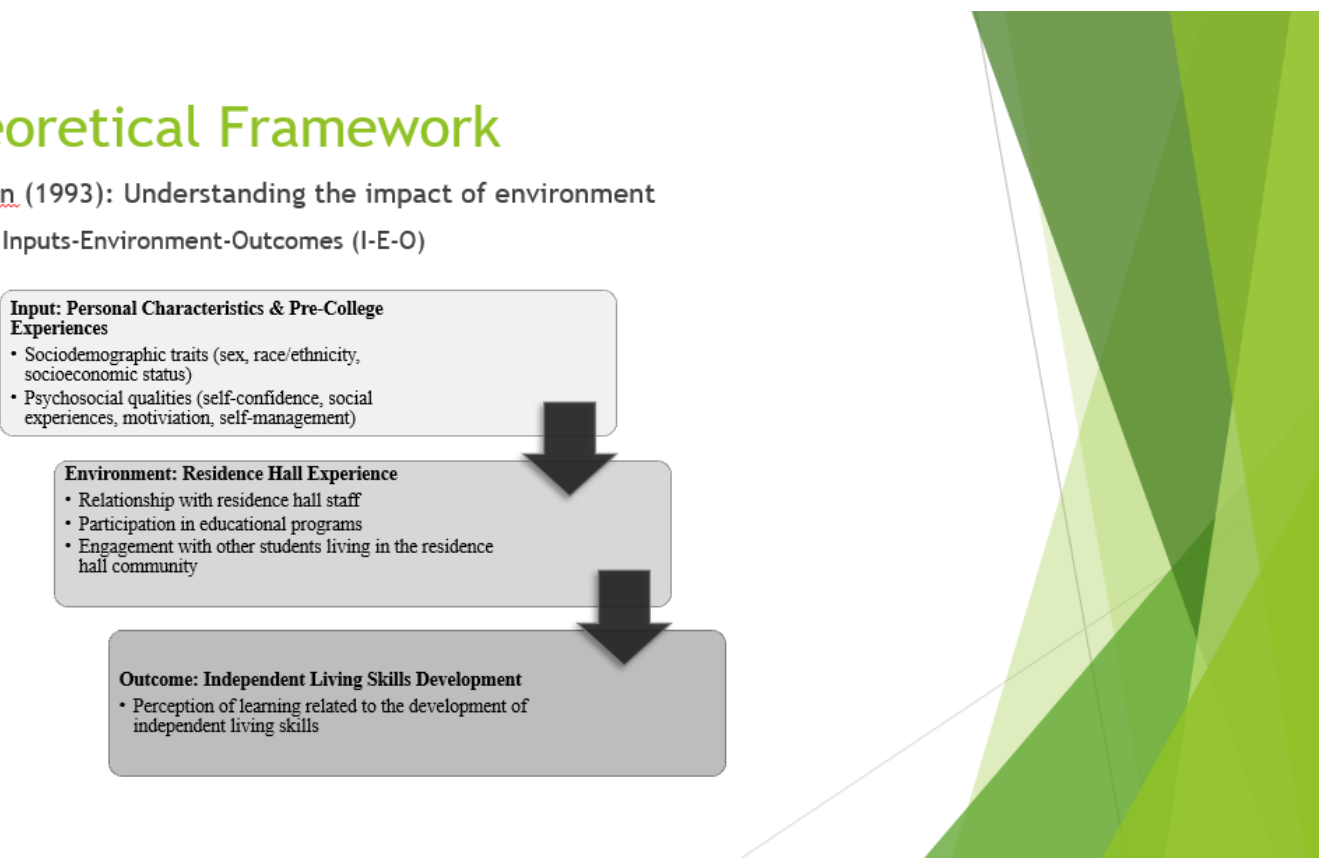

To best capture the impact of the residence hall experience, I used Astin's IEO framework. Astin established that students come to college having had experiences that will influence how college impacts their continued development (input). The environment, in this case, the residence halls, further impacts their development resulting in the output or in our case the outcome of developing independent living skills. 


\section{Theoretical Framework}

- Strayhorn et al. (2006) Frameworks for Assessing Learning \& Development Outcomes (FALDOS)

- Exhibits self-reliant behaviors

- Exhibits ability to function interdependently

- Manages time effectively

- Makes decisions and acts in congruence with personal values

- Identifies personal, work, and lifestyle values

- Manages personal finances well

- Accepts supervision as needed

- Functions without need for constant reassurance from others

- Acknowledges individual strengths and weaknesses

- Sets and pursues individual goals (Strayhorn, p. 80)

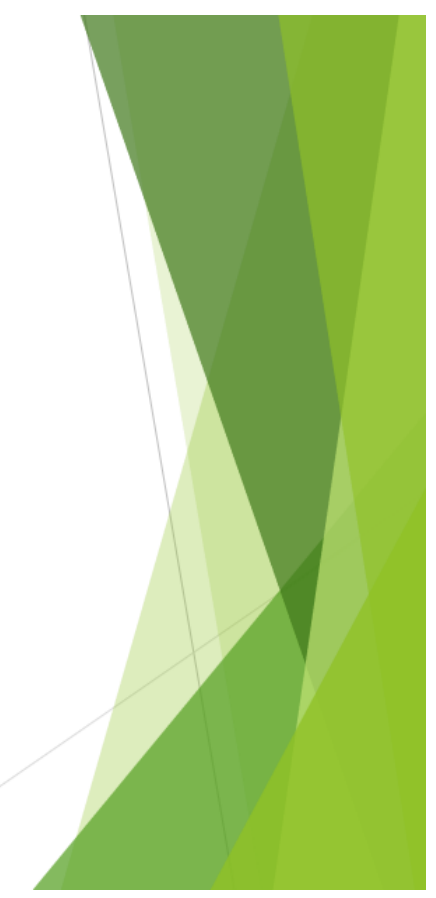

Defining what independent living skills I would explore was an essential step. I used the Council for the Advancement of Standards in Higher Education's (CAS) Frameworks for Assessing Learning and Development Outcomes to establish specific skills that would be explored in this study. You can see from this list that there are skills that are very practical and skills that are often referred to as "soft skills" or more focused on personal development and relationships with others. 


\section{Research Methods}

\footnotetext{
- Participants \& Setting: Students living in the residence halls during the 20192020 academic year (fourth week Spring 2020 occupancy was 1,625 students)

- Focus Groups: Provided an opportunity to further unpack and explore survey responses, looking closely at specific residence hall learning strategies

- 11 participants
}

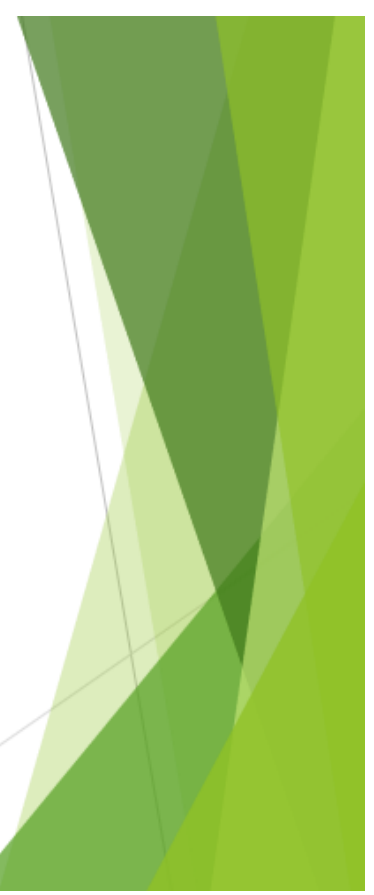

Participants in this study included students living in the residence halls during the 20192020 academic year. 124 students responded to the survey. *Describe sociodemographic information, see table below*

I created a resident survey that was sent out to this group of students. They responded to a retrospective post-then-pre survey which asked them to reflect on pre-college as well as residence hall experiences that impacted their development of independent living skills. They were also asked to provide input on specific residence hall experiences and resources that supported their development.

Once students submitted the survey, they were automatically redirected to an optional focus group registration form. Two focus groups were facilitated to further unpack and explore survey responses, looking closely at specific residence hall learning strategies.

\section{Sociodemographic Characteristics of Survey Respondents}

\begin{tabular}{lll}
\hline $\begin{array}{l}\text { Demographic } \\
\text { Description }\end{array}$ & \multicolumn{2}{l}{ Respondent Description } \\
\hline Class standing & - $\quad 60.66 \%$ of respondents were first year students in 2019-2020 \\
& - $\quad 85.95 \%$ of survey respondents were first-year and second-year students in \\
& & $2019-20$ having lived in the residence halls for the duration of their time at \\
& & Missouri S\&T \\
Housing style & - & $77 \%$ of respondents lived in suite or apartment style housing \\
Gender identity & - $41.18 \%$ women \\
& - $51.26 \%$ men \\
& - $2.522 \%$ non-binary \\
Racial identity & - $82.03 \%$ White \\
& - $3.91 \%$ Black or African American \\
& - $4.69 \%$ Asian \\
& - $3.13 \%$ Hispanic \\
& & $1.56 \%$ American Indian \\
\hline
\end{tabular}




\section{Quantitate Results}

\begin{tabular}{|c|c|c|c|}
\hline $\begin{array}{c}\text { Independent Living } \\
\text { Skill }\end{array}$ & $\begin{array}{c}\text { Average Competency } \\
\text { BEFORE Living in } \\
\text { Residence Halls }\end{array}$ & $\begin{array}{c}\text { Average Competency } \\
\text { AFTER Living in } \\
\text { Residence Halls }\end{array}$ & $\begin{array}{c}\text { Effect Size } \\
\text { (Cohen's) }\end{array}$ \\
\hline Managing Conflict & 3.00 & 3.29 & 0.486 \\
\hline $\begin{array}{c}\text { Recognize Personal } \\
\text { Strengths \& Challenges }\end{array}$ & 3.13 & 3.36 & 0.406 \\
\hline Communication & 3.12 & 3.32 & 0.318 \\
\hline $\begin{array}{c}\text { Independently Navigate } \\
\text { Problems }\end{array}$ & 3.24 & 3.41 & 0.312 \\
\hline Aware of \& Manage Own \\
Emotions
\end{tabular}

There were six areas of independent living skills development that were explored in the survey. These are listed in the quantitative results table ranked by effect size. There was significant development because of the residence hall experience noted by residents in all but one category - empathy. 


\section{Qualitative Results}

- Sharing living spaces with peers is a significant developmental experience

- One respondent expressed that "consistent in-person communication with friends on the floor and in the suite" was significant to their communication skills development.

- One focus group participant expressed that residential communities celebrated individual successes where family members are more inclined to point out weaknesses. Their peers were more apt to provide feedback in a more positive, supportive way.

Upperclassmen vs. first-year students have distinctly different needs when it comes to their relationship with their RA

- First-year student comments: “...having RA's as mentors, being independent from parents and having to solve my own problems." "Having an RA and being able to talk to them when problems arose was helpful."

- Development of independent living skills and serving as a Resident Assistant or being involved with hall government is a significant developmental experience

- "I learned how to better communicate and be more assertive by taking on leadership roles within Reslife. Because of my role as an RA/SRA, I became more aware of my strengths and challenges, through evaluations and reflection."

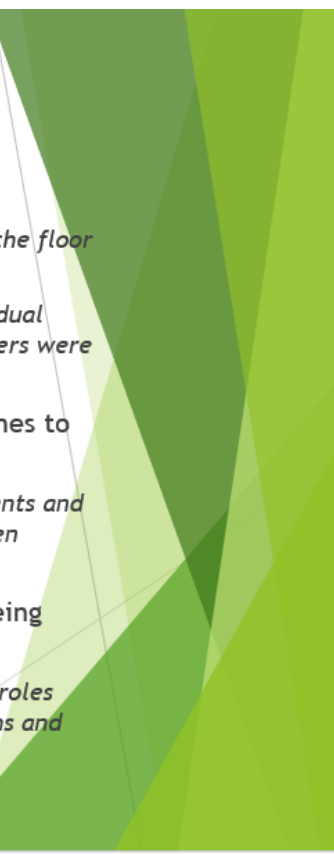

Survey comments provided by residents in addition to comments shared by focus group participants provided some helpful insight about the residence hall experience. Here are some examples shared by participants. 


\section{Implications for Policy \& Practice}

- Development of independent living skills and serving as a Resident Assistant or being involved with hall government is a significant developmental experience

- Focus groups attributed a decrease in needing and wanting a connection with their RA to having developed a support network on campus their first year.

- Upperclassmen residents appreciate knowing who their RA is and that they are available if needed.

- Examples of memorable RA interactions provided by upperclassmen

- Help with work orders or maintenance issues

- Getting connected to campus as a transfer student (academic GroupMe channels)

- Assistance in the event of an emergency

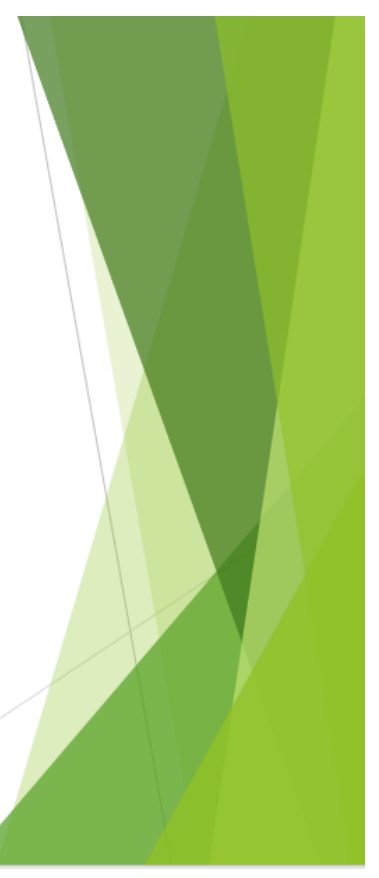

Some students reported that their relationship with their Resident Assistant (RA) supported their development of independent living skills, but this was not a significant trend among most of the survey and focus group respondents. Findings indicate that upperclass students find value in simply knowing their RA and knowing they are available should they need assistance. However, first-year students express that their RA is vital in making personal connections and navigating personal challenges

1. Adjust RA role in upperclass communities. We need to find out more about individual residents, their characteristics (e.g., transfer students, first-generation college student, etc.) and the RA in these communities should design their interactions around what each student may need or want from them. Students expressed wanting a more hands-off approach, but it was important that they knew their RA and/or knew they were there if they needed anything. 


\section{Implications for Policy \& Practice}

- Revisions needed for the roommate agreement

- Described as too tedious (too long)

- Offered too late in the semester

- Too formal

- Examples provided by participants

- If they completed one, they did not revisit it if an issue came up

- Upperclassmen provided examples of having a discussion and a verbal agreement on certain things

- Issues with the form link working and/or being able to go back and look at it to revisit agreement

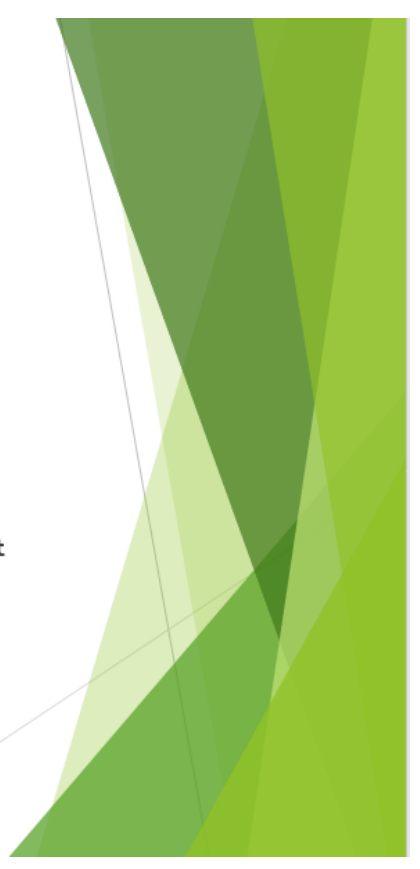

The roommate agreement process was described as too tedious (the agreement form was too long), offered too late in the semester (roommates had already established patterns and/or had conversations about coexisting), and too formal. Suggestions from participants included shifting from an agreement to move of a guided conversation or handout to support students in having discussions about sharing space. 


\section{Implications for Policy \& Practice}

- Educational programs for specific groups of students, facilitated by subject matter experts

- Programs were not memorable and/or not attended

- Residents attended programs based on a specific connection they had with the program topic

- Examples provided by participants

- Memorable programs included STEPUP! Training, BANGO program on sexual health, alcohol awareness program (trivia night with mocktails, career themed programs

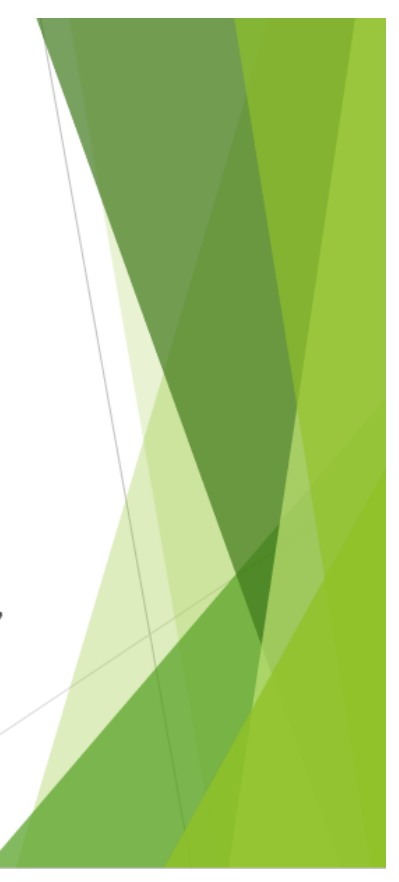

Educational programs were not memorable and/or not attended by participants. Programs that participants highlighted were attended due to their specific connection with the program topic (e.g., bystander intervention training for hall government leaders, academic recovery programs for students who were deficient and contacted directly). A recommendation is to offer more targeted program, focusing on specific student populations and engage campus experts/partners in facilitating these programs. 


\section{Implications for Policy \& Practice}

- Need to explore single-gender communities to better support the experience of women living in the residence halls

- Women expressed feelings of discomfort living in single-gender communities.

- Examples provided by participants

- "Living in TJ and on the only female floor is strange. Being surrounded by males. People would invite females to $\underline{\underline{T J}}$ and they would go to $10 S$ to use showers."

- One resident shared the following story: Living by herself freshman year she consistently locked her door but one night she left it unlocked by mistake and male resident came into her room intoxicated. They took their shoes off and got in her bed thinking that they were in their own room. The resident knocked on RA's door and the RA got the intoxicated male resident out of her room. She couldn't sleep so she washed her sheets and tried to calm down.

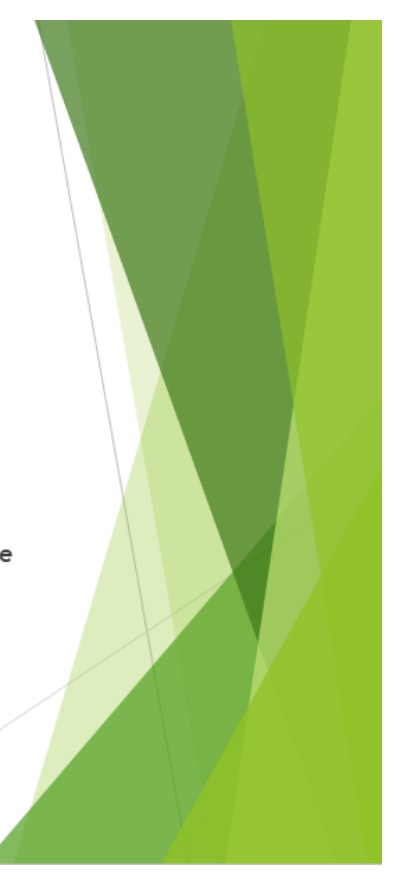

Lastly, women expressed feelings of discomfort, living in single-gender communities. They felt singled out or on the receiving end of unwanted attention. The recommendation was to expand on mixed gender housing/communities in TJ hall. 


\section{References}

Astin, A. W. (1993). Assessment for excellence: The philosophy and practice of assessment and evaluation in higher education. Phoenix, AZ: Oryx Press.

- Mayhew, M. J., Rockenbach, A. B., Bowman, N. A., Seifert, T. A., Wolniak, G. C., Pascarella, E. T., \& Terenzini, P. T. (2016). How college affects students. 21 st century evidence that higher education works. San Francisco, CA: Jossey-Bass.

- Pratt, C. (2000). Measuring program outcomes: Using retrospective pretest methodology. The American Journal of Evaluation, 21(3), 341-349.

- Strayhorn, T. L., Creamer, D. G., Miller, T. K., \& Arminio, J. L. (2006). Frameworks for assessing learning and development outcomes. Washington, DC: Council for the Advancement of Standards in Higher Education.

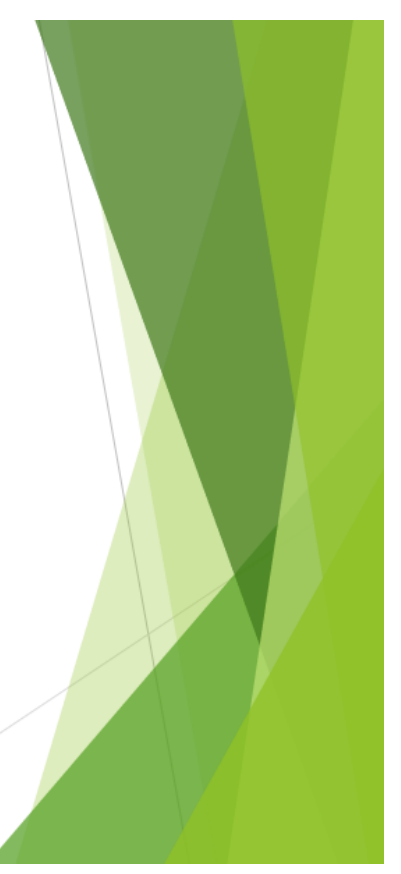

That brings me to the end of my presentation, I would like to open up discussion on this research and identify how we move forward.

Facilitation questions:

- What are your thoughts about the research implications and recommendations for practice? (jump back to implications slide)

- What additional questions does this research bring up?

- How can we utilize this methodology in the future?

- Revisit summer research topics (roommate agreement \& upperclass student engagement) and brainstorm ways to address these areas. 


\section{SECTION FIVE}

CONTRIBUTION TO SCHOLARSHIP 
Over 2,100 colleges and universities across the United States offer on-campus housing, and just over 3.2 million students reside on-campus while attending college (National Center for Educational Statistics, 2019). Often the cost of on-campus housing options and the overall rising cost of higher education may be barriers for some students (Douglas-Gabriel, 2015, Oliver, 2019). Factors such as maintaining facilities and operation costs associated with programming and staffing contribute to students' inflated price to live on-campus (Derosier, 2017, Kerr et al., 2020). With concerns for benefits outweighing the cost, residential life programs face growing scrutiny from university leadership, students, families, and even state lawmakers (Derosier, 2017).

Mayhew et al. (2016) ascertain that most research studies regarding on-campus living experiences do not reasonably address the benefits of living on-campus. Learning Reconsidered 2 (Keeling, 2006) explains that the means, knowledge, and staffing resources to evaluate a program's impact are often left out when implementing learning strategies. The curricular approach to learning beyond the classroom fosters student learning by using learning goals, outcomes, and educational strategies. Learning assessment techniques serve to gauge how learning strategies impact students. The curricular approach includes the intentional implementation of learning strategies in residence halls paired with assessing their effectiveness.

Regarding the student experience, this study looks closely at interpersonal and intrapersonal skills development. Interpersonal and intrapersonal skills have a direct correlation to a student's sense of belonging. Depression, feelings of isolation, and social anxiety are significantly reduced when college students experience a sense of belonging (Moeller et al., 2020; O'Keeffe, 2013). The problem of practice that this study explores 
addresses the need to know more about how learning happens in residence halls. Limited research exists that highlights the most effective strategies to facilitate learning in the residence halls. While the curricular movement in student affairs is gaining significant momentum, there is still limited peer-reviewed literature that addresses the curricular approach (Blimling, 2015; Kennedy, 2016; Kerr et al., 2020; Kerr et al., 2017; Kerr \& Tweedy, 2006; Lichterman \& Bloom, 2019; Stauffer \& Kimmel, 2019) and one professional blog (Brown, 2020). The bulk of the existing literature focuses on practitioners and implementing a curricular approach. This study aims to contribute to knowledge about how strategies created using a curricular approach influence student learning.

The purpose of this mixed-methods case study is to describe how the Department of Residential Life at Missouri University of Science and Technology (Missouri S\&T) has impacted student's perceptions of learning as it relates to developing independent living skills, paying particular attention to interpersonal and intrapersonal development. This research looks at the department's educational interventions and strategies utilized to develop these skills. This study addresses the following research question: How do students perceive their development of interpersonal and intrapersonal skills due to the residence hall experience at Missouri S\&T?

\section{Literature Review}

Literature establishes how independence is developed in emerging adults, and specific residence hall experiences that support the development of independent living skills helped inform this research study. This section highlights a series of scholarly 
resources that establish how emerging adults develop independence and the residence hall experiences that contribute to their development.

\section{Developing Independence}

"[Independence] has to do with a sense of one's own identity. It involves an ability to act independently and to exert some control over one's environment and includes a sense of task mastery, internal locus of control, self-agency, and self-efficacy" (Benard, 1995, p. 67). College-age students living on their own for the first time in a residence hall can explore their independence as they move into adulthood. Buzz words such as those noted in this established definition of independence point to understanding oneself and being rooted in the knowledge of having agency and control of one's choices, life direction, and priorities.

Chickering and Reisser (1993) establish a framework for considering how college students develop their identity. For this study, Chickering and Reisser's third vector, developing autonomy, informs research on developing independent living skills. This vector establishes the developmental tasks of taking care of oneself from a practical standpoint by becoming independent from one's family unit. This transition includes participating in activities related to managing day-to-day tasks that address personal needs. For college-age students, this could consist of problem solving, initiative, and selfdirection. Emotional independence and being able to self-soothe and work through problems effectively are a part of this vector.

Mayhew et al. (2016) describe psychosocial changes experienced during the college years. A key source of psychosocial development in college experiences that cause chaos or disruption. The college environment offers students the opportunity to 
face unique challenges. These challenges move individuals along Erikson's eight stages of psychosocial development. Erikson $(1963,1968)$ explains that challenges result in developing strengths that support the individual to resolve subsequent challenges. This development occurs sequentially from birth to adulthood. Traditional college-age students tend to straddle stages five and six, focusing on identity development and relationships (McCLeod, 2018). Mayhew et al. (2016) found a significant increase in leadership, positive self-concept, and independence from perceived authority figures due to the college experience. The researchers did note that some students backslide concerning identity development during this period. (Mayhew et al., 2016).

\section{Developing Independence in Residence Halls}

Regarding the impact of on-campus residential living, Mayhew et al. (2016) report some concerning insights. "...on-campus residence in the twenty-first century is sparse for most outcomes, and the findings often do not suggest benefits of the experience" (p. 545). The researchers note mixed findings of subject matter proficiency, cognitive growth, and attitudes related to diversity. A collection of research studies suggests that residing on campus harms mental health, most notably in the first year of college (Mayhew et al., 2016).

Still, researchers continue to identify positive results from living on campus. Blimling (2015) explains that the most typical type of independent living option within on-campus housing is apartments owned and managed by the university. The significance of offering apartment-style housing on campus fosters opportunities to develop the selfconfidence needed to pursue independence. Blimling (2015) describes, "The community experience of conventional residence halls that is so important to their psychosocial 
development and to their integration into the university community as first- and secondyear students become less critical as they mature and seek increased independence" (p. 113). Students face new encounters related to managing roommate relationships and a shared living environment when they transition to apartment-style housing (Blimling, 2015). Blimling establishes the need to look closely at what experiences contribute to student development, distinguishing the early college career needs versus the needs and desires of upperclass students.

\section{Assessing Learning and Development of Independent Living Skills}

The Council for the Advancement of Standards (CAS) in Higher Education published Frameworks for Assessing Learning and Development Outcomes (FALDOs) under the leadership of principal author Dr. Terrell Strayhorn and associates (2006). The authors describe a digestible explanation of rationale and methods for assessment. Learning assessment addresses two distinct purposes: improvement and accountability. The term improvement suggests the importance of a summative approach to gathering insight into developing programs, policies, or educational strategies. The act of accountability considers the summative impact of programs, policies, and strategies, addressing overall effectiveness.

For this study, FALDOs serve as a framework for exploring specific variables related to developing independent living skills. The authors describe the developmental phase of working toward independence to be characterized by "increased emotional and instrumental independence, which includes self-directedness and freedom from the need for validation of others. A clear sense of identity leads toward self-acceptance, selfreliance, and ultimately an understanding of one's connectedness with others" (p. 79). To 
elaborate further, the authors provided the following list of constructs related to developing independence.

- Exhibits self-reliant behaviors

- Exhibits ability to function interdependently

- Manages time effectively

- Makes decisions and acts in congruence with personal values

- Identifies personal, work, and lifestyle values

- Manages personal finances well

- Accepts supervision as needed

- Functions without need for constant reassurance from others

- Acknowledges individual strengths and weaknesses

- Sets and pursues individual goals (Strayhorn et al., p. 80)

Strayhorn et al. (2006) acknowledge that this list is not comprehensive of all possible variables. It does serve as a starting point for assessing learning related to developing independent living skills.

\section{Conceptual Framework}

Considering pre-college experiences that contribute to student development of independent living skills is a key consideration to effectively gauge the impact of residence hall experiences. Astin's (1993) inputs-environments-outcomes (IEO) framework guided this study. This section highlights the frameworks utilized to guide the methodology used to explore the residence hall experience's effects on developing independent living skills. 


\section{Astin: Understanding the Impact of Environment}

Astin's framework, which is among the most cited theories used in higher education, acknowledges that students have experiences that occur before coming to college and general attributes that influence their college experience. These individual experiences and characteristics impact college engagement and how students develop or change due to the college environment. Pre-college experiences (I), residence hall environment (E), and the development of independent living skills (O) make up the components included in this study. Figure 5 highlights these specific components. Sociodemographic traits and psychosocial qualities are relevant when considering how residence hall experiences influence students' perception of learning related to developing independent living skills. 


\section{Figure 5}

IEO Research Framework

\section{Input: Personal Characteristics \& Pre-College Experiences}

- Sociodemographic traits (sex, race/ethnicity, socioeconomic status)

- Psychosocial qualities (self-confidence, social experiences, motiviation, self-management)

\section{Environment: Residence Hall Experience}

- Relationship with residence hall staff

- Participation in educational programs

- Engagement with other students living in the residence hall community

\section{Outcome: Independent Living Skills Development}

- Perception of learning related to the development of independent living skills

\section{Inputs}

Astin (1993) describes inputs as personal characteristics and experiences students bring as they enter college. These characteristics may include demographic details such as class standing, race, and gender, in addition to factors such as work experience, extracurricular activities, and personal motivation. This study looks at pre-college experiences that influence independent living skills development to most effectively gauge the impact of the residence hall experience. Not all students arrive on-campus with equal footing or levels of independence. Being mindful of these varied experiences and competence levels is crucial to ascertain the impact of the learning strategies implemented in residence halls. 
Scholar-practitioners cannot take a prescriptive approach to establish strategies for student learning. Learning is not one size or strategy fits all. The IEO framework first establishes what characteristics students possess as they enter college. Educational practitioners account for these characteristics as they create programs that aim to address independent living skills. Dean (2013) explains,

Students learn and develop as a result of their interactions with the total collegiate environment, including the programs and services with which they engage. We need to understand our students, we need to understand the programs and services they experience, and we need to understand the effects that their experiences have on their learning and development. (p. 28)

Considering these personal characteristics and experiences, researchers may explore how the college environment impacts student learning, leading to specific outcomes. Inputs, coupled with the college environment, work hand and hand to mold student development. The environment includes student affairs programs, residential life staff interactions, policies, and faculty.

\section{Environment}

Astin (1993) describes the college environment as all of the experiences both in and beyond the classroom that students may have during college. These experiences include student affairs programs, residential life staff interactions, peer relationships, policies, and faculty. While Astin emphasizes several environmental factors resulting in a spectrum of college experience outcomes, this study focuses on how the residence hall environment impacts independent living skills development. Residence halls, as a stand- 
alone entity, foster student learning just from their pure existence. Blimling (2015) explains:

If residence life professionals did nothing but assigned students to residence halls and left students alone, students would still learn from each other. What they learned, how much they learned, and how safe the environments might be is open to conjecture. (p. 88)

Residential life professionals and student staff work to enhance the residence hall environment by providing experiences that optimize student learning. There are five critical aspects of a residential life professional's work that we call upon to create learning experiences in the residence halls. These dimensions include: (1) developing and using residential curriculums and learning experiences; (2) employing instructional methods; (3) managing the learning environment; (4) providing advocacy and institutional representation; and (5) conducting and using assessment. Table 3 offers some examples of strategies for each of the five student learning areas in the residence halls. 


\section{Table 3}

Managing Student Life and Learning in Residence Halls (Blimling, 2015)

Managing Student Life and Learning in Residence Halls

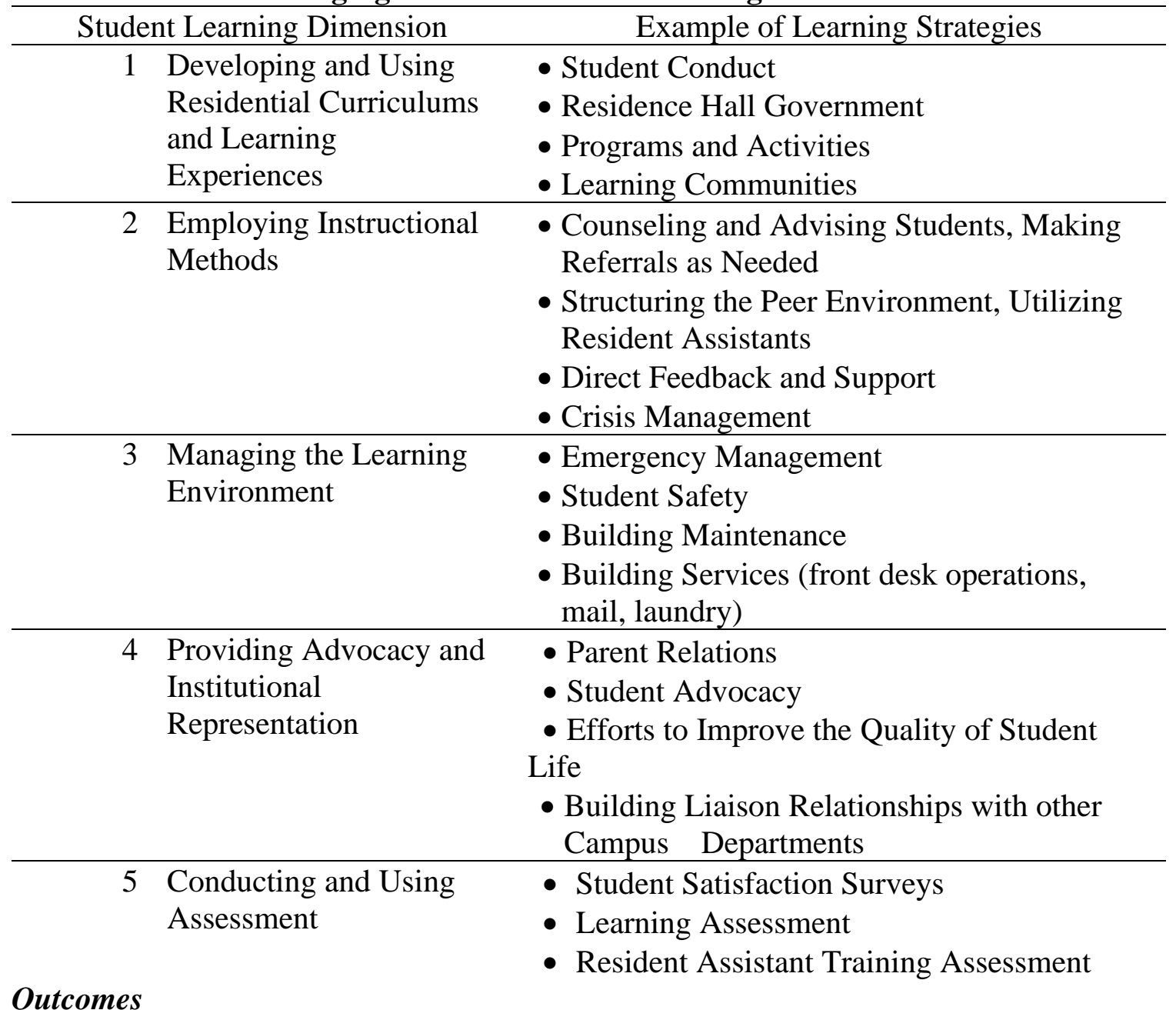

In the context of Astin's theory (1993), outcomes include characteristics, knowledge, attitudes, beliefs, and values that a student possesses because of their college experience. Astin describes outcomes as a function or development of inputs and environments. Chickering and Reisser (1993) establish a framework for considering how college students develop their identity. Their framework includes seven developmental vectors or tasks that students face when they attend college. These tasks are not accomplished all at once. Instead, these developmental markers are acquired after 
repeated experience, which fosters or facilitates development. The college environment offers many avenues for learning. Much of this learning occurs beyond the classroom experience.

In addition to the independent living skills established by Strayhorn et al. (2006), Chickering and Reisser's third vector, developing autonomy, informs research on developing independent living skills. This vector's successful mastery involves managing to be emotionally self-sufficient and learning to navigate life without the persistent need for comfort, affirmation, and approval from others. This vector also establishes the developmental tasks of taking care of oneself from a practical standpoint by becoming independent from one's family unit. This transition includes participating in activities related to managing day-to-day tasks that address personal needs. For college-age students, this could consist of problem solving, initiative, and self-direction.

Interpersonal and intrapersonal skills fall under the larger umbrella of emotional intelligence. Emotional intelligence, using the most basic definition, refers to the ability to recognize and navigate one's own emotions as well as the emotions of others (Goleman, 2001). Emotional intelligence has great significance for college students because they are launched into community living and collaborative learning which creates many situations in which they must learn to navigate social interactions and relationships. Goleman established a competency model which describes four constructs of emotional intelligence. These constructs which align with interpersonal and intrapersonal skills include self-awareness, self-management, social awareness, and relationship management. Goleman emphasized that these competencies are not natural gifts or talents, rather they must be learned and actively pursued by individuals. 
Lopes et al. (2003), found that emotional intelligence directly impacts an individual's satisfaction with social relationships. Most notably research participants expressed having greater levels of emotional regulation which led to them being more likely to report experiencing positive relationships with others. Interpersonal and intrapersonal skills directly connect to navigating relationships which is an essential skill when it comes to a student experiencing a sense of belonging. Strayhorn (2012) defines sense of belonging in college students as:

In terms of college, sense of belonging refers to students' perceived social support on campus, a feeling or sensation of connectedness, and the experience of mattering or feeling cared about, accepted, respected, valued by, and important to the campus community or others on campus such as faculty, staff, and peers. (p. 4)

The residence hall experience centers around community living and connections. Supporting students in navigating interpersonal relationships and pursuing their own sense of belonging is essential. Depression, feelings of isolation, and social anxiety are significantly reduced when college students experience a sense of belonging ( $\mathrm{O}^{\prime} \mathrm{Keeffe}$, 2013; Moeller et al., 2020). Residence hall intervention and engagement strategies have the capacity to support students as they seek social connections in pursuit of belonging.

\section{Research Methodology}

This illustrative mixed-methods case study involves residence hall students who have lived in the residence halls at Missouri University of Science and Technology (Missouri S\&T). Missouri S\&T is a public land grant institution and member of the University of Missouri System. Most of the 8,096 students study engineering, business, 
sciences, and mathematics. However, the 99-degree programs offered also address subjects such as information science and technology, humanities, and arts. (Missouri S\&T, 2020).

Merriam (1998) established that the most significant case study research characteristic is setting the case's boundaries. Merriam explains, "...the case as a thing, a single entity, a unit around which there are boundaries" (p. 27). For this research study, the case is the student learning strategies implemented as a part of the residential curriculum. This case study aimed to provide "an intensive, holistic description and analysis of a bounded phenomenon..." (p. xiii). The bounded phenomenon, of course, is the development of independent living skills in the residence halls.

The residence halls at Missouri S\&T include both traditional style and suite or apartment-style units. Traditional style residence halls refer to double occupancy bedrooms, typically shared with one other individual, with shared community restrooms located on each floor. Each floor shares a lounge and kitchen space where students gather to study and socialize. Suite or apartment-style units offer additional privacy for students. This housing option includes private and double occupancy bedrooms located in a suite with anywhere between 4 to 8 students. Semi-private restrooms are located in each suite or apartment and only shared among the individuals assigned to that particular suite or apartment versus the entire residence hall floor. Suites and apartments include living room space and furniture, kitchen or kitchenette, and washer and dryer units (Missouri S\&T, n.d.).

While suite or apartment-style housing options are popular among college students and their families, it does serve to establish a challenge for residence hall staff. 
Suite and apartment-style housing increase the barriers or number of doors between Resident Assistant staff and students. This setup creates a unique challenge for fostering relationships and interactions with residents. Furthermore, students living in suite-style or apartment-style housing do not have to leave their space as frequently as students living in traditional residence halls. This behavior is primarily due to the amenities provided in their suite or apartment, such as a restroom, kitchen, lounge space, washer, and dryer. The minor inconvenience of students going down the hall to use the bathroom or going to the first floor to do laundry offers students an opportunity to interact with their peers, including their Resident Assistant. Every day or regular interactions among peers and residence hall staff serve as a foundation for further connection and learning.

Due to the physical differences noted above between suite or apartment-style and traditional housing, my findings report unique and similar ways learning occurs in both types of housing options. This distinction is essential as insights about how the physical environment impacts student engagement in learning strategies inform our continued residential curriculum approach to developing independent living skills in each housing area (Brown et al., 2019).

\section{Participants}

This study engaged students living in the residence halls at Missouri S\&T during the 2019-2020 academic year. Looking at the Spring 2020 fourth week occupancy numbers, the total occupancy in the residence halls was 1,625 students (A. Walters, personal communication, April 7, 2021). The students living in residence as of the fourth week of the Spring 2020 semester received an email (see Appendix A) sent from the Residential Life department email account on my behalf, inviting them to participate in 
this research study. The email included a link to a survey that prompted students to reflect on their perceived development of independent living skills. Once students submitted the survey, their web browser automatically loaded an optional focus group registration form (see Appendix B). Interested participants completed the focus group registration form and submitted their responses. Krueger and Casey (2009) advise that the optimal size for a focus group is five to eight participants. This study included two focus groups involving 11 student participants. See Table 4 for additional sample information.

\section{Table 4}

\section{Sociodemographic Characteristics of Survey Respondents}

\begin{tabular}{|c|c|}
\hline $\begin{array}{l}\text { Demographic } \\
\text { Description }\end{array}$ & Respondent Description \\
\hline Class standing & $\begin{array}{l}\text { - } 60.66 \% \text { of respondents were first year students in } 2019-2020 \\
\text { - } 85.95 \% \text { of survey respondents were first-year and second-year } \\
\text { students in } 2019-20 \text { having lived in the residence halls for the } \\
\text { duration of their time at Missouri S\&T }\end{array}$ \\
\hline Housing style & - $77 \%$ of respondents lived in suite or apartment style housing \\
\hline Gender identity & $\begin{array}{l}\text { - } 41.18 \% \text { women } \\
\text { - } 51.26 \% \text { men } \\
\text { - } 2.522 \% \text { non-binary }\end{array}$ \\
\hline Racial identity & $\begin{array}{l}\text { - } 82.03 \% \text { White } \\
\text { - } 3.91 \% \text { Black or African American } \\
\text { - } 4.69 \% \text { Asian } \\
\text { - } 3.13 \% \text { Hispanic } \\
\text { - } 1.56 \% \text { American Indian }\end{array}$ \\
\hline
\end{tabular}

\section{Data}

This study utilized a mixed-methods approach, including a survey instrument and focus groups. Creswell (2009) describes a mixed-methods approach to research as collecting, analyzing, and integrating quantitative and qualitative data into one research study. Creswell goes on to assert that by using a mixed-methods approach, researchers may expand their understanding of the problem of practice being explored. 


\section{Survey Instrument}

This study's primary instrument was a survey (see Appendix C) distributed to students who lived in the residence halls during the 2019-2020 academic year. This study invited students residing in the residence halls during the 2019-2020 academic year. The survey was sent to students living in the residence halls as of the fourth week of the Spring 2020 semester. Fourth week occupancy was 1,625 students. Of these students, 124 responded to the survey.

The survey collected basic demographic information and residence hall assignment, room type, and length of time living on campus. Utilizing Astin's (1993) IEO framework, the survey explores student experiences before and after living in the residence halls at Missouri S\&T. Variables included in the survey were interpersonal and intrapersonal as well as practical independent living skills. These variables align with the framework for assessing independent living skills established by Strayhorn et al., (2006).

Using a retrospective post-then-pre method (Pratt et al., 2000), survey respondents provided a retrospective account of their experiences in the residence halls related to developing independent living skills. The survey asked participants to indicate their competence level before and after living in the residence halls at Missouri S\&T utilizing a four-point scale where one indicated no competence and four indicated advanced competence. Survey respondents were also asked to provide examples of experiences that impacted their development in these areas.

Variables. The two competence areas or variables utilized for this study were interpersonal and intrapersonal skills. These variables were selected from the list of constructs provided by Strayhorn et al. (2006). Participants then indicated how residence 
hall support resources such as staff, other students, educational programs, residence hall government, student conduct interventions, and services impacted their development of independent living skills.

\section{Focus Group}

After participants submitted their survey responses, they were redirected to a registration form to opt-in to participate in a follow-up focus group. This study included two focus groups involving 11 student participants. The focus groups provided an opportunity to unpack and further explore responses to the resident survey and highlight the impact of specific learning strategies implemented in the residence halls.

The focus group protocol looked closely at how residence hall support resources reinforced student development of independent living skills. Survey data indicated that students perceived that different resources had more or less impact compared to others. The Resident Assistant role had the most impact, according to survey respondents. The focus group asked participants to describe the relationship they had with their Resident Assistant (RA) and share examples of how their RA supported their independent living skills development.

Focus group participants reviewed a list of independent living skills modeled from the constructs developed by Strayhorn et al. (2006). Using this list of skills as a reference, participants commented on the impact of other residence hall resources and experiences, including roommate relationships, programs, and access to building services such as the front desk and dining hall. Respondents then commented on skills that were shown to have little impact, according to survey results. Finally, focus group participants 
shared examples of how their personal identities impacted their development of independent living skills while living in the residence halls.

\section{Data Analysis}

Survey quantitative data were analyzed utilizing a paired T-test. The T-test highlighted any shift in self-reported independent living skills competence students experience due to the residence hall experience at Missouri S\&T. Written survey responses and focus group qualitative data was read and initially categorized using open coding. Merriam and Tisdell (2016) describe open coding as being open to any themes that come up in the data versus searching for specific themes. After reviewing qualitative data, open coding notes were used to identify categories. This process is referred to as analytical coding, which allows researchers to extrapolate and consider the meaning of what participants share.

Categorized data was then analyzed by looking for patterns utilizing a logic model. Astin's (1993) IEO framework, described in the theoretical framework section, is mirrored in the logic model used for data analysis (see Table 5). Logic models allow researchers to identify cause-effect scenarios. For this case study, the cause-effect relationship being explored is the residence hall learning strategies influence on students' development of independent living skills. Based on themes that emerge, theories about how the residence hall experiences influence student's development of independent living skills may be identified (Baškarada, 2014). 


\section{Table 5}

Logic Model Analysis

\begin{tabular}{llll}
\hline & \multicolumn{1}{c}{ Input } & \multicolumn{1}{c}{ Environment } & \multicolumn{1}{c}{ Outputs } \\
\hline & Personal & & $\begin{array}{l}\text { Perception of learning } \\
\text { related to the }\end{array}$ \\
Framework & $\begin{array}{l}\text { Characteristics and } \\
\text { description }\end{array}$ & Residence hall & $\begin{array}{l}\text { Revelopment of } \\
\text { Experiences }\end{array}$ \\
& experiences & $\begin{array}{l}\text { independent living } \\
\text { skills }\end{array}$ \\
\hline
\end{tabular}

- Relationship with residence hall staff

- Participation in educational

Research - Prior experiences Study reported by students Details and that they bring to Findings Missouri S\&T programs

- Engagement with other students living in the residence hall community
- Participant perceptions will be noted here.

\section{Results}

Results from the two-stage data collection methodology (Creswell, 2013) focus on the six interpersonal and intrapersonal skills outlined by Strayhorn et al. (2006). Both quantitative and qualitative data are discussed in each sub-section to describe the overall findings from both the survey and focus groups. Table 6 shows the average competency students reported both before and after living in the residence halls. Table 6 also includes T-Test, P-Value, and effect size. 
Table 6

Independent Living Skills Quantitative Data Report

\begin{tabular}{llllll}
\hline $\begin{array}{l}\text { Independent Living } \\
\text { Skill }\end{array}$ & $\begin{array}{l}\text { Average } \\
\text { Competency } \\
\text { BEFORE } \\
\text { Living in } \\
\text { Residence } \\
\text { Halls }\end{array}$ & $\begin{array}{l}\text { Average } \\
\text { Competency } \\
\text { AFTER Living } \\
\text { in Residence } \\
\text { Halls }\end{array}$ & $\begin{array}{l}\text { Change in } \\
\text { Competenc }\end{array}$ & P-Value & $\begin{array}{l}\text { Effect } \\
\text { Size } \\
\text { (Cohen's) }\end{array}$ \\
\hline $\begin{array}{l}\text { Managing Conflict } \\
\text { Communication }\end{array}$ & 3.00 & 3.29 & 0.29 & $<0.01$ & 0.486 \\
$\begin{array}{l}\text { Recognize Personal } \\
\text { Strengths \& }\end{array}$ & 3.13 & 3.32 & 0.20 & $<0.01$ & 0.318 \\
Challenges & 3.36 & 0.23 & $<0.01$ & 0.406 \\
$\begin{array}{l}\text { Empathy } \\
\begin{array}{l}\text { Aware of \& } \\
\text { Manage Own }\end{array}\end{array}$ & 3.04 & 3.28 & 0.03 & 0.551 & 0.055 \\
Emotions & & 3.25 & 0.21 & $<0.01$ & 0.306 \\
$\begin{array}{l}\text { Independently } \\
\text { Navigate Problems }\end{array}$ & 3.24 & 3.41 & & & \\
\hline
\end{tabular}

\section{Managing Conflict}

Student survey respondents self-reported competence for managing conflict, utilizing a four-point scale where one indicated no competence and four indicated advanced competence. Students reported a mean value of 3.00 for competence related to managing conflict before living in the residence halls at Missouri S\&T. On average, students had a moderate level of competence for managing conflict before residing in the residence halls at Missouri S\&T.

Survey respondents provided examples of how extracurricular activities provided an opportunity to develop conflict management skills. "Sports helped me understand 
teamwork and conflict management skills"; "In high school, I participated in drama club where I was Manager for the makeup and hair Crew. This helped me manage conflict and navigate problems as I was in charge of a team of 10 females". Extracurricular activities were a significant contributor to development and were noted frequently by research participants.

Utilizing the same four-point scale where one indicated no competence and four indicated advanced competence, survey respondents reported a mean value of 3.29 after living in the residence halls at Missouri S\&T. A paired T-test analysis showed that the 0.29 increase in self-reported mean competence for managing conflict was statistically significant $(\mathrm{p}<.05)$ with an estimated Cohen's-d effect size of 0.486 .

When asked to provide examples of residence hall experiences that impacted their ability to manage conflict, survey respondents discussed living with others and sharing space as significant contributors to their development in this area. One respondent noted examples of navigating roommate relationships and setting social boundaries. "Having roommates that occasionally had disagreements helped me realize how important it was to confront people early if you have a problem, or it will devolve into resentment." Another survey respondent noted, "Having seven roommates in UC helped communication and conflict resolution skills." Finally, one respondent expressed how living among peers within a community impacted their development in this area. "It was easy to live in my house with my family. Moving to TJ, I struggled in my social life because I saw my friends too often, which led to conflict (like sibling relationships).” Close contact with peers while living in the residence halls offers students many opportunities to practice conflict management skills. 
Students who had served as a Resident Assistant noted their training and responsibilities, which prompted significant growth concerning managing conflict. One survey respondent shared, "RA training has made me much more effective at working and getting along with other people." One strategy Resident Assistants utilize to support students in navigating the roommate relationship is the roommate agreement. Focus group participants were asked to discuss the roommate agreement as a tool to promote communication about shared living among roommates. Participants noted that the roommate agreement is a helpful tool for helping students have conversations about their living environment and roommate relationship. However, students expressed rarely returning to the roommate agreement when conflicts came up. Participants also noted that the roommate agreement is very long and takes a significant amount of time to complete. The length of time it takes to complete the agreement is a barrier for some students who may choose not to complete the agreement or take it seriously when completing it with their roommates.

\section{Communication}

Students self-reported their competence level with communicating, utilizing a four-point scale where one indicated no competence and four indicated advanced competence. For competence with communicating before living in the residence halls at Missouri S\&T, the mean value was 3.17. These results suggest that, on average, students reported a moderate level of competence for managing conflict before living in the residence halls at Missouri S\&T.

Students shared examples of experiences that led to developing communication skills in high school. Extracurricular activities were once again noted as a key factor in 
development. "Sports, band, Boy Scouts and sea cadets were my main sources of social communication as well as how I developed my inter/intrapersonal skills.” Employment in high school was another significant contributor to communication skills development, especially jobs involving customer service.

Utilizing the same four-point scale where one indicated no competence and four indicated advanced competence, students reported a mean value of 3.32 after living in the residence halls at Missouri S\&T. A paired T-test analysis showed that the 0.15 increase in self-reported mean competence for communication was statistically significant $(p<.05)$ with an estimated Cohen's-d effect size of 0.318 .

When asked to provide examples of residence hall experiences that impacted their ability to communicate, one survey respondent shared that the following regarding living with roommates, “...having roommates and getting to interact with one another to cook and clean and delegate tasks amongst ourselves and sticking to a routine on who did what." Other respondents noted that the simple act of living was impactful as it forced interaction with others. One respondent expressed that "consistent in-person communication with friends on the floor and in the suite" was significant to their communication skills development. Focus group respondents discussed the importance of living in the residence halls during their first year. Being around other students was important for fostering friendships and meeting other students. The opportunity to build these connections in the residence halls was specifically noted as important among students who consider themselves introverts. 


\section{Possess a Healthy Level of Empathy for Others}

Students self-reported competence for possessing a healthy level of empathy for others utilizing a four-point scale where one indicated no competence and four indicated advanced competence. For competence with empathy before living in the residence halls at Missouri S\&T, the mean value was 3.26. This shift suggests that, on average, students reported a moderate level of competence for managing conflict before living in the residence halls at Missouri S\&T.

Survey respondents did not share any specific examples of how they developed empathy before coming to college. When asked about empathy development, focus group participants expressed that they felt as though they had natural abilities to empathize with others.

Utilizing the same four-point scale where one indicated no competence and four indicated advanced competence, students reported a mean value of 3.28 after living in the residence halls at Missouri S\&T. A paired T-test analysis indicated that the 0.02 increase in self-reported mean competence for empathy was not statistically significant $(\mathrm{p}<.05)$ with an estimated Cohen's-d effect size of 0.055 . Survey respondents expressed that the experience did open their eyes to other perspectives. One student noted,

Living with another person that is not from your immediate family opens your eyes because you get to experience other peoples' habits and ways of living. This not only helps you learn about other people and where they come from but also helps you learn/realize things about yourself you may have never thought of before. 
Beyond this example, survey respondents did not explicitly describe how the residence hall experience impacted their ability to empathize with others.

\section{Aware of and Manage Own Emotions}

Students survey respondents self-reported competence for being aware of and managing their own emotions utilizing a four-point scale where one indicated no competence and four indicated advanced competence. For competence in this area before living in the residence halls at Missouri S\&T, the mean value was 3.04. This shift suggests that, on average, students reported a moderate level of competence for managing their emotions before living in the residence halls at Missouri S\&T.

Utilizing the same four-point scale where one indicated no competence and four indicated advanced competence, students reported a mean value of 3.25 after living in the residence halls at Missouri S\&T. A paired T-test analysis showed that the 0.21 increase in self-reported mean competence for being aware of and managing emotions was statistically significant $(\mathrm{p}<.05)$ with an estimated Cohen's-d effect size of 0.306 .

Interactions with other students in the residence halls was again highlighted as influential with development. "Even though in college I have lived in a single room, I have been able to engage with my community and be aware of my own emotions as well as others." One student described how their residence hall leadership role coupled with counseling resources supported their development in this area.

A big change for me was being aware and managing my emotions. During my freshman year of college, I decided to seek out counseling services to help with my depression and anxiety. This helped me gain healthy coping skills. Also, I learned how to better communicate and be more assertive by 
taking on leadership roles within Reslife. Because of my role as an

RA/SRA, I became more aware of my strengths and challenges, through evaluations and reflection.

Residence hall support resources paired with campus resources are noted, in this instance, as a high-impact experience. This example highlights the limitations of the residence hall experience and the importance of engaging key campus experts supporting the student learning experience.

\section{Independently Navigate Problems}

Students survey respondents self-reported competence for independently navigating problems utilizing a four-point scale where one indicated no competence and four indicated advanced competence. For competence in this area before living in the residence halls at Missouri S\&T, the mean value was 3.24. This shift suggests that, on average, students reported a moderate level of competence for navigating problems before living in the residence halls at Missouri S\&T.

Once again, extracurricular involvement was noted as impactful when it came to developing in this area. "FBLA allowed me to experience real-world-like problems which helped me in my journey in becoming an adult." Students credited their parents with establishing some routines for developing independence. One student noted, "When I was in middle school, my parents forced me to cook dinner 2 times a week to help me learn how to grocery shop, follow recipes, and cook". This example suggests that the parents perceived the importance of giving their child a task to navigate independently, which developed essential life skills. 
Utilizing the same four-point scale where one indicated no competence and four indicated advanced competence, students reported a mean value of 3.41 after living in the residence halls at Missouri S\&T. A paired T-test analysis showed that the 0.17 increase in self-reported mean competence for independently navigating problems was statistically significant $(\mathrm{p}<.05)$ with an estimated Cohen's-d effect size of 0.312 . Survey respondents shared examples of how they developed in this area while living in the residence halls, away from family. “(I) was living on my own so (I) had to take responsibility of taking care of things, laundry, food, time, etc.." Another student noted, "Learning to overcome challenges without my parents getting involved."

Focus group participants noted that establishing independence was an important milestone of their first year living in the residence halls. They felt well-established in this area after their first year living in the residence halls. The Resident Assistant role was again noted as having a significant impact on development; "having RA's as mentors, being independent from parents and having to solve my own problems." Another student shared, "Having an RA and being able to talk to them when problems arose was helpful." Focus group participants expressed that living away from parents forced them to problem solve and realize their abilities without additional guidance.

\section{Recognize Personal Strengths and Challenges}

Student survey respondents self-reported competence for recognizing personal strengths and challenges utilizing a four-point scale where one indicated no competence and four indicated advanced competence. For competence in this area before living in the residence halls at Missouri S\&T, the mean value was 3.13. This shift suggests that, on 
average, students reported a moderate level of competence for recognizing strengths and challenges before living in the residence halls at Missouri S\&T.

Regarding high school experiences that impacted development in this area, one student shared, "National Honors Society allowed me to volunteer with underprivileged youths, which helped me be more aware of myself and my personal strengths.” Another student noted "living with siblings and parents who made me do things myself" was influential in allowing them to test their limits and explore personal strengths and challenges.

Utilizing the same four-point scale where one indicated no competence and four indicated advanced competence, students reported a mean value of 3.36 after living in the residence halls at Missouri S\&T. A paired T-test analysis showed that the 0.23 increase in self-reported mean competence recognizing personal strengths and challenges was statistically significant $(\mathrm{p}<.05)$ with an estimated Cohen's-d effect size of 0.406 .

One survey respondent expressed how their role as a Resident Assistant was impactful. "Because of my role as an RA/SRA, I became more aware of my strengths and challenges, through evaluations and reflection.” One focus group participant expressed that residential communities celebrated individual successes where family members are more inclined to point out weaknesses. Their peers were more apt to provide feedback in a more positive, supportive way.

\section{Discussion}

The goal for this case study was to identify how students perceive their development of independent living skills because of the residence hall experience at Missouri S\&T. Results from this two-stage data collection methodology provide an 
important perspective regarding student perceptions of how the residence hall experience impacts their development as an emerging adult. Using Astin's IEO framework, by considering pre-college experiences that influence competence with independent living skills, this study presents findings that support important ways in which the residence hall experience significantly impacts student development of the independent living skills established by Strayhorn et al. (2006).

Revisiting this study's research question: How do students perceive their development of interpersonal and intrapersonal skills due to the residence hall experience at Missouri S\&T? findings from this case study highlight the most significant development of interpersonal and intrapersonal skills students experience is a result of sharing space with peers. More specifically, students reported that roommate and community relationships were essential avenues for developing communication and conflict management skills. Some students reported that their relationship with their Resident Assistant (RA) supported their development of independent living skills, but this was not a significant trend among most of the survey and focus group respondents. Findings indicate that upperclass students find value in simply knowing their RA and knowing they are available should they need assistance. However, first-year students express that their RA is vital in making personal connections and navigating personal challenges.

Students who served in the RA role indicated significant development with communication and conflict management skills. Several participants expressed that RA training was a high-impact learning opportunity. RA training provided essential knowledge related to their RA position, but they could apply knowledge in other areas of 
their life. Similarly, residence hall government student leaders reported significant development of communication skills. Many also noted an increase in their ability to manage their time due to balancing their leadership position responsibilities and their role as a student.

\section{Limitations}

Though this study provides valuable information for practitioners working in residence halls, several limitations may be addressed in future research. This study only examined the residence hall experience on one campus during one academic year. Also, the timeframe in which participants were asked to consider was impacted by the COVID19 pandemic. Due to the COVID-19 pandemic, most residence hall students left campus in the middle of March. Therefore, the residence hall experience was effectively cut short by two months. These students had less context or experience to draw from when considering how the residence hall experience shifted their competence for developing independent living skills. Future research studies may provide different or even richer insight from students experiencing a full academic year living on campus.

\section{Implications for Research and Literature}

This study builds on previous literature by exploring the impact of educational strategies implemented in the residence hall setting. Blimling (2015) explains that the most typical type of independent living option within on-campus housing is apartments owned and managed by the university. The significance of offering apartment-style housing on campus fosters opportunities to develop the self-confidence needed to pursue independence. Blimling (2015) describes, "The community experience of conventional residence halls that is so important to their psychosocial development and to their 
integration into the university community as first- and second-year students become less critical as they mature and seek increased independence" (p. 113). Students face new encounters related to managing roommate relationships and a shared living environment when they transition to apartment-style housing (Blimling, 2015). This research supported Bliming's assertion and highlighted the role of the residence hall experience in helping students transition to living off-campus and further establishing their independence. Reconsidering the upperclass residence hall experience will contribute to development of independent living skills and eventual transition to off-campus living and beyond.

This example of learning assessment will serve as a framework for other practitioners to explore how the learning outcomes they have established as part of a residential curriculum are being addressed through their efforts. Furthermore, the postthen-pre design may serve as a helpful research framework to help educational practitioners gauge residence hall impact with other curricular and residence hall experience strategies. Lastly, while this study centered on interpersonal and intrapersonal skills described by Strayhorn et al. (2006) could be further explored in future studies.

Finally, experiences of Black, Indigenous, and people of color (BIPOC) need to be more closely considered. The experience of BIPOC students in the residence halls should also be more closely considered and further explored. A focus group participant noted an incident where a derogatory term was said in their presence. Though not explicitly directed at them, they still confronted the person but pointed out that the individual seemingly did not understand the impact of using that term. Of the 124 survey respondents, 105 respondents were White. Of the two focus groups facilitated, only one 
person of color participated. This limited representation concludes that more stories exist that should be explored to better identify barriers that exist and strategies that would help promote learning among BIPOC residence hall students.

\section{Implications for Policy and Practice}

The Resident Assistant role serves as a cornerstone of the residence hall experience. Because RAs live among their peers, they have a unique opportunity to build close relationships and directly support student learning and development. However, this research highlights a need to reconsider the role and expectations of RAs working in primarily first-year residence halls versus RAs working in communities with more of a mix of upperclass or returning students. Student research participants expressed that during their first year living in the residence halls, the RA was essential to helping them connect with other students and support new students with getting involved on campus. In many cases, the RA also helped first-year students navigate personal and academic challenges. However, as upperclass, students noted that their relationship with their RA became more distant. They had already established a support network among peers, so it was more important that they knew the RA was on stand-by if something came up that required them to seek additional support.

Based on these findings, making adjustments to the RA role in primarily upperclass communities is prudent. Residents in upperclass areas may have varying experiences that influence how they want and need to engage with their RA. For example, transfer students may benefit from a closer connection to their RA as they build social relationships and become involved in co-curricular activities. However, a thirdyear student living in an apartment with close friends may prefer to have more limited 
contact with their RA. A strategy to better equip RAs in mostly upperclass or returning student areas is to provide the RA with more information about each resident to engage residents intentionally. One strategy that may help provide RAs with additional information about their upperclass or returning students is an individual survey that explores questions related to existing campus connections, preferred communication method with RA, and personal or academic topics the student may be interested in having additional support from their RA.

Another implication addressed with this research study is the need to reconsider the roommate agreement strategy. Each year, residents are invited to complete a roommate agreement (see Appendix F) which guides them through a list of prompts and questions to explore boundaries, expectations, and shared living considerations. Study participants indicated that while the roommate agreement was a helpful tool for guiding conversations about shared living among roommates, the agreement form itself was very long and tedious to complete. Furthermore, students indicated that the process was altogether too formal, and the agreement felt too contractual. An alternate option such as a conversation guide or list of roommate considerations versus a contract or agreement would be preferable. Lastly, the roommate agreement process occurred too late for many students. By the time their RA talked about the agreement, the roommates already had informal conversations about living together. This pattern was particularly true among upperclass students. Sending out the roommate agreement or guide over the summer may be a helpful strategy to encourage students to begin thinking about how they wish to coexist with roommates. When students move into their room, they have a framework for conversing with roommates about living together and sharing space. 
In addition to the roommate agreement, another core strategy considered with this research was educational programs. Students indicated very little knowledge of educational programs offered in the residence halls. Students either reported having never attended an educational program, or if they did attend a program, they did not take away new knowledge due to the program. One student discussed attending the bystander intervention program facilitated by our campus wellness office. They participated in this program due to their role as a residence hall government leader. This example reinforces implementing educational programs intended for particular groups of students, facilitated by subject matter experts. We have seen this type of programming be well-attended, and specific assessment strategies have indicated that students take away new skills as a result of targeted educational programs.

Finally, the experiences of women living in the residence halls need to be more closely considered. Women expressed feelings and concerns about their safety. Women studying science, technology, engineering, and math (STEM) represent $17.3 \%$ of the overall population of first-year women enrolled in higher education, whereas $32.2 \%$ of men enrolled major in STEM fields of study (Pryor et al., 2009). At Missouri S\&T, women account for $23 \%$ of enrolled students (Missouri S\&T, n.d.). Women noted concerns about living on a single-gender floor and the attention or perception that they may be a target. No specific examples were provided regarding actual threats or concerning behavior that occurred. Instead, women reported overall hypervigilance or insecurity about being a woman and minority among their peers. Focus group participants noted considerations about housing assignment location. Focus group participants indicated that single-gender communities made them hyper-aware of being one of only a 
few communities in the building that were women. These women expressed concerns over unwanted attention from male communities or students and a sense of being a potential target for threatening behavior.

\section{Conclusion}

This research study focused on a particular department learning outcome and explored how the residence hall experience impacted independent living skills development. Aside from offering perspective and insight on this area of student learning, this study highlighted the opportunity to explore further other learning outcomes and strategies provided in the residence halls. The key takeaway from this research is to isolate further the needs of specific groups living in the residence halls. This study further emphasizes the unique needs of first year and upperclass and individuals underrepresented in the residence halls. Our work must consider these unique needs when implementing learning strategies. Research and assessment of beyond the classroom learning can sometimes be intimidating for educational practitioners. However, assessment is simply a more formal approach to what we frequently do in our day-to-day roles. We explore our students' lived experiences to understand better how our work supports or does not support their development. When our learning strategies are executed appropriately, both student and educator benefit from a curricular approach to learning beyond the classroom. 


\section{SECTION SIX}

PRACTITIONER REFLECTION 
My journey of linking theory and research to practice was propelled forward when I began to accept my new identity as a scholar-practitioner. Perry (2016) suggests, "The Steward of the Practice sits in two worlds - the world of practice and the world of scholarship" (p. 302). As a practitioner, I used my job-related training to perform specific skills. As a scholar, I must utilize research to address problems of practice. Impostor syndrome, or the internalized fear of being found out to be a fraud (Sakulku, 2011), was a significant barrier to accepting this new identity. As a first-generation college student, the academic environment has typically felt very intimidating. My profound passion for my work in Residential Life, coupled with a strong support network of peer-learners, has been instrumental in contributing to my persistence in learning about scholarly work and choosing to explore this research topic.

\section{The Dissertation Process and My Role as an Educational Practitioner}

This research helped connect me to the student experience in our residence halls. Through reviewing the survey data and engaging students in focus groups, I felt grounded in my practice as a scholar-practitioner. I noticed our students also feeling inspired by this research. As research-centered learners, our students understand the value of research. In many ways, I sense that the students who engaged in this study have greater respect for this work. They see how research helps inform what we do and the science behind what may come across as more impromptu. The student experiences and learning strategies we have implemented in the residence halls happen by design, and these students were able to witness the process more directly.

This process has most notably impacted me as a leader and supervisor. I have begun identifying research that is needed to address other learning strategies or processes 
within our department. I find myself directing my staff to establish a research question when facing a problem or asking questions about a process or strategy. This summer, we will launch a few small-scale research projects that I am hopeful will help guide our work and continue to move our department forward. This movement would not have been something I would have considered before my dissertation work.

\section{The Dissertation Process and My Role as a Scholar}

This dissertation process has been equal parts challenging and rewarding. Admittedly I went into the dissertation process feeling a heightened sense of imposter syndrome. I had never participated in, let alone solely executed, a research study before starting this dissertation process. I was very self-conscious of this fact. However, after embracing the dissertation as a learning process, I let go of my self-imposed unrealistic expectations for perfection and open myself to learning and exploring the lesser known.

I am eager to seek opportunities to support up and coming scholar-practitioners in student affairs, leaning on my experiences and skills gained through the dissertation process. I aim to support scholar-practitioners by building on mentoring and supervisory relationships and finding opportunities to engage professionals in scholarly work. In my department, I have mapped out plans to launch individual or small group research projects to address our work areas that have been less than effective. Establishing a tradition of continued research and improvement with my department will further bolster my aspiration to take my experience and scholarship into the classroom. I aim to pursue opportunities to teach and center my research on student learning beyond the classroom. My goal is to teach full-time in a Student affairs graduate program and advise master's and doctoral students as they complete their capstone or dissertation projects. 


\section{Conclusion}

Having completed this research and, more importantly, used it to inform and adjust my practice, I feel confident in accepting and using the title of a scholar. I have used this process to consider what my subsequent research study will explore. There is so much I want to know more about concerning the residence hall experience and beyond. As a scholar, the possibilities are endless. This dissertation process and this academic program have influenced me to continue research and seek opportunities to guide and develop Student affairs educational practitioner learning both in and beyond the classroom. 


\section{References}

American College Personnel Association. (1996). The student learning imperative: Implications for student affairs.

Ackoff, R. L. (1989). From data to wisdom. Journal of Applied Systems Analysis 15, 3-9.

Arnett, J. J. (2000). Emerging adulthood: A theory of development from the late teens through the twenties. American Psychologist, 55(5), 469-480. doi:10.1037/0003066x.55.5.469

Astin, A. W. (1984). The American freshman: National norms for fall 1984. Higher Education Research Institute, Graduate School of Education, University of California, Los Angeles.

Astin, A. W. (1993). Assessment for excellence: The philosophy and practice of assessment and evaluation in higher education. Oryx Press.

Barr, M. J., \& Desler, M. K. (2000). The handbook of student affairs administration. Jossey-Bass.

Barker, L. J., \& Garvin-Doxas, K. (2004). Making visible the behaviors that influence learning environment: A qualitative exploration of computer science classrooms. Computer Science Education, 14(2), 119-145.

doi:10.1080/08993400412331363853

Baškarada, S. (2014). Qualitative case study guidelines. The Qualitative Report, 19(40),

1-18. https://nsuworks.nova.edu/tqr/vol19/iss40/3

Benard, B. (1995). Fostering resilience in children. ERIC Clearinghouse on Elementary and Early Childhood Education. University of Illinois. 
Blimling, G. S., \& Schuh, J. H. (2015). Student learning in college residence halls: What works, what doesn't, and why. Jossey-Bass.

Bolman, L., \& Deal, T. (2017). Reframing Organizations, (6 $6^{\text {th }}$ ed.). Jossey-Bass.

Bresciani, M. J., Gardner, M. M., \& Hickmott, J. (2009). Case studies for implementing assessment in student affairs. Jossey-Bass.

Brown, J, Volk, F., Spratto, E.M. (2019). The hidden structure: The influence of residence hall design on academic outcomes, Journal of Student Affairs Research and Practice. 56(3), 267-283.

Brown, P.G. (2021, February 23). Residential curriculum \& curricular approaches. https://paulgordonbrown.com/residential-curriculum/\#list.

Chang, M.J., Denson, N., Sáenz, V., \& Misa, K. (2006) The educational benefits of sustaining cross-racial interaction among undergraduates. The Journal of Higher Education, 77(3), 430-455. doi: 10.1080/00221546.2006.11778933

Cherniss, C., \& Goleman, D. (2001). The emotionally intelligent workplace: how to select for, measure, and improve emotional intelligence in individuals, groups, and organizations. Jossey-Bass.

Chickering, A. W., \& Reisser, L. (1993). Education and identity. Jossey-Bass.

Council for the Advancement of Standards in Higher Education (2019). CAS professional standards for higher education (10th ed.).

Correll, S. J., Seymour, E., \& Hewitt, N. M. (1997). Talking about leaving: Why undergraduates leave the sciences. Contemporary Sociology. 26(5), 644. doi:10.2307/2655673 
Creswell, J. w. (2009). Research design: Qualitative, quantitative, and mixed methods approaches. SAGE Publications, Inc.

Creswell, J. W. (2013). Qualitative inquiry and research design: Choosing among five approaches. Sage Publications.

Dean, L. A. (2013). Using the CAS standards in assessment projects. New Directions for Student Services, 142, 25-33.

Derosier, A. (2017, February 24). Missouri lawmaker wants to prevent public universities from requiring students to live in campus housing past freshman year. Retrieved November 24, 2020, from https://www.missourinet.com/2017/02/24/missourilawmaker-wants-to-prevent-public-universities-from-requiring-students-to-live-incampus-housing-past-freshman-year/

Digest of Education Statistics, 2019. (n.d.). Retrieved November 23, 2020, from https://nces.ed.gov/programs/digest/d18/tables/dt18_330.20.asp

Douglas-Gabriel, D. (2015, September 29). Freshman residency rules sometimes force students to pay prohibitive costs. Washington Post. Retrieved 2020, from https://www.washingtonpost.com/local/education/freshman-residency-rulessometimes-force-students-to-pay-prohibitive-costs/2015/09/29/4693aed6-63b511e5-b38e-06883aacba64_story.html

Erikson, E. H. (1963). Youth: Change and challenge. Basic Books.

Erikson, E. H. (1968). Identity: Youth and crisis. Faber \& Faber.

Evans, N. J., Forney, D. S., \& Guido-DiBrito, F. (1998). Student development in college: Theory, research, and practice. Jossey-Bass.

Goleman, D. (1998). Working with emotional intelligence. Bantam Books. 
Harper, S. R., \& Quaye, S. J. (2009). Beyond sameness, with engagement and outcomes for all: An introduction. Student engagement in higher education: Theoretical perspectives and practical approaches for diverse populations. Routledge.

Hevel, M. S. (2016). Toward a history of student affairs: A synthesis of research, 19962015. Journal of College Student Development,57(7), 844-862.

Hunter, M. S, Tobolowsky, B.F., Gardner, J. N., Evenbeck, S.E., Pattengale, M.S., Schreiner, L.A. (2010). Helping sophomores succeed: understanding and improving the second-year experience. Jossey-Bass.

Keeling, R. P., \& Dungy, G. J. (2004). Learning reconsidered: A campus-wide focus on the student experience. American College Personnel Association.

Keeling, R.P. (2006). Learning reconsidered 2: A practical guide to implementing a campus-wide focus on the student experience. American College Personnel Association, Association of College and University Housing Officers

International, Association of College Unions - International, National Academic Advising Association, National Association of Student Personnel Administrators, \& National Intramural-Recreational Sport Association.

Keniston, K. (1971). Youth and dissent: The rise of a new opposition. Harcourt Brace Jovanovich.

Kennedy, K. (Ed.). (2016). Making a difference: Improving residence life assessment practices. Association of College \& University Housing Officers - International.

Kerr, K. G., \& Tweedy, J. (2006). Beyond seat time and student satisfaction: A curricular approach to residential education. About Campus, 11(5), 9-15. doi:10.1002/abc.181 
Kerr, K. G., Tweedy, J., Edwards, K. E., \& Kimmel, D. (2017). Shifting to curricular approaches to learning beyond the classroom. About Campus, 22(1), 22-31.

Kerr, K., Edwards, K., Knerr, A., Lichterman, H., \& Tweedy, J. (2020). The curricular approach to student affairs: A revolutionary shift for learning beyond the classroom. Stylus Publishing, LLC.

Krueger, R. A., \& Casey, M. A. (2009). Focus groups: A practical guide for applied research. SAGE.

Levinson, D. J. (1978). The seasons of a man's life: With Charlotte N. Darrow. Knopf.

Lichterman, H., \& Bloom, J. L. (2019). The curricular approach to residential education: Lessons for student affairs practice. College Student Affairs Journal, 37(1), 54-67. doi:10.1353/csj.2019.0004

Lopes, P. N., Salovey, P., \& Straus, R. (2003). Emotional intelligence, personality, and the perceived quality of social relationships. Personality and Individual Differences, 35(3), 641-658. https://doi.org/10.1016/s0191-8869(02)00242-8

Mayhew, M. J., Rockenbach, A. B., Bowman, N. A., Seifert, T. A., Wolniak, G. C., Pascarella, E. T., \& Terenzini, P. T. (2016). How college affects students. 21st century evidence that higher education works. CA: Jossey-Bass.

McCleod, Saul (2018). Simply Psych. https://www.simplypsychology.org/ErikErikson.html?ezoic_amp=1

McKeown, G. (2014). Essentialism: The disciplined pursuit of less. Currency, an imprint of Crown Publishing Group.

Merriam, S. B., \& Tisdell, E. J. (2016). Qualitative research: A guide to design and implementation. Jossey-Bass. 
Missouri University of Science and Technology Department of Residential Life. (2016).

Educational Priority, Learning Objectives, and Outcomes.

Missouri University of Science and Technology. (2021, March 15). Institutional research and data management. https://data.mst.edu/student-data/

Missouri University of Science and Technology. (2020, November 23). Residential Life. http://reslife.mst.edu/

Missouri University of Science and Technology. (2020, March 15). Common data set. https://data.mst.edu/media/administrative/data/documents/cds/CDS_20192020\%20GOLDv1.6\%206-26-2020.xlsx\#200629082428.

Missouri University of Science and Technology. (2020, November 23). About. https://www.mst.edu/about/

Moeller, R. W., Seehuus, M., \& Peisch, V. (2020). Emotional Intelligence, Belongingness, and Mental Health in College Students. Frontiers in Psychology, 11. https://doi.org/10.3389/fpsyg.2020.00093

National Center for Education Statistics. (2020, November 23). IPEDS data explorer. https://nces.ed.gov/ipeds/Search?query=

National Research Council (2020, March 15). Committee on the Assessment of 21st Century Skills. National Academies Press (US).

O'Keeffe, P. (2013). A Sense of Belonging: Improving Student Retention. College Student Journal, 47(4). 605-613

Oliver, D. (2020, November 24). Colleges should stop forcing students to live oncampus. https://www.jamesgmartin.center/2019/01/colleges-should-stop-forcingstudents-to-live-on-campus/ 
Perry, J.A. (2016). Contemporary approaches to dissertation development and research methods. IGI Global.

Poston, L., and Boyer, E. L. (1992). Priorities of the professoriate. Academe. 78(4), 43.

Pratt, C. (2000). Measuring program outcomes: Using retrospective pretest methodology. The American Journal of Evaluation, 21(3), 341-349.

Pryor, J. H., Hurtado, S., DeAngelo, L., Palucki-Blake, L., \& Tran, S (2009). The American freshman: National norms for fall 2009. Higher Education Research Institute.

Roberts, D. C. (2012). The student personnel point of view as a catalyst for dialogue: 75 years and beyond. Journal of College Student Development, 53(1), 2-18. doi:10.1353/csd.2012.0006

Sakulku, J. (2011). The impostor phenomenon. The Journal of Behavioral Science, 6(1), 75-97.

Sax, L. J., Astin, A. W., Korn, W. S., \& Mahoney, K. M. (1996). The American freshman national norms for fall 1996. ERIC Clearinghouse.

Schaller, M. A. (2018). Intentional design of the college sophomore year. New Directions for Higher Education, 2018(183), 23-34. https://doi.org/10.1002/he.20290

Strayhorn, T. L. (2012). College students' sense of belonging: a key to educational success for all students. Routledge.

Strayhorn, T. L., Creamer, D. G., Miller, T. K., \& Arminio, J. L. (2006). Frameworks for assessing learning and development outcomes. Council for the Advancement of Standards in Higher Education. 
Strenta, C., Elliott, R., Adair, R., Mattier, M., \& Scott, J. (1994). Choosing and leaving science in highly selective institutions. Research in Higher Education. 35, 513547. https://doi.org/10.1007/BF02497086

Tierney, William G. (1992) An anthropological analysis of student participation in college. The Journal of Higher Education. 63(6), 603-618.

doi: 10.1080/00221546.1992.11778391

Williamson, E. G. (1949). The student personnel point of view. American Council on Education. 


\section{Appendix A}

\section{Student Email Survey Invitation}

Subject: 2019-20 Resident Survey

I would like to invite you to complete a brief resident survey, focusing on the 2019-20 academic year. The survey is one component of my dissertation research study exploring how students perceive their development of independent living skills as a result of living in the residence halls at Missouri $S \& T$. Findings will also be used to support the development of the Residential Life program at Missouri $S \& T$. To complete the survey, please use the following survey link: LINK.

Thank you in advance for your willingness to participate in this study.

Best regards,

Joni Burch

Associate Director, Missouri S\&T Residential Life 


\section{Appendix B}

Thank you for completing this survey. Your responses have been recorded. If you are willing to participate in a follow-up focus group, please complete the following information.

If you are not interested in participating in a focus group, you may exit this page and no additional personal information will be collected.

Participant's Name:

Participant's Email Address:

Please indicate your availability to participate in a one-hour focus group held via Zoom (please check all times that you are available). You will receive an email, with additional details including your confirmed focus group date/time and a Zoom meeting link.

- Date, Time

- Date, Time

- Date, Time

- Date, Time

- Date, Time 


\title{
Appendix C
}

\section{Missouri S\&T Residential Life 2019-20 Resident Survey}

Q1 You are being invited to complete this research survey because you lived in the residence halls at Missouri S\&T during the 2019-2020 academic year. Your responses to this survey will contribute to research being completed as a part of a dissertation research study. Findings will also be used to support the development of the Residential Life program at Missouri S\&T.

\section{Q2 By selecting "I agree to participate in this study" below, you indicate that you have read the information provided below and voluntarily agree to participate. If you do not wish to participate in this research study survey, please exit the survey now.}

\begin{abstract}
ABOUT THIS STUDY
The research question guiding this study is: How do students perceive their development of independent living skills due to the residence hall experience at Missouri S\&T. The survey questions will ask you to provide a retrospective account of your experiences in the residence halls, focusing on the 2019-2020 academic year. The questions will center on your development of independent living skills due to your residence hall experiences. They survey will take approximately 10 minutes to complete.
\end{abstract}

This study is being completed as a part of the doctoral dissertation research by Joni Burch, Associate Director of Residential Life at Missouri S\&T. In order to manage this potential conflict of interest, research assistants will assist in reviewing data and facilitating focus groups to help control for bias. Students who choose to participate in this study will not face any potential repercussions to their current housing assignment (if they still live on campus).

\section{CONFIDENTIALITY}

The information we collect about you will be stored in the researcher's electronic/computer or paper files. Computer files are protected with a password and the computer is in a locked office that only study team members can open. Paper files are kept in a locked drawer in a locked office that only study team members can open.

We will give your records a code number and they will not contain your name or other information that could identify you. The code number that connects your name to your information will be kept in a separate, secure location. Information that may identify you may not be given to anyone who is not working on this study without your written consent, or if required by law.

We will do our best to make sure that your personal information from this study is kept private, but we cannot guarantee total privacy. We may give out your personal information if the law requires it. If we publish the results of this study or present them at 
scientific meetings, we will not use your name or other personal information.

The information we collect from you for this study will not be used or shared with other investigators for future research studies. This applies even if we remove all information that could identify you from your information.

Taking part in this study is voluntary. If you do decide to take part, you have the right to change your mind and drop out of the study at any time. Whatever your decision, there will be no penalty to you in any way.

We will tell you about any new information discovered during this study that might affect your health, welfare, or change your mind about taking part.

Survey respondents will not be paid.

All participants must be at least 18 years of age.

OPTIONAL FOCUS GROUP DETAILS

Participants who complete this survey will have the opportunity to participate in a followup focus group. Focus groups will be held via Zoom and scheduled for one hour during the month of February 2021. You will indicate your availability within this registration survey. Participants will be emailed an invitation to their designated focus group along with a Zoom link. Focus groups will be recorded to assist with research. We are required to obtain your permission to use the recordings we take of you during the study. By submitting this consent form, you are agreeing to be recorded as a part of this focus group. Focus group participants will not be paid.

If you have more questions about this study at any time, you can call Joni Burch at 573341-7811 or email burchj1@mst.edu.

You may contact the University of Missouri Institutional Review Board (IRB if you:

Have any questions about your rights as a study participant; Want to report any problems or complaints, or Feel under any pressure to take part or stay in this study. The IRB is a group of people who review research studies to make sure the rights of participants are protected. Their phone number is 573- 882-3181. If you want to talk privately about your rights or any issues related to your participation in this study, you can contact the University of Missouri Research Participant Advocacy by calling 888280-5002 (a free call), or emailing MUResearchRPA@ missouri.edu.

I agree to participate in this study (1) 
Q3 Please select which residence hall you lived in during the 2019-2020 academic year.

Thomas Jefferson hall (1)

Residential Commons (2)

University Commons (3)

Miner Village (4)

Rolla Suites (5)

Q4 Please indicate the type of room you lived in during the 2019-2020 academic year.

Single bedroom within a suite or apartment in RC, UC, or Miner Village (1)

Double bedroom within a suite or apartment in RC, UC, or Miner Village (2)

No roommates (single bedroom in a TJ or Rolla Suites) (3)

Double bedroom in TJ (4)

Q5 Did you self-select your roommate(s) or was your roommate(s) assigned by Residential Life?

I chose my roommate(s) (1)

Residential Life assigned my roommate(s) (2)

Not applicable (3) 
Q6 As of May 2020, please select how many semesters you lived in the residence halls at Missouri S\&T.

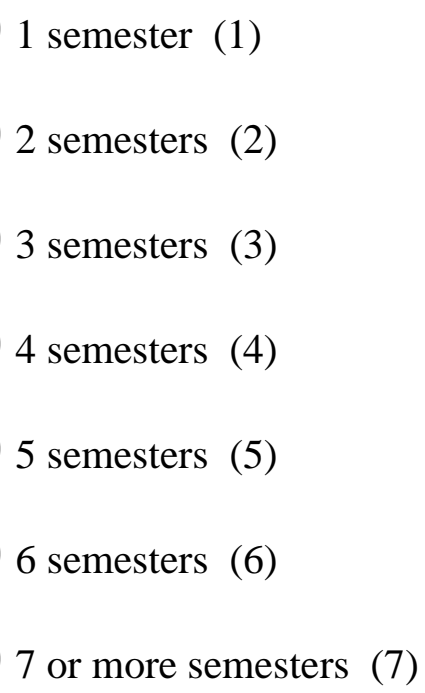

Q7 As of May 2020, please indicate how many semesters you have attended Missouri S\&T.

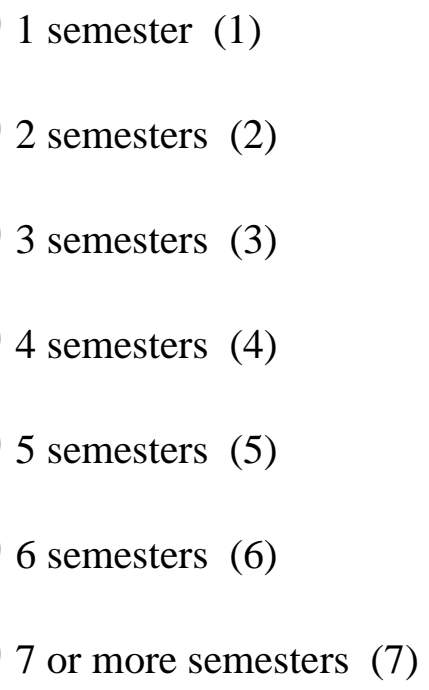


Q8 In light of the COVID-19 pandemic, please select the month that you checked out of your residence during the spring 2020 semester.

\section{March 2020}

April 2020 (2)

May 2020 (3)

I continued to live on-campus through the summer of 2020 (4)

\section{Page Break}

Q9 This section highlights some independent living skills and asks you to consider and indicate your level of competence BEFORE living in the residence halls at Missouri S\&T. 
Q10 Interpersonal \& Intrapersonal Skills

Please select your level of competence BEFORE living in the residence hall at Missouri S\&T.

\begin{tabular}{c|ccc} 
Mo & $\begin{array}{c}\text { Minimal } \\
\text { Competence } \\
(2)\end{array}$ & $\begin{array}{c}\text { Moderate } \\
\text { Competence }\end{array}$ & $\begin{array}{c}\text { Advanced } \\
\text { Competence } \\
\text { Competence }\end{array}$ \\
\hline $\begin{array}{c}\text { Managing } \\
\text { conflict (1) }\end{array}$ & & & $(3)$ \\
Communication \\
(actively listens, \\
aware of non- \\
verbal \\
communication, \\
effectively \\
express myself) \\
(2)
\end{tabular}

Q11 Prior to coming to college, what activities did you engage in that helped support you in developing these interpersonal \& intrapersonal skills? Please provide examples. 
Q12 Practical Skills

Please select your level of competence BEFORE living in the residence hall at Missouri S\&T.

\begin{tabular}{|c|c|c|c|c|}
\hline & $\begin{array}{c}\text { No } \\
\text { Competence } \\
\text { (1) }\end{array}$ & $\begin{array}{c}\text { Minimal } \\
\text { Competence } \\
\text { (2) }\end{array}$ & $\begin{array}{c}\text { Moderate } \\
\text { Competence } \\
\text { (3) }\end{array}$ & $\begin{array}{c}\text { Advanced } \\
\text { Competence } \\
\text { (4) }\end{array}$ \\
\hline $\begin{array}{c}\text { Practice } \\
\text { cleanliness } \\
\text { and personal } \\
\text { hygiene (2) }\end{array}$ & $\bigcirc$ & 0 & 0 & 0 \\
\hline $\begin{array}{c}\text { Managing } \\
\text { time } \\
\text { effectively (3) }\end{array}$ & 0 & 0 & 0 & 0 \\
\hline $\begin{array}{l}\text { Managing } \\
\text { personal } \\
\text { finances (4) }\end{array}$ & 0 & 0 & 0 & 0 \\
\hline $\begin{array}{l}\text { Effectively } \\
\text { obtain or } \\
\text { prepare food } \\
\quad(5)\end{array}$ & 0 & $\bigcirc$ & 0 & 0 \\
\hline
\end{tabular}

Q13 Prior to coming to college, what activities did you engage in that helped support you in developing these practical skills? Please provide examples. 
Q14 This section highlights some independent living skills and asks you to consider and indicate your level of competence AFTER living in the residence halls at Missouri S\&T.

Q15 Interpersonal \& Intrapersonal Skills

Please select your level of competence AFTER living in the residence hall at Missouri S\&T.

\begin{tabular}{c|ccc} 
No & $\begin{array}{c}\text { Minimal } \\
\text { Competence }\end{array}$ & $\begin{array}{c}\text { Moderate } \\
\text { Competence }\end{array}$ & $\begin{array}{c}\text { Advanced } \\
\text { Competence }\end{array}$ \\
$\begin{array}{c}\text { Managing } \\
\text { conflict (1) }\end{array}$ & $(1)$ & $(3)$ & $(4)$ \\
Communication \\
(actively listens, \\
aware of non- \\
verbal \\
communication, \\
effectively \\
express myself) \\
(2)
\end{tabular}


Q16 Thinking about your residence hall experience at Missouri S\&T, what experiences and resources were most impactful when it came to supporting your development of independent living skills?

\section{Q17 Practical Skills}

Please select your level of competence AFTER living in the residence hall at Missouri S\&T.

\begin{tabular}{|c|c|c|c|c|}
\hline & $\begin{array}{c}\text { No } \\
\text { Competence } \\
\text { (1) }\end{array}$ & $\begin{array}{c}\text { Minimal } \\
\text { Competence } \\
\text { (2) }\end{array}$ & $\begin{array}{c}\text { Moderate } \\
\text { Competence } \\
\text { (3) }\end{array}$ & $\begin{array}{c}\text { Advanced } \\
\text { Competence } \\
\text { (4) }\end{array}$ \\
\hline $1(1)$ & & & & \\
\hline $\begin{array}{c}\text { Practice } \\
\text { cleanliness } \\
\text { and personal } \\
\text { hygiene (2) }\end{array}$ & & & & \\
\hline $\begin{array}{c}\text { Managing } \\
\text { time } \\
\text { effectively (3) }\end{array}$ & & & & \\
\hline $\begin{array}{c}\text { Managing } \\
\text { personal } \\
\text { finances }(4)\end{array}$ & & & & \\
\hline $\begin{array}{c}\text { Effectively } \\
\text { obtain or } \\
\text { prepare food } \\
\text { (5) }\end{array}$ & & & & \\
\hline
\end{tabular}

Q18 Thinking about your residence hall experience at Missouri S\&T, what experiences and resources were most impactful when it came to supporting your development of independent living skills? 


\section{Page Break}

Q19 This section highlights some specific residence hall support resources. Please indicate your perception of how these resources influenced your development of the independent living skills noted in the previous section.

Q20 Residence Hall Relationships Please indicate your perception of how these resources influenced your development of the independent living skills noted in the previous section.

\begin{tabular}{|c|c|c|c|c|}
\hline & No Impact (1) & $\begin{array}{c}\text { Minimal } \\
\text { Impact (2) }\end{array}$ & $\begin{array}{l}\text { Moderate } \\
\text { Impact (3) }\end{array}$ & $\begin{array}{l}\text { Significant } \\
\text { Impact (4) }\end{array}$ \\
\hline $\begin{array}{l}\text { Relationship } \\
\text { with Resident } \\
\text { Assistant(s) (1) }\end{array}$ & & & & \\
\hline $\begin{array}{l}\text { Relationships } \\
\text { with Resident } \\
\text { Director (2) }\end{array}$ & & & & \\
\hline $\begin{array}{l}\text { Living in a } \\
\text { community/on a } \\
\text { floor with other } \\
\text { students (3) }\end{array}$ & & & & \\
\hline
\end{tabular}

Q21 Please share any specific examples of how these support resources impacted your development of independent living skills. 
Q22 Residence Hall Programs Please indicate your perception of how these resources influenced your development of the independent living skills noted in the previous section.

\begin{tabular}{|c|c|c|c|c|c|}
\hline & N/A (1) & $\begin{array}{l}\text { No Impact } \\
\text { (2) }\end{array}$ & $\begin{array}{l}\text { Minimal } \\
\text { Impact (3) }\end{array}$ & $\begin{array}{l}\text { Moderate } \\
\text { Impact (4) }\end{array}$ & $\begin{array}{l}\text { Significant } \\
\text { Impact (5) }\end{array}$ \\
\hline $\begin{array}{l}\text { Residence } \\
\text { hall } \\
\text { government } \\
\quad(1)\end{array}$ & 0 & 0 & 0 & 0 & 0 \\
\hline $\begin{array}{l}\text { Roommate } \\
\text { agreement } \\
\text { (2) }\end{array}$ & 0 & 0 & 0 & 0 & 0 \\
\hline $\begin{array}{l}\text { Educational } \\
\text { programs (3) }\end{array}$ & 0 & 0 & 0 & 0 & 0 \\
\hline $\begin{array}{c}\text { Student } \\
\text { conduct } \\
\text { process }(4)\end{array}$ & $\bigcirc$ & 0 & 0 & 0 & 0 \\
\hline
\end{tabular}

Q23 Please share any specific examples of how these support resources impacted your development of independent living skills.

Q24 Were there any other residence hall experiences that were not included above that impacted your development of independent living skills? 
Q25 Please describe your gender identity.

Woman (1)

Man (2)

Non-binary / third gender (3)

Prefer not to say (4)

Prefer to self-describe (5)

Q26 Please describe your racial identity. Please check all that apply.

American Indian or Alaska Native (1)

Asian (2)

Black or African American (3)

Hispanic or Latino (4)

Native Hawaiian or Other Pacific Islander (5)

White (6)

Race or Ethnicity Unknown (7)

Prefer not to say (8)

Prefer to self-describe (9) 


\section{Appendix D}

\section{Introduction - (Joni)}

- Thank you for participating in today's focus group my name is Joni Burch and I serve as the Associate Director for Residential Life here at S\&T. This study is a component of the research being completed as a part of my dissertation research study. Findings will also be used to support the development of the Residential Life program at Missouri S\&T.

- The research question guiding this study is: How do students perceive their development of independent living skills due to the residence hall experience at Missouri $S \& T$.

- This focus group will ask you to provide a retrospective account of your experiences in the residence halls, thinking about your first year living on campus until now. The questions will center on your development of independent living skills due to your residence hall experiences.

- This focus group will be recorded to allow me to review what is shared to support my research process. We will also be taking some notes so you may hear us typing from time to time.

- I am going to pause and turn things over to my research assistant and allow him to introduce himself and get us started.

\section{Opening question/s (Jennings)}

- Hello, my name is Jennings Randolph, I am Joni's student research assistant. I will be asking questions and taking notes alongside Joni today.

- To get started, we would like you to introduce yourself and share how many semesters you have lived on campus. You are welcome to use your real name or a pseudonym. We will use your name for the duration of this focus group and the final research project.

\section{Questions exploring residence hall support resources}

- (Jennings) The Resident Assistant (RA) role is designed to support students and help foster learning and development among peers. Given this context.....

- Describe the relationship you had with your RA.

- How do you recall your RA providing support to you navigating personal challenges?

- Describe a time when your RA referred you to campus resources. Would you have utilized the campus resource had your RA not referred you?

- Was there ever a time your RA provided guidance during an emergency? If so, how was that impactful for you?

- (Joni) For the following questions, I will post a list of independent living skills on the screen. You will be asked to share examples of how various residence hall support strategies impacted your development of these skills. - PPT Slide 


\begin{tabular}{|c|c|}
\hline Inter \& Intrapersonal Skills & Practical Skills \\
\hline $\begin{array}{l}\text { - Managing conflict } \\
\text { - Communication (active listening, awareness of non- } \\
\text { verbal communication, effectively expressing } \\
\text { yourself) } \\
\text { - Possess a healthy level of empathy for others } \\
\text { - Awareness and management of own emotions } \\
\text { - Independently navigating problems } \\
\text { - Recognizing personal strengths \& challenges }\end{array}$ & $\begin{array}{l}\text { - Practicing cleanliness and } \\
\text { personal hygiene } \\
\text { - Managing time effectively } \\
\text { - Managing personal } \\
\text { finances } \\
\text { - Effectively obtaining or } \\
\text { preparing food }\end{array}$ \\
\hline
\end{tabular}

- How did living with roommates and/or in a community with other students have on your development of these skills?

- If you were involved in residence hall government, what experiences contributed to your development of these skills?

- The survey indicated a significant increase in development as a result of the res hall experience in a few areas. We would like to invite you to share examples of what fostered your development in these areas.

- Managing conflict

- Recognizing personal strengths and challenges

- Effectively managing time

- The survey results indicated little change in the area of empathy for others and students had very little to share about their experiences related to empathy development both before and after their residence hall experience. Talk about experiences, both before and after living in the residence halls, that have impacted your ability to empathize with others.

- (Jennings) Residence hall programs and resources - Joni stop screen share PPT

- Did you complete a roommate agreement? If so, how did that experience impact your ability to share space and manage your roommate relationship/s?

- The survey indicated that many students completed the roommate agreement but did not ever revisit it if a disagreement came up. Can any of you expand upon why this might be?

- Some residents indicated that the roommate agreement was not helpful. Do any of you feel this way? If so, please share why you feel this way.

- What educational programs did you attend? What did you learn from those programs?

- How did access to or utilizing residence hall services such as the front desk, dining hall, and laundry impact your ability to function independently?

\section{Person-specific questions}

- (Joni) How have your identities, such as race, ethnicity, and/or gender, impacted your development of independent living skills while living in the residence halls? 


\section{Ending Question/s (Jennings)}

- If you had a chance to advise the Director of Residential Life, how would you advise them to make adjustments to the res hall experience to help students become more independent?

\section{Adjourn (Joni)}

- Thank you for participating in today's focus group. You provided some helpful insights. We appreciate you taking the time to participate. 
Appendix E

\begin{tabular}{|c|c|c|c|}
\hline \multicolumn{4}{|c|}{ Logic Model Analysis } \\
\hline $\begin{array}{c}\text { IEO } \\
\text { Framework } \\
\text { Description }\end{array}$ & Inputs & Environment & Outputs \\
\hline $\begin{array}{l}\text { Framework } \\
\text { Description }\end{array}$ & $\begin{array}{c}\text { Personal } \\
\text { characteristics \& } \\
\text { pre-college } \\
\text { experiences }\end{array}$ & $\begin{array}{l}\text { What experiences in } \\
\text { the residence halls } \\
\text { supported your } \\
\text { development of } \\
\text { independent living } \\
\text { skills? }\end{array}$ & $\begin{array}{l}\text { What is the impact of } \\
\text { residence hall } \\
\text { experiences on } \\
\text { development of ILS? }\end{array}$ \\
\hline $\begin{array}{l}\text { Research } \\
\text { Study } \\
\text { Details \& } \\
\text { Findings }\end{array}$ & $\begin{array}{l}\text { Inter/intrapersonal } \\
\text { skills development } \\
\text { Practical skills } \\
\text { development }\end{array}$ & $\begin{array}{l}\text { Inter/intrapersonal } \\
\text { skills development } \\
\text { Access and/or } \\
\text { relationship with } \\
\text { RA } \\
\text { Living with } \\
\text { roommates/sharing } \\
\text { space with others } \\
\text { Women noted their } \\
\text { experience being } \\
\text { among the } \\
\text { minority } \\
\text { population on- } \\
\text { campus } \\
\text { Being an RA or } \\
\text { serving in hall } \\
\text { government } \\
\text { Practical skills } \\
\text { development } \\
\text { RA promoting } \\
\text { study groups } \\
\text { Access to a } \\
\text { kitchen, front desk } \\
\text { supplies/cleaning } \\
\text { supplies }\end{array}$ & $\begin{array}{l}\text { Inter/intrapersonal } \\
\text { skills development } \\
\text { RAs help make } \\
\text { personal connections } \\
\text { and navigate personal } \\
\text { challenges } \\
\text { Roommate } \\
\text { relationships help } \\
\text { foster communication } \\
\text { and conflict } \\
\text { management skills. } \\
\text { Women noted that } \\
\text { their residence hall } \\
\text { experience highlighted } \\
\text { concerns for them } \\
\text { related to safety (they } \\
\text { became more aware of } \\
\text { the limited number of } \\
\text { women on-campus). } \\
\text { Hall government } \\
\text { involvement is high } \\
\text { impact experience } \\
\text { when it comes to } \\
\text { developing } \\
\text { communication and } \\
\text { time management } \\
\text { skills. } \\
\text { The RA role is a high } \\
\text { impact experience } \\
\text { when it comes to } \\
\text { developing } \\
\text { communication and }\end{array}$ \\
\hline
\end{tabular}




\begin{tabular}{|l|l|l|}
\hline & & $\begin{array}{l}\text { conflict management } \\
\text { skills. RA training has } \\
\text { been highly } \\
\text { influential. }\end{array}$ \\
& & \\
& & \\
\hline
\end{tabular}




\section{Appendix F}

\section{Roommate Agreement Form}

Introduction

The Roommate Agreement Form is designed to help roommates discuss common issues that may create conflict in the room, suite, or apartment while also considering roommate rights. Roommate rights include:

1. The right to establish agreed upon guidelines as outlined by a department of residential life roommate agreement.

2. The right to read and study, free from undue interference in one's room. Unreasonable noise and other distractions inhibit the exercise of this right.

3. The right to sleep without undue disturbance from noise, guests of roommate, etc.

4. The right to expect that a roommate will respect one's personal belongings.

5. The right to a clean living environment.

6. The right to free access to one's room and facilities without pressure from a roommate.

7. The right to privacy.

8. The right to host guests with the expectation that guests are to respect the rights of the host's roommate and other hall residents.

9. The right for redress of grievances. Residence hall staff are available for assistance in settling conflicts.

10. The right to expect reasonable cooperation in the use of "room shared" space.

11. The right to expect reasonable cooperation in the use of "room shared" appliances (telephone, refrigerator, etc.) and a commitment to honor agreed upon payment procedures.

12. The right to be free from peer pressure or ridicule regarding your choice to drink or not drink alcoholic beverages.

Some key things to remember when completing your roommate agreement:

- ALL roommates should be present and contribute to this discussion;

- Your *Resident Assistant will assist you in ensuring the agreement is complete and all roommates are comfortable with the standards set forth;

- Your responsibilities to the community are just as important as those to your roommate(s) - take into account your floor, residence hall, The Residence Hall Guide, The UM System Collected Rules, and the laws of the City of Rolla throughout the entire process;

- Living together is an ever-changing experience, so remember to revisit this agreement from time to time and make adjustments as necessary.

\section{CONSIDERATIONS FOR COVID-19:}

In an effort to mitigate risk of transmission of COVID-19, community spaces have reduced occupancy and guests/outside visitors are not permitted at this time until further notice. This includes parents, guardians, friends, family, significant others, and other folks who live outside of your residence hall.

Please adhere to the steps and signs posted in the living spaces to maintain and clean the spaces in which you live.

General Information

Please indicate the building that you live in:

\section{Miner Village \\ C Residential Commons}




\section{Rolla Suites \\ C Thomas Jefferson Hall \\ University Commons}

Please enter your room, suite, or apartment number.

Write-In Answer

Roommate Information - Names

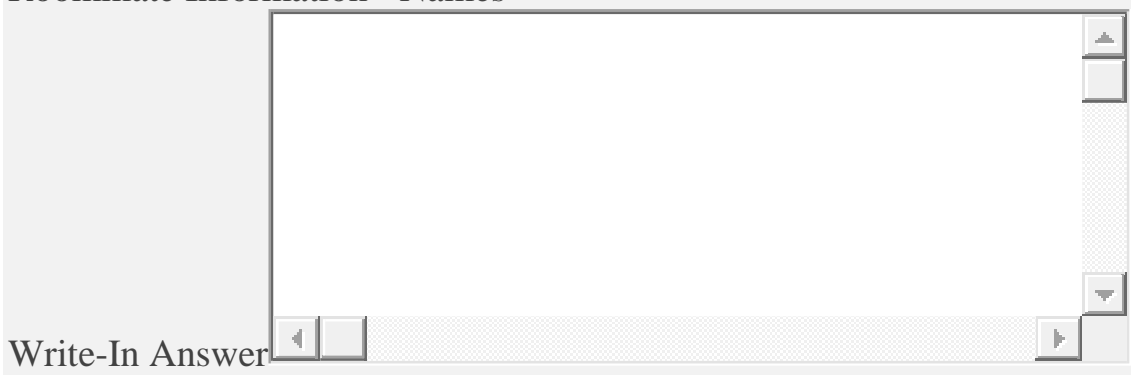

Hobbies and Interests

Roommate 1: What are some of your hobbies of interests?

Write-In Answer

Roommate 2: What are some of your hobbies of interests?

Write-In Answer

Roommate 3: What are some of your hobbies of interests?

Write-In Answer

Roommate 4: What are some of your hobbies of interests?

Write-In Answer

Roommate 5: What are some of your hobbies of interests?

Write-In Answer

Roommate 6: What are some of your hobbies of interests?

Write-In Answer

Roommate 7: What are some of your hobbies of interests?

Write-In Answer

Roommate 8: What are some of your hobbies of interests?

Write-In Answer

Stressors

Roommate 1: What are some things that cause you stress? When you are upset, how do you express your self? What is the best way for your roommates to approach you if you are upset?

Write-In Answerl

Roommate 2: What are some things that cause you stress? When you are upset, how do you express your self? What is the best way for your roommates to approach you if you are upset?

Write-In Answer

Roommate 3: What are some things that cause you stress? When you are upset, how do you express your self? What is the best way for your roommates to approach you if you are upset?

Write-In Answer 
Roommate 4: What are some things that cause you stress? When you are upset, how do you express your self? What is the best way for your roommates to approach you if you are upset?

Write-In Answer

Roommate 5: What are some things that cause you stress? When you are upset, how do you express your self? What is the best way for your roommates to approach you if you are upset?

Write-In Answerl

Roommate 6: What are some things that cause you stress? When you are upset, how do you express your self? What is the best way for your roommates to approach you if you are upset?

Write-In Answerl

Roommate 7: What are some things that cause you stress? When you are upset, how do you express your self? What is the best way for your roommates to approach you if you are upset?

Write-In Answer

Roommate 8: What are some things that cause you stress? When you are upset, how do you express your self? What is the best way for your roommates to approach you if you are upset?

Write-In Answer

Cleanliness

Roommate 1: I don't like it when my room, suite, or apartment is:

Г untidy

Г too neat

Г noisy

$\Gamma$ quiet

Г empty

$\Gamma$ overcrowded

Roommate 2: I don't like it when my room, suite, or apartment is:

$\Gamma$ untidy

Г too neat

$\Gamma$ noisy

$\Gamma$ quiet

$\Gamma$

empty

$\Gamma$ overcrowded

Roommate 3: I don't like it when my room, suite, or apartment is:

Г untidy

Г too neat

$\Gamma$ noisy

Г

quiet

$\Gamma$ empty

ए overcrowded 
Roommate 4: I don't like it when my room, suite, or apartment is:

$\begin{array}{ll}\Gamma & \text { untidy } \\ \Gamma & \text { too neat } \\ \Gamma & \text { noisy } \\ \Gamma & \text { quiet } \\ \Gamma & \text { empty } \\ \Gamma & \text { overcrowded }\end{array}$

Roommate 5: I don't like it when my room, suite, or apartment is:

Г

untidy

Г

too neat

$\Gamma$ noisy

$\Gamma$ quiet

$\Gamma$ empty

$\Gamma$ overcrowded

Roommate 6: I don't like it when my room, suite, or apartment is:

$\Gamma$

untidy

$\Gamma$

too neat

$\Gamma$ noisy

$\Gamma$ quiet

$\Gamma$ empty

Г overcrowded

Roommate 7: I don't when my room, suite, or apartment is:

$\Gamma$ untidy

ए too neat

$\Gamma$ noisy

$\Gamma$ quiet

$\Gamma$ empty

$\Gamma$ overcrowded

Roommate 8: I don't like it when my room, suite, or apartment is:

$\Gamma$

untidy

$\Gamma$ too neat

$\Gamma$ noisy

$\Gamma$ quiet 
$\Gamma$ empty

$\Gamma$ overcrowded

Describe the level of cleanliness that is acceptable given everyone's preferences:

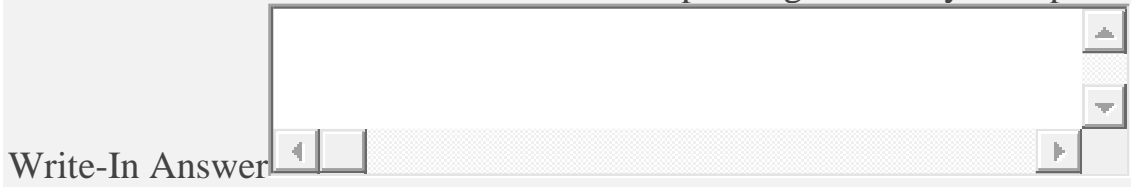

For cleaning the shared space, we will:

regularly clean together

T take turns cleaning the space

Г each take care of our own area

- other (please specify)Write-In Answer

We suggest you make a cleaning schedule with assigned responsibilities. Who is responsible for doing what? How often should cleaning happen?

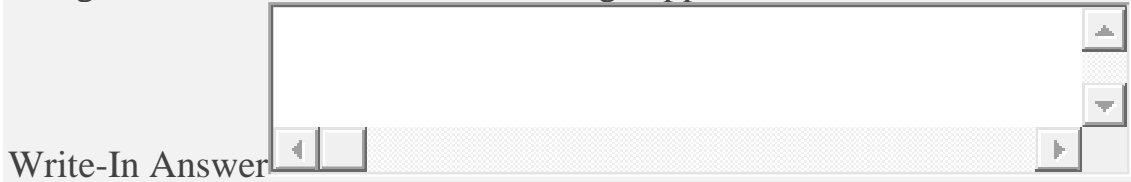

How should you address each other if cleanliness becomes an issue of someone doesn't clean up after themselves?

Write-In Answer

Personal Hygiene

What is personal hygiene? Select all that apply:

Г

bathing

Г odor

ए washing hands

ए room cleanliness

$\Gamma$ otherWrite-In Answer

If personal hygiene becomes an issue, how should we handle it initially?

C. face to face

involve RA

$c$ roommate meeting

otherWrite-In Answer

Space

What items CAN be borrowed in the room, suite, or apartment? Who replaces something that is broken or used? (e.g. appliances, gaming systems, clothes, shoes, cleaning supplies, toiletries, school supplies, etc.) 


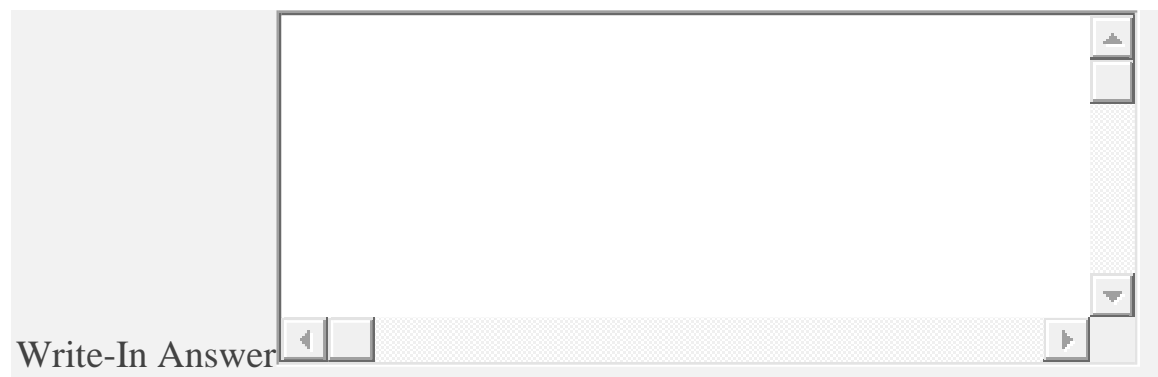

What items CANNOT be borrowed in the room, suite, or apartment? (e.g. appliances, gaming systems, clothes, shoes, cleaning supplies, toiletries, school supplies, etc.)

-In Answer

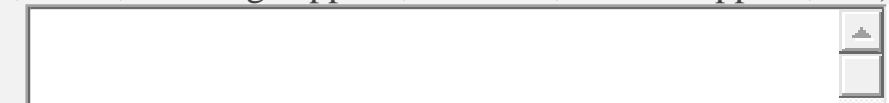

How will we decide to set the temperature?

Write-In Answer

When a roommate is sleeping, can the other roommate(s) watch TV or play video games?

Write-In Answer

When a roommate is sleeping, can the other roommate(s) listen to music?

Write-In Answerl

When a roommate is sleeping, can the other roommate(s) have the lights on?

Write-In Answer

When a roommate is sleeping, can the other roommate(s) talk on the phone?

Write-In Answer

When a roommate is sleeping, can the other roommate(s) have guests over? (Reminder: due to COVID-19, S\&T is NOT permitting any guests or visitors who do not live in your residence hall):

Write-In Answer

What times during the week and weekend should the room have quiet hours to ensure sleep schedules are maintained?

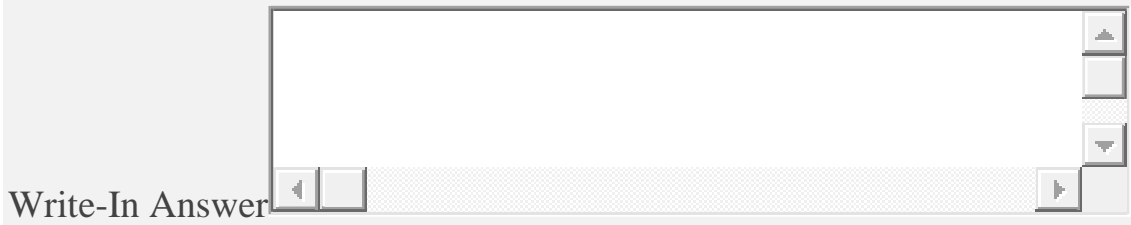

How will we share the common space when one of us wants alone time?

Write-In Answer

Studying

Roommate 1: I prefer to study in...

Write-In Answer

Roommate 2: I prefer to study in... 
Write-In Answer

Roommate 3: I prefer to study in...

Write-In Answer

Roommate 4: I prefer to study in...

Write-In Answer

Roommate 5: I prefer to study in...

Write-In Answer

Roommate 6: I prefer to study in...

Write-In Answer

Roommate 7: I prefer to study in...

Write-In Answer

Roommate 8: I prefer to study in...

Write-In Answer

While studying in the room, suite, or apartment, can we listen to music?

C yes

C no

While studying in the room, suite, or apartment, can we watch TV and play video games?

C

no

While studying in the room, suite, or apartment, can we have guests over? (Reminder: due to COVID-19, S\&T is NOT permitting any guests or visitors who do not live in your residence hall):

C yes

no

Would we like to establish study hours? If yes, indicate the start and end time for weekdays and weekends:

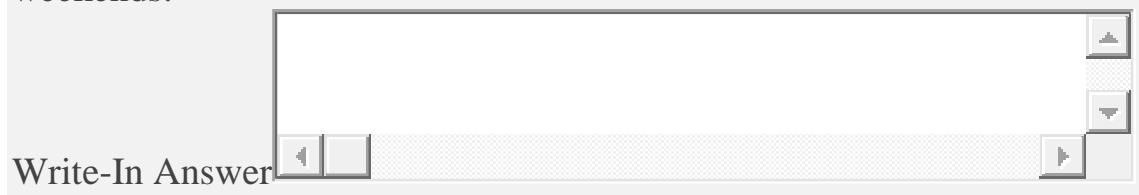

Food

Can we eat each other's food? Will we be sharing any food? If so, who buys what? What happens if someone eats the last of something? What happens if the fridge becomes excessively dirty or smelly?

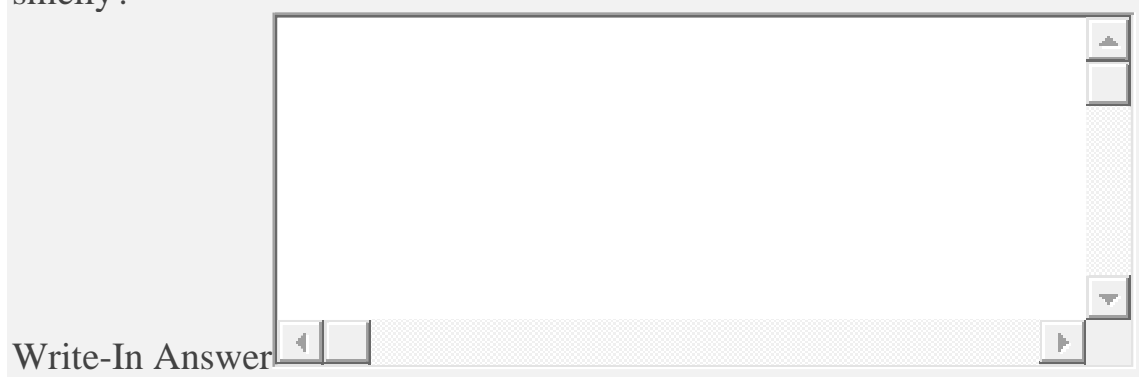


Any allergies to food, products, or scents we would like our roommate(s) to be aware of?

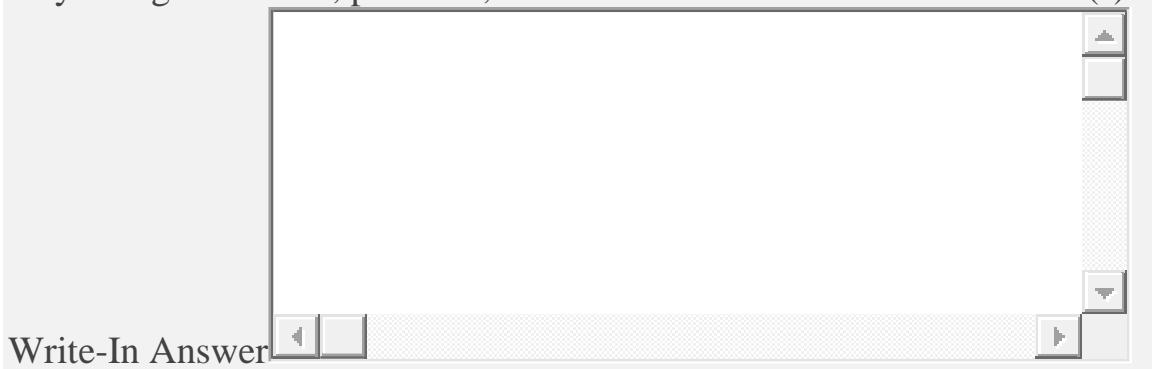

Guests and Visitors

Reminder: due to COVID-19, S\&T is NOT permitting any guests or visitors who do not live in your residence hall at this time. This decision is subject to change depending on the level of risk assessed.

When is it appropriate to have guests in the room? How many guests are allowed to be over at one time?

Write-In Answerl

Are we okay with our roommate's friends hanging out on our bed while we are gone? What about our desk?

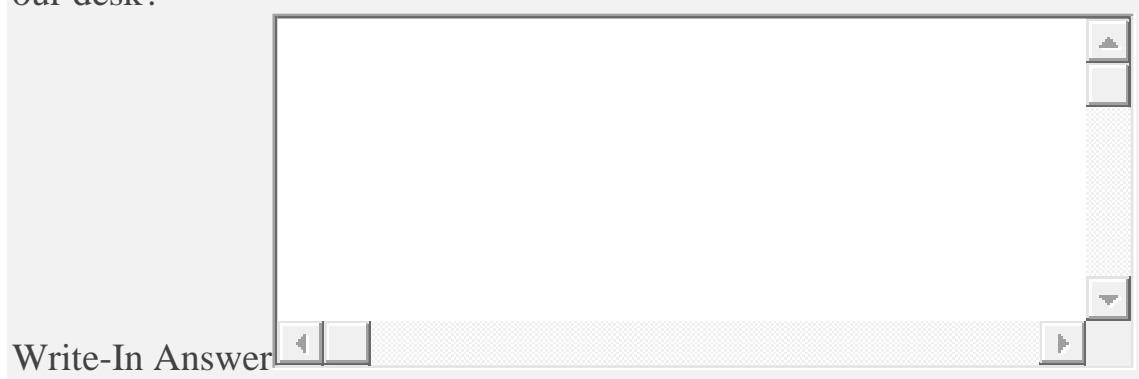

How will we notify one another of a guest coming over? If we have a concern about a guest coming over, how will we communicate this with our roommate(s)?

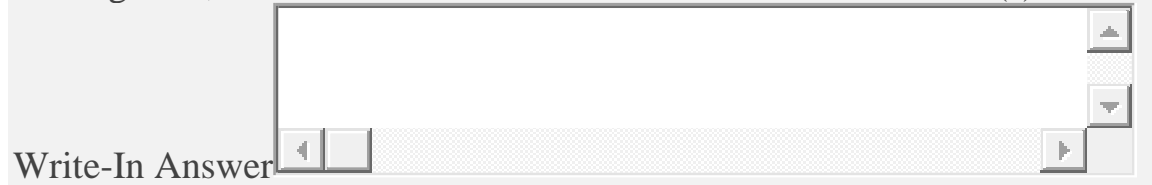

What items are guests permitted to use? (e.g. food, drinks, appliances, gaming systems, clothes, shoes, cleaning supplies, toiletries, school supplies, etc.)

Write-In Answer

Can guests sleep in our roommate's bed or bedroom?

C yes

no

C ask

Can guests of various genders stay overnight?

C

yes

c no

C ask

Can guest of various genders shower in our restroom (suite or apartment)? 
C nes

Communication

When concerns come up and we need to resolve them, we will:

talk directly to each other

write a note/email/text

otherWrite-In Answer

When we have an issue with a roommate, what the time frame for addressing it (i.e. a day, a week, etc.)?

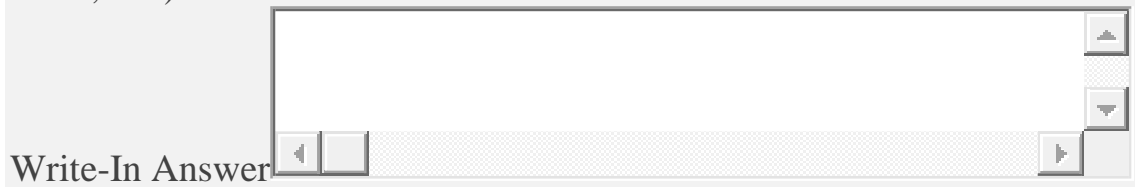

In what ways can we post online about our roommate(s)?

Г photos

$\Gamma$ videos

$\Gamma$ status updates

Г locations

If something about our living environment is not ideal (roommate issues, building issues, etc.), we can share information to others about it on:

$\Gamma$ Twitter

$\Gamma$ Snapchat

Г Instagram

$\Gamma$ GroupMe

$\Gamma \quad$ YouTube

$\Gamma$ Discord

$\Gamma$ TikTok

Г Reddit

$\Gamma$ otherWrite-In Answer

If we are going to be gone for a long period of time, we:

C will let our roommate(s) know ahead of time

c prefer not to tell our roommate(s)

How will we leave messages for our roommate(s)?

Write-In Answer

Where will we leave messages?

Write-In Answerl 
Add Reviewers

Please enter the email address(es) of your roommate(s) and resident assistant(s).

Enter up to five email addresses that will be added as Reviewers to your submission. Please note:

- Email addresses must belong to a member of your campus community.

- Added Reviewers will be given full access to view, comment, and vote on your form submission.

- At least one email address is required to proceed.

Email

REMOVE REVIEWER

+ ADD ANOTHER REVIEWER

NEXT 


\section{Vita}

Joni Burch holds a Bachelor of Science degree in Individual Studies with an emphasis on Student Affairs from Western Illinois University as well as a Master's of Education degree in Counseling, Adult and Higher Education from Northern Illinois University. Joni is expected to complete her Doctor of Education degree in Educational Leadership and Policy Analysis from the University of Missouri in May 2021. She has spent the past 16 years working in Residential Life serving in both live-in and department leadership roles. Joni currently serves as the Associate Director for Residential Life at Missouri University of Science and Technology. 